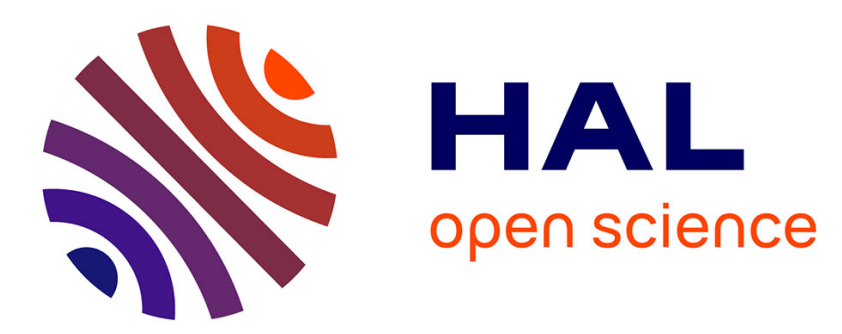

\title{
Review of Waterborne Organic Semiconductor Colloids for Photovoltaics
}

Alexandre Holmes, Elise Deniau-Lejeune, Christine Lartigau-Dagron, Antoine Bousquet, Sylvain Chambon, Natalie P. Holmes

\section{- To cite this version:}

Alexandre Holmes, Elise Deniau-Lejeune, Christine Lartigau-Dagron, Antoine Bousquet, Sylvain Chambon, et al.. Review of Waterborne Organic Semiconductor Colloids for Photovoltaics. ACS Nano, 2021, 15 (3), pp.3927-3959. 10.1021/acsnano.0c10161 . hal-03169082

\section{HAL Id: hal-03169082 https://hal-univ-pau.archives-ouvertes.fr/hal-03169082}

Submitted on 10 Nov 2021

HAL is a multi-disciplinary open access archive for the deposit and dissemination of scientific research documents, whether they are published or not. The documents may come from teaching and research institutions in France or abroad, or from public or private research centers.
L'archive ouverte pluridisciplinaire HAL, est destinée au dépôt et à la diffusion de documents scientifiques de niveau recherche, publiés ou non, émanant des établissements d'enseignement et de recherche français ou étrangers, des laboratoires publics ou privés. 


\title{
Review of Waterborne Organic Semiconductor Colloids for Photovoltaics
}

Alexandre Holmes ${ }^{1}$, Elise Deniau ${ }^{1}$, Christine Lartigau-Dagron ${ }^{1}$, Antoine Bousquet ${ }^{1 *}$, Sylvain Chambon ${ }^{2 *}$, Natalie P. Holmes ${ }^{3,4^{*}}$

1: Universite de Pau et des Pays de l'Adour, E2S UPPA, CNRS, IPREM, Pau, France

2: LIMMS/CNRS-IIS (UMI2820), Institute of Industrial Science, The University of Tokyo, 4-6-1 Komaba, Meguro-ku, Tokyo, 153-8505, Japan

3: Centre for Organic Electronics, University of Newcastle, University Drive, Callaghan NSW 2308, Australia

4: Australian Centre for Microscopy and Microanalysis, The University of Sydney, Madsen Building F09, NSW 2006, Australia

*Corresponding authors: antoine.bousquet@univ-pau.fr; chambon@iis.u-tokyo.ac.jp; natalie.holmes@sydney.edu.au

\begin{abstract}
:
Development of carbon neutral and sustainable energy sources should be considered as a top priority solution for the growing worldwide energy demand. Photovoltaics are a strong candidate, and more specifically organic photovoltaics (OPV), enabling the design of flexible, light-weight, semi-transparent and low-cost solar cells. However, the active layer of OPV is, for now, mainly deposited from chlorinated solvents, harmful for the environment and for human health. Active layers processed from health and environmentally friendly solvents have over recent years formed a key focus topic of research, with the creation of aqueous dispersions of conjugated polymer nanoparticles arising. These nanoparticles are formed from organic semi-conductors (molecules and macromolecules) initially designed for organic solvents. The topic of nanoparticle OPV has gradually garnered more attention, up to a point where in 2018 it was identified as a "trendsetting strategy" by leaders in the international OPV research community. Hence, this review has been prepared to provide a timely roadmap of the formation and application of aqueous nanoparticle dispersions of active layer components for OPV. We provide a thorough synopsis of recent developments in both nanoprecipitation and miniemulsion for preparing photovoltaic inks, facilitating readers in acquiring a deep understanding of the crucial synthesis parameters affecting particle size, colloidal concentration, ink stability, and more. This review also showcases the experimental levers for identifying and optimizing the internal donor-acceptor morphology of the nanoparticles, featuring cutting-edge X-ray spectromicroscopy measurements reported over the past decade. The different strategies to improve the incorporation of these inks into OPV devices and to increase their efficiency (to the current record of $7.5 \%$ ) are reported, in addition to critical design choices of surfactant type and the advantages of single-component vs. binary nanoparticle populations. The review naturally culminates by presenting the upscaling strategies in practice for this environmentally friendly and safer production of solar cells.
\end{abstract}




\section{Table of content image}

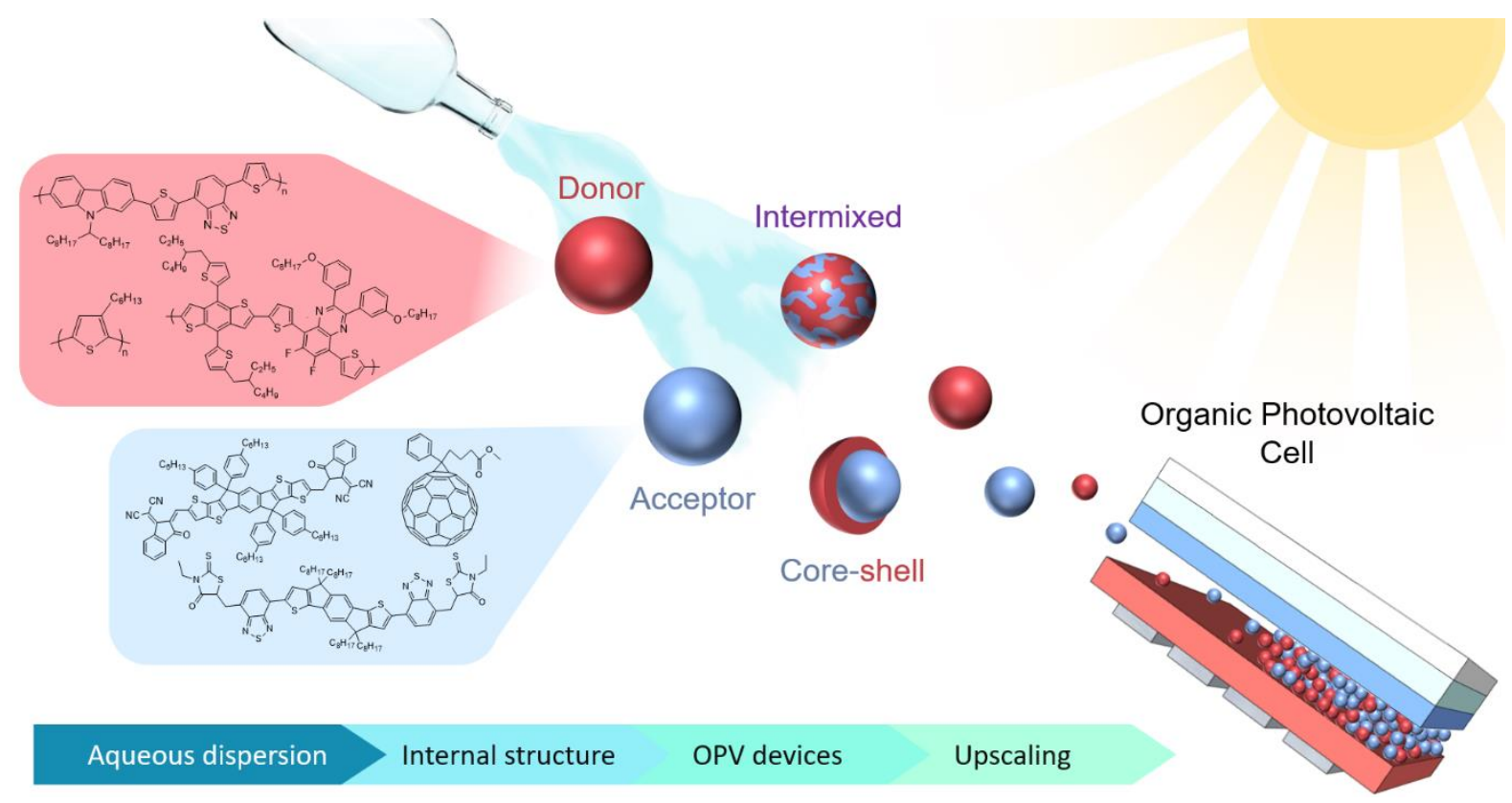

\section{Keywords:}

"organic photovoltaics, solar cells, conjugated polymers, organic semiconductors, nanoparticles, aqueous dispersion, miniemulsion, nanoprecipitation, nanoparticle morphology, surfactant"

\section{Vocabulary:}

Bulk-Heterojunction: Light-absorbing layer with nanoscale blend of donor and acceptor materials.

Power conversion efficiency: Corresponds to the quotient between the final electrical power delivered and the initial power of the incident photoexcitation.

Scanning Transmission X-ray Microscopy: Microscopy technique on thin section sensitive to the X-ray absorption spectra of sample analyzed.

Dynamic Light Scattering: Analysis technique which gives access to the hydrodynamic diameter of nanoparticle colloids dispersed in non-solvent.

Surfactant: Molecule or macromolecule presenting an amphiphilic behavior that helps stabilize particles

Micelle: Aggregation or supramolecular assembly of surfactant molecules dispersed in a liquid resulting in the formation of a colloidal suspension. 


\section{Introduction}

At the beginning of the $21^{\text {st }}$ century, carbon neutral and sustainable energy sources need to be considered instead of exhaustible fossil fuels to meet the growing energy demand and combat global warming. From 1971 to 2017, the world total energy consumption increased by about 2.3 times, and the world total primary energy supply increased more than 2.5 times. ${ }^{1}$ In 2017 , renewable energy represented $13.6 \%$ of this total energy supply. Among the renewable sources, solar, wind, tidal and geothermal sources represent only $1.8 \%$ of the total energy production worldwide, solar photovoltaics being one of the less represented (Figure 1a). ${ }^{2}$ However, the annual growth rate of photovoltaics, between 2000 and 2018, averaged around $40.1 \%$ per year, ${ }^{2}$ which is the highest growth rate of all of the renewable energy categories, making photovoltaics a candidate of interest. In the photovoltaic horizon, organic photovoltaics (OPV) seem promising, since this technology enables the production of light-weight, low-cost, flexible, and semi-transparent solar cells, promising a lifetime of over five years and a short pay-back time. Therefore, OPV is well positioned to be a competitive and environmentally friendly energy source, especially considering the manufacture utilizes low-cost, large scale production processes such as printing and coating techniques. ${ }^{3-7}$

OPV devices are comprised of an active layer, which is made of at least two organic semiconductors: an electron donor semiconductor and an electron acceptor semiconductor. The pair of organic semiconductors is carefully selected such that the acceptor has a deeper HOMO and LUMO than the donor (See Figure 1b). The active layer is inserted between two electrodes, one of which must be transparent. In addition, electron and hole transport layers can be used between the active layer and the electrodes to improve charge selection at the interface (Figure 1c). Upon absorption of an incident photon by the active layer (donor or acceptor material), the electron is promoted from the HOMO to the LUMO of the organic semiconductor, creating an electron-hole pair (exciton). As organic semiconductors possess molecular orbitals rather than bands (as in inorganic semiconductors) and low dielectric constants, the electron and hole are localized which results in a strongly bound exciton, known as a Frenkel exciton. As a result, the thermal energy at room temperature is not sufficient to 
dissociate it. In order to form free charges, the exciton must find an interface between the donor and acceptor material. Due to the energetic mismatch between the LUMO of the donor and acceptor materials, the exciton formed in the donor material will undergo an electron transfer from the LUMO of the donor to the LUMO of the acceptor. Conversely, a similar phenomenon happens for the exciton formed in the acceptor material. At the donor/acceptor interface, the hole transfer from the HOMO of the acceptor to the HOMO of the donor occurs. Both phenomena will lead to a charge separated state and free charges, electrons and holes in the acceptor and donor phases, respectively. Once separated, these charges can travel through the active layer in their respective phase and be collected at their respective electrode. ${ }^{3,5,8}$ Because OPV is rapidly evolving, record efficiencies are often beaten, with a current champion of power conversion efficiency (PCE) of $17.6 \%$ certified for a single-junction OPV device in January $2020 .{ }^{9}$

The ability to use simple manufacturing methods is considered a great advantage of organic solar cell technology - devices are comprised of several layers (Figure 1c) that can be printed with different coating techniques on a large scale. ${ }^{8}$ 
a)
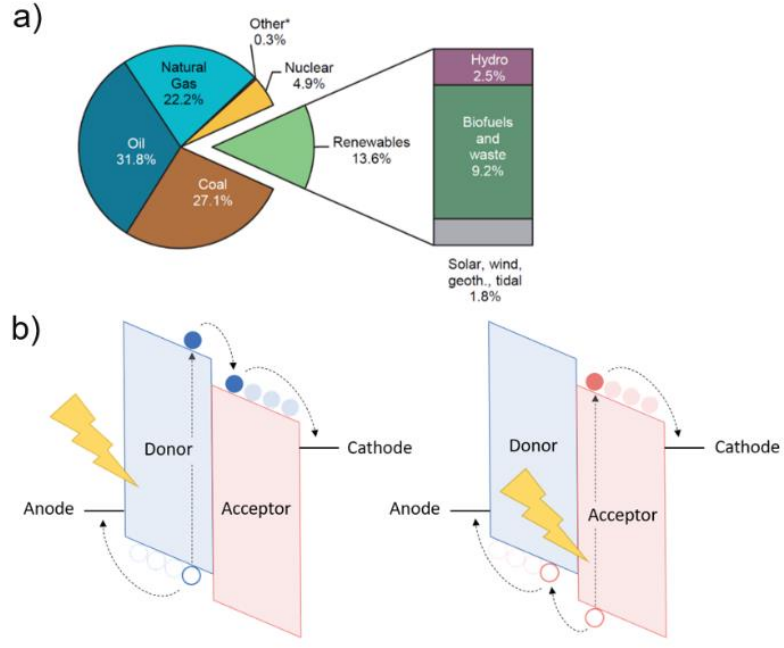

c)

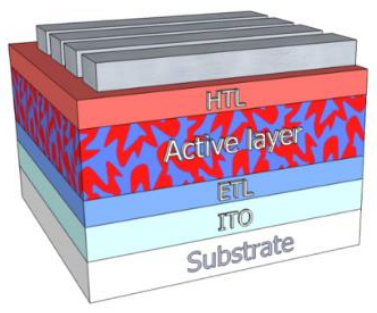

Figure 1. a) 2017 fuel shares in world total primary energy supply (where other* refers to non-renewable waste and other sources not included elsewhere such as fuel cells). Percentages listed have been rounded to 1 decimal place. b) Generation and dissociation of the exciton in the donor or in the acceptor domain. c) Device structure of an inverted architecture organic solar cell. HTL referencing to hole transporting layer and ETL to electron transporting layer. Panel a) adapted with permission from ref 2, IEA 2019, Renewables Information: Overview, All rights reserved.

However, the active layer, a bulk-heterojunction (BHJ) of donor and acceptor materials, is mainly processed from toxic chlorinated or aromatic solvents like dichlorobenzene (DCB), chlorobenzene (CB), or chloroform (CF), ${ }^{10}$ which are harmful to the environment and human health (Figure 2). ${ }^{11}$ To overcome this limitation, a subset of the OPV community has devoted their research to the substitution of these solvents by more environmentally friendly alternatives, also accepted by industry (Figure 2). ${ }^{12,13}$ The use of halogen-free solvents would lead to less environmental accumulation and would render the industrial manufacturing of OPV devices safer and more sustainable. Among the "green" solvents already used, it is important to mention that their green feature is relative to the 
chlorinated solvents used, and some of them (aromatics mainly) are not without risk. Toluene and tetrahydrofuran (THF), for example, are highly toxic and carcinogenic, THF can even lead to the formation of explosive peroxides (according to REACH registrations). Other green solvents for preparing organic solar cells include limonene and anisole. ${ }^{14}$

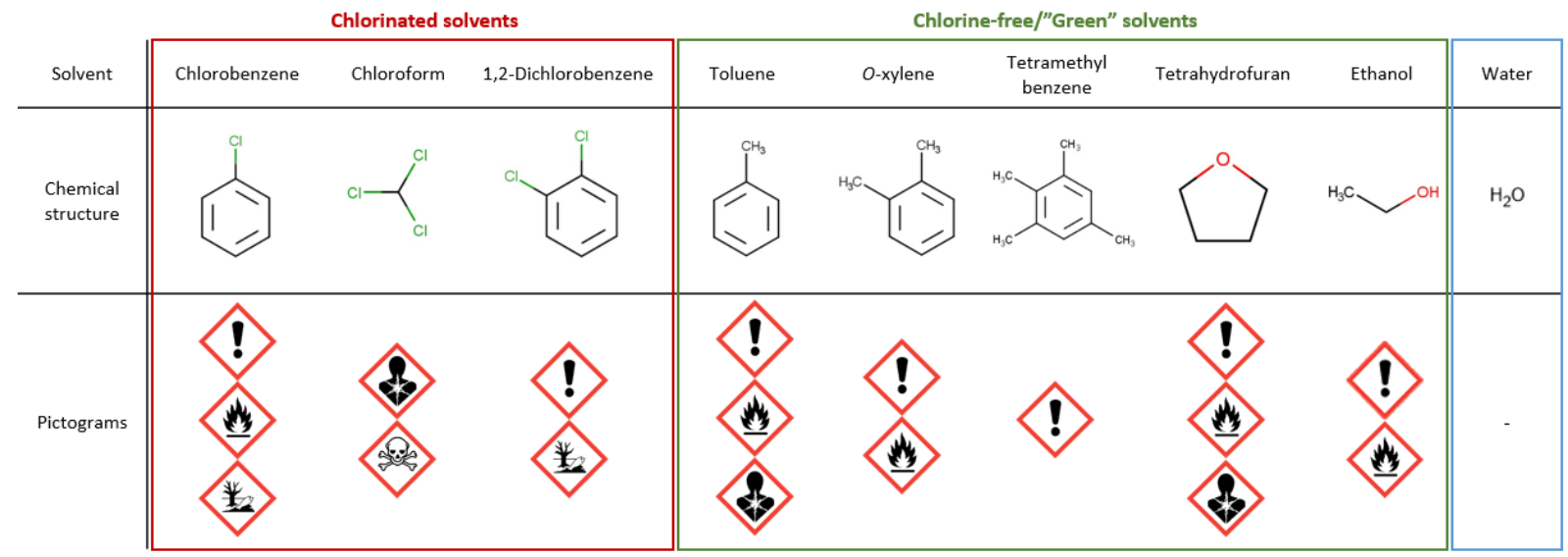

Figure 2. Chemical structure and associated chemical risks for the commonly used solvents for OPV fabrication, according to REACH registrations. Pictograms concerning the safety of chemicals are in accordance with the ECHA-REACH registrations.

Thus, these last two decades have seen the development of methodologies to use water as the solvent for coating the active layer. The main issue with these methodologies lies in the fact that the majority of conjugated polymers and acceptor molecules are insoluble in water due to their hydrophobicity. The processability of solar cells in water relies on chemical modification of the materials in order to increase their solubility, by means of hydrophilic or polar side chain addition. This approach is already thoroughly reported in other reviews, ${ }^{11,12,15,16}$ and will not be covered here. Since this strategy is limited to a small range of materials and is demanding in terms of synthesis, another more versatile technique was studied - the aqueous dispersion of conjugated polymer (and small molecule) nanoparticle colloids. In brief, due to their insolubility in water, the polymers/molecules are dispersed in water in the form of nanoparticles. Some groups have worked on the dispersion of nanoparticles in alcoholic medium but this will not be covered in this review. ${ }^{11,12,17-24}$ Figure 3 illustrates the records of efficiency 
for the three categories previously described to achieve the deposition of the active layer: from chlorinated solvents, from non-chlorinated solvents, and finally from aqueous dispersions of nanoparticles based on conjugated polymers. Even though chlorinated solvent processed solar cells are leading the race for $\mathrm{PCE},{ }^{9}$ non-chlorinated solvents and aqueous nanoparticle dispersion based solar cells are very promising, with a PCE of $17.3 \%$ and $7.5 \%$, respectively. ${ }^{25,26}$ Considering the recent efficiency record, as well as the safe and sustainable processability of water-based solar cells, aqueous nanoparticle dispersions are already a prospective way of manufacturing organic solar cells.

\section{Solvent toxicity decreasing}
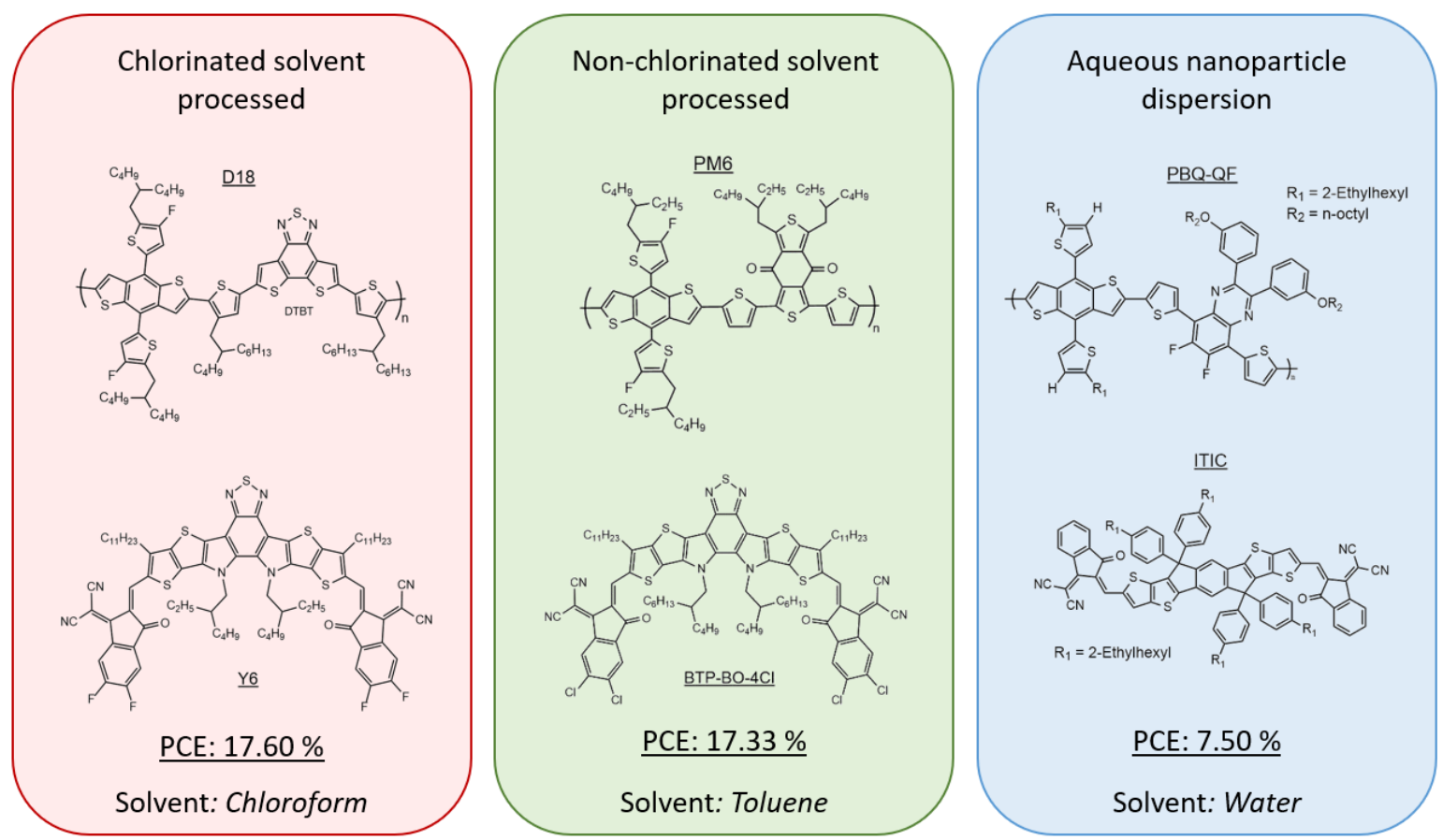

Figure 3. Systems achieving the best PCE as of $1^{\text {st }}$ October 2020 for the three main approaches: Standard BHJ using chlorinated solvent, ${ }^{9} \mathrm{BHJ}$ processed with "green"/non-chlorinated solvent, ${ }^{25}$ and finally solar cells from aqueous dispersion of nanoparticles. ${ }^{26}$

The scope of this review focuses on the elaboration of conjugated (macro)molecule dispersions and their integration in solar cells. We aim to give a complete overview of the dispersion procedures, the parameters influencing the size and morphology of the particles, the stability of the dispersions 
(referred to as nanoparticle inks), and to present results of their integration in devices, compatible with production upscaling by roll-to-roll or ink-deposition techniques.

\section{Dispersion Techniques}

\section{Basic Considerations}

There are numerous ways of preparing nanoparticles from polymers. Rao et al. reviewed the main methods in a publication dedicated to non-conjugated, non-conductive, coil polymers. ${ }^{27}$ Nanoparticles are defined as solid and colloidal objects, most of the time spherical but not always, and presenting a diameter ranging from 1 to $100 \mathrm{~nm} \cdot{ }^{28}$ Nanoparticles of organic semiconductors can be obtained from two main approaches: the top-down approach, which corresponds to the dispersion of preformed polymers in the dispersed media, or the bottom-up approach, which involves the polymerization of hydrophobic monomers in the dispersed media. ${ }^{29}$ Techniques such as precipitation or dialysis are routinely used for the production of nanoparticles from polymer solutions. Other methodologies, such as emulsion, can be applied from either monomer or polymer solutions. The polymerization in dispersed medium has already been used to create dispersions of organic semiconductors. ${ }^{29-32}$ One of which led to a commercial success - the aqueous oxidative polymerization of 3,4-(ethylenedioxy)thiophene (EDOT) by iron(III) salts forming a dispersion of poly(3,4-(ethylenedioxy)-thiophene) (PEDOT), positively charged and stabilized by poly(styrene sulfonate) (PSS). ${ }^{33}$ PEDOT:PSS solutions are commonly used to coat or print hole transporting layers in organic and hybrid solar cells. However, this approach is limited to a few polymers, such as polyaniline, polyacetylene, polypyrrole, or poly(phenylenethynylene), that are not used for solar cell active layers due to their low light absorption in the visible range. Other conjugated polymers, such as poly(3-hexylthiophene) (P3HT) or the last generation of low band-gap polymers, are polymerized by polycoupling involving catalysts that are often highly water-sensitive, thus requiring anhydrous solvents. ${ }^{29,34-36}$ In addition, purification steps are quite limited upon polymerization in dispersed medium, leading to residual impurities (monomers, initiators, catalysts), which can be detrimental to the final OPV device performance. ${ }^{37}$ 


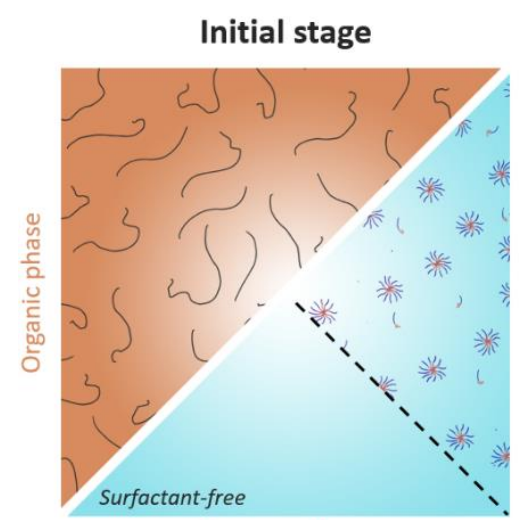

Aqueous phase

3 Polymer Surfactant

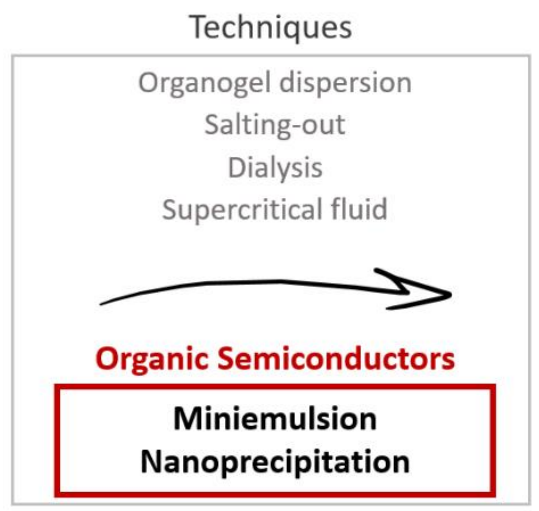

Micelle

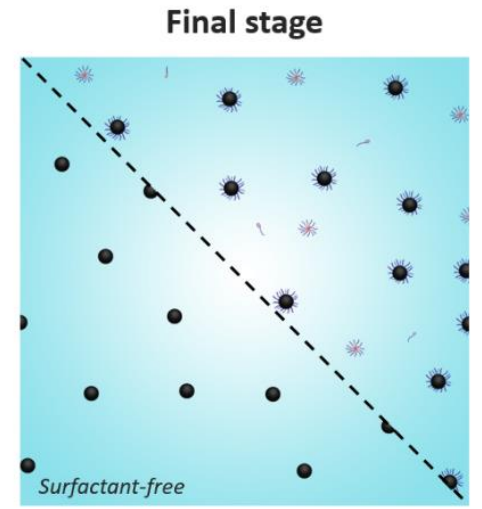

Waterborne nanoparticle dispersion

Surfactant-stabilized nanoparticle

Figure 4. Preparation techniques to achieve aqueous nanoparticle dispersions of organic semiconductors. Techniques used for conjugated polymers with OPV applications are framed in red.

This review is therefore focused on the top-down approach, creating a dispersion from preformed single donor, single acceptor, or donor:acceptor blends. Indeed, another advantage of this technique compared to the polymerization route is the ability to create a blend of material into each nanoparticle and to control the donor:acceptor ratio by varying the initial feed ratio. Also, polymers are already synthesized before the preparation, therefore the range of potential materials that can be used is almost unlimited, as long as the chosen material can be dispersed in a non-solvent. Several methods to prepare nanoparticles from a preformed polymer are well-established. The main methods used are miniemulsion, nanoprecipitation, salting out or dialysis (Figure 4) and are described elsewhere. ${ }^{27}$ Among these techniques, dispersions of semiconducting materials were almost exclusively reported by miniemulsion and nanoprecipitation, and hence will be focused on in this review. ${ }^{10,29,38}$ It has to be mentioned that another alternative to miniemulsion or nanoprecipitation has been proposed by Richards et al., by dispersing P3HT nanoparticles through fragmentation of P3HT organogels in water (with a surfactant). However, since no other work described the use of such technique in the OPV community and the fact that it could not be applied to every type of organic semiconductor, we will not focus on this approach. ${ }^{39,40}$ 
Since OPV active layers are composed of an electron donor and an electron acceptor material, two main types of particles can be produced: (i) single-component nanoparticles, which are comprised of either the donor or the acceptor material, and (ii) composite nanoparticles, prepared by the mixing of both materials in each individual nanoparticle. In the case of single-component nanoparticles, in order to form an active layer comprised of both donor and acceptor material, both types of nanoparticles are combined in aqueous media prior to film deposition. ${ }^{41,42}$ Both type (i) and (ii) will be discussed in this review. For ease of reading, the donor:acceptor blend will be referred to using the term "organic semiconductors".

In the first section of this review focused on dispersion techniques, attention will be paid to the three main features of nanoparticle dispersions: the nanoparticle size, the colloidal stability, and the concentration in aqueous media (solids content). Indeed, as it will be explained in sections III and IV0, the nanoparticle size plays a major role in determining the organic semiconductor morphology, but also on the donor and acceptor domain size, driving the final device performance. ${ }^{43,44}$ The colloidal stability of the dispersion should also be considered since the final goal is the production of a stable water dispersion for industrial-scale device manufacturing. Finally, the concentration of nanoparticles in the aqueous dispersion should reach a minimum value of a few tens of $\mathrm{mg} \cdot \mathrm{mL}^{-1}$ to be viable in the deposition process of active layers of sufficient film thickness.

\section{Miniemulsion}

For the miniemulsion technique, the nanoparticle formation mechanism relies on the non-miscibility of the polymer solvent (mainly volatile solvents such as chloroform, but also high boiling point solvents such as xylene and dichlorobenzene) and the non-solvent (aqueous phase). ${ }^{27}$ The organic semiconductor(s) is first dissolved in an appropriate organic solvent, and an aqueous phase containing surfactant molecules is then added to the organic solution. As depicted in Figure 5, initially, two nonmiscible phases are observed, from where, in general, a primary macroemulsion is formed by conventional stirring. Then, nanodroplets containing the organic semiconductors and the organic 
solvent are produced by applying high shear using ultrasonic waves or high-speed homogenization (step A, Figure 5). Evaporation of the organic solvent from the dispersed phase droplets leads to the formation of solid nanoparticles dispersed in water (step B, Figure 5). An additional step aiming to remove the excess of free-surfactant and also to reduce the volume of the aqueous phase, in order to concentrate the dispersion, is often required (step C, Figure 5). This can be achieved by various washing procedures using Millipore ${ }^{\mathrm{TM}}$ membranes, ${ }^{45,46}$ dialysis, ${ }^{47}$ or centrifugal dialysis. ${ }^{48}$ For instance, Andersen et al. concentrated large volumes of low-band gap polymer nanoparticle dispersions of 12 $\mathrm{mg} \cdot \mathrm{mL}^{-1}$ using a Millipore ${ }^{\mathrm{TM}}$ filter system in order to prepare inks with a solids content of $60 \mathrm{mg} \cdot \mathrm{mL}^{-1}$, allowing the efficient deposition of nanoparticle-based active layer. ${ }^{49}$ Kietzke et al. reported the reduction of the sodium dodecyl sulfate (SDS) surfactant total weight by a factor of 25 by dialysis. ${ }^{37}$

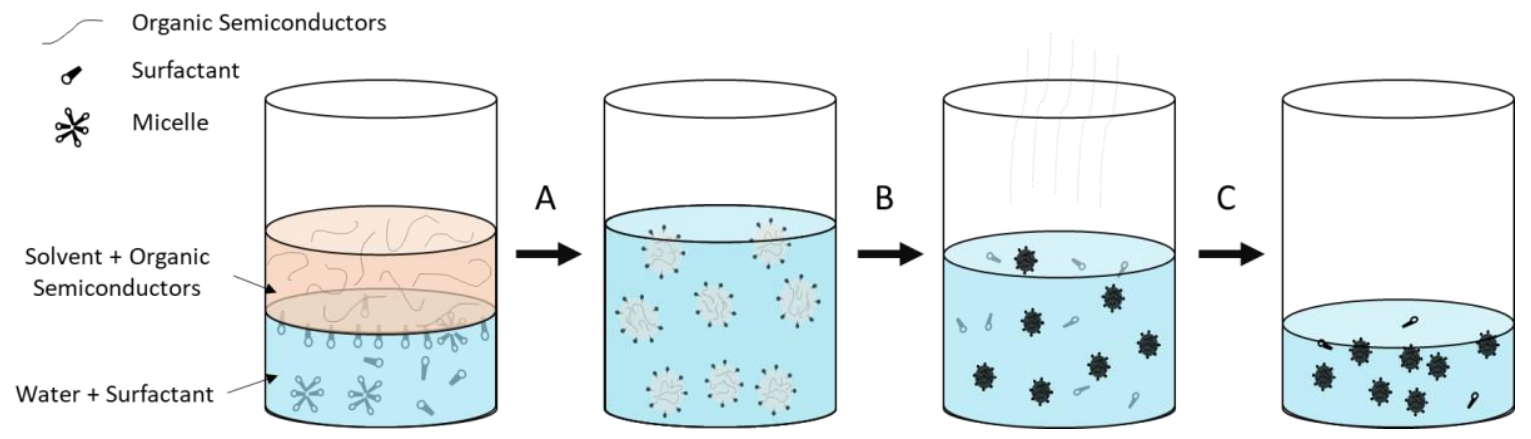

Figure 5. Miniemulsion preparation technique: sonication applied to form a miniemulsion (A) followed by the solvent evaporation step, leading to the formation of nanoparticles (B). Finally, concentration of the dispersion and removal of the surfactant excess by dialysis or centrifugal dialysis (C).

In 2002, Landfester et $a .^{50}$ reported the preparation of conjugated polymer nanoparticles using the miniemulsion technique. During the miniemulsion process, the surfactant used, here SDS, stabilized the droplets from collision and aggregation and the organic semiconductor solution was sufficiently hydrophobic to prevent the Ostwald ripening (mass exchange between droplets). ${ }^{50,51}$ The authors reported stable dispersions of three different conjugated polymers (methyl substituted ladder-type poly(para-phenylene) (Me-LPPP), polyfluorene (PF) and polycyclopenta-dithiophene (PCPDT)), with 
nanoparticle sizes ranging from 75 to $250 \mathrm{~nm}$, by varying the amount of surfactant, yielding a solids content of 2.2 to $9.3 \mathrm{wt} \%$ after evaporation of the organic solvent (chloroform in this case). In this seminal work, the authors developed single-component nanoparticles that could be used for organic light emitting diodes (OLED). ${ }^{52}$

Later, Kietzke et al. reported a solar cell obtained from spin-coated layers of nanoparticle dispersion made by the miniemulsion process. ${ }^{37}$ They compared the morphology and photovoltaic performance of films coated from either a blend of single-component nanoparticles or of individual composite nanoparticles, as represented in Figure 6. The nanoparticle preparation was similar for both systems, the only differences being that donor and acceptor were mixed with the desired ratio during the solubilization step for the composite particles. Using a blend of the electron-acceptor polymer poly(9,9-dioctylfluorene-co-benzothiadiazole (F8BT) and the hole-acceptor polymer poly(9,9dioctylfluorene-co-N,N-bis(4-butylphenyl)-N,N-diphenyl-1,4-phenylenediamine) (PFB) they fabricated photovoltaic devices with external quantum efficiencies (EQE) up to $1.7 \%$ and reported nanoparticle size to be a key parameter in controlling the organic semiconductor domain size in the final film. Therefore, one of the advantages of using nanoparticle dispersions to prepare films for OPV applications is that the photovoltaic properties can be tuned by controlling the nanoparticle size.

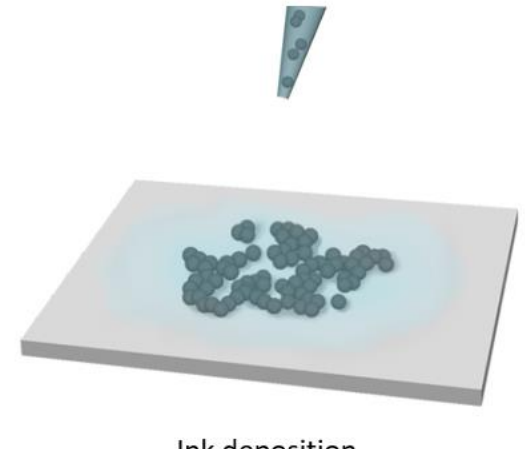

Ink deposition

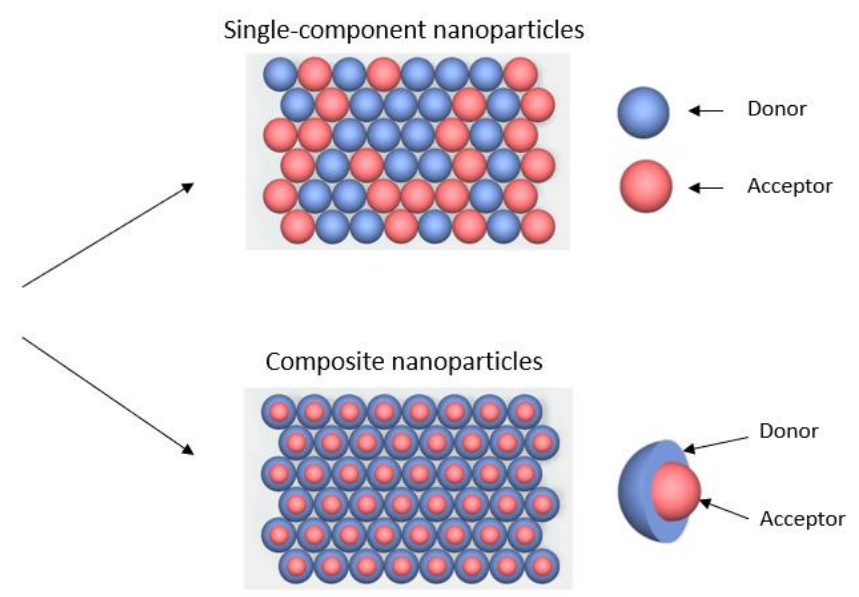

Figure 6. Deposition of active material on a substrate, and morphology of the active layer as cast for blends of single-component nanoparticles or composite nanoparticles prepared via miniemulsion. Inspired from ref 37. 
In the miniemulsion process, the nanoparticle size can be easily controlled during the nanoparticle formation, by varying experimental parameters. The shear force applied when mixing both phases, the initial concentration of polymer in the organic phase, and the surfactant nature and surfactant concentration are the main parameters influencing the nanoparticle size. In addition, other parameters such as the oil/water volume ratio seem to influence the nanoparticle size. Table 1 offers a general overview of different conjugated nanoparticle dispersion features obtained by miniemulsion and the corresponding experimental conditions. The chemical structures of chemicals contained in Table 1 are summarized in Figure 7.

Table 1. Experimental conditions of miniemulsion techniques for the preparation of aqueous organic semiconductor nanoparticle dispersions.

\begin{tabular}{|c|c|c|c|c|c|c|c|c|c|}
\hline Entry & System & Solvent & $\begin{array}{l}{[\mathrm{AM}]_{\mathrm{OP}}{ }^{a}} \\
(\mathrm{mg} / \mathrm{mL})\end{array}$ & $\begin{array}{c}\text { [NPs] }^{\mathrm{b}} \\
(\mathrm{mg} / \mathrm{mL})\end{array}$ & Surfactant & $\begin{array}{l}C_{\text {surfactant }} \\
(\mathrm{mg} / \mathrm{mL})\end{array}$ & $\begin{array}{l}\text { Diameter } \\
(\mathrm{nm})^{\mathrm{d}}\end{array}$ & $\begin{array}{c}\text { Stability } \\
\text { (day) }\end{array}$ & Ref \\
\hline \multirow{4}{*}{1} & \multirow{4}{*}{ PDPP5T-2:PC ${ }_{71} \mathrm{BM}$} & \multirow{4}{*}{$\mathrm{CHCl}_{3}$} & 40 & \multirow{4}{*}{$60^{c}$} & \multirow{4}{*}{ SDS } & \multirow{4}{*}{5} & 107 & \multirow{4}{*}{$>60$} & \multirow{4}{*}{41} \\
\hline & & & 30 & & & & 73 & & \\
\hline & & & 30 & & & & 36 & & \\
\hline & & & 15 & & & & 4.6 & & \\
\hline \multirow{3}{*}{2} & \multirow{4}{*}{ PCDTBT-PC ${ }_{71} \mathrm{BM}$} & & 5 & 1 & \multirow{3}{*}{ SDS } & 10 & 30 & \multirow{3}{*}{$>180$} & \multirow{3}{*}{53} \\
\hline & & $\mathrm{CHCl}_{3}$ & 30 & 6 & & 10 & 140 & & \\
\hline & & & 30 & 6 & & 30 & 55 & & \\
\hline 3 & & $O-D C B$ & 10 & $40^{c}$ & SDS & 4 & 52 & - & 46 \\
\hline \multirow{2}{*}{4} & \multirow{2}{*}{ PDPP5T:PC ${ }_{61}$ BM } & \multirow{2}{*}{$\mathrm{CHCl}_{3}$} & \multirow{2}{*}{40} & \multirow{2}{*}{$38^{c}$} & \multirow{2}{*}{ SDS } & 10 & 62 & $>10$ & \multirow{2}{*}{44} \\
\hline & & & & & & 41 & 34 & $>10$ & \\
\hline \multirow{3}{*}{5} & \multirow{3}{*}{ P3HT } & \multirow{3}{*}{$\mathrm{CHCl}_{3}$} & \multirow{3}{*}{30} & \multirow{3}{*}{3} & SDS & 28 & 139 & \multirow{3}{*}{-} & \multirow{3}{*}{54} \\
\hline & & & & & SDBS & 5 & 145 & & \\
\hline & & & & & DOBS & 2 & 162 & & \\
\hline \multirow{5}{*}{6} & \multirow{5}{*}{ PNDI-TVT } & \multirow{5}{*}{$\mathrm{CHCl}_{3}$} & \multirow{5}{*}{2} & \multirow{5}{*}{1} & SDS & 20 & 157 & \multirow{5}{*}{-} & \multirow{5}{*}{55} \\
\hline & & & & & SDBS & 12 & 109 & & \\
\hline & & & & & BDAB & 6 & 92 & & \\
\hline & & & & & C16TAB & 4 & 99 & & \\
\hline & & & & & C12TAB & 4 & 70 & & \\
\hline 7 & PTNT:PC ${ }_{71} B M$ & $\mathrm{CHCl}_{3}$ & 56 & $60^{c}$ & SDS & 12 & $32^{1}$ & - & 56 \\
\hline & & $o$-xylene & & & & & $27^{1}$ & & \\
\hline
\end{tabular}




\begin{tabular}{|c|c|c|c|c|c|c|c|c|c|}
\hline & PFB:F8BT & $\mathrm{CHCl}_{3}$ & 6 & 4 & SDS & 0.5 & $\begin{array}{l}53 \\
49\end{array}$ & - & 37 \\
\hline \multirow{6}{*}{8} & P3HT $5 K^{\mathrm{e}}: \mathrm{PC}_{61} \mathrm{BM}$ & \multirow{6}{*}{$\mathrm{CHCl}_{3}$} & \multirow{6}{*}{28} & \multirow{6}{*}{12} & \multirow{6}{*}{ SDS } & \multirow{6}{*}{0,4} & 149 & \multirow{6}{*}{-} & \multirow{6}{*}{34} \\
\hline & P3HT 9Ke: $\mathrm{PC}_{61} \mathrm{BM}$ & & & & & & 135 & & \\
\hline & P3HT $12 K^{\mathrm{e}}: \mathrm{PC}_{61} \mathrm{BM}$ & & & & & & 157 & & \\
\hline & P3HT $16 K^{e}: \mathrm{PC}_{61} \mathrm{BM}$ & & & & & & 158 & & \\
\hline & P3HT $44 K^{\mathrm{e}}: \mathrm{PC}_{61} \mathrm{BM}$ & & & & & & 146 & & \\
\hline & P3HT $72 K^{\mathrm{e}}: \mathrm{PC}_{61} \mathrm{BM}$ & & & & & & 161 & & \\
\hline 9 & \multirow{2}{*}{ P3HT:PC 61 BM } & \multirow{2}{*}{$\mathrm{CHCl}_{3}$} & 54 & $60^{c}$ & SDS & 12 & 29 & - & 57 \\
\hline 10 & & & 25 & 11 & SDS & 15 & 31 & - & 47 \\
\hline 11 & \multirow{2}{*}{ PFB:F8BT } & \multirow{2}{*}{$\mathrm{CHCl}_{3}$} & \multirow{2}{*}{25} & \multirow{2}{*}{11} & \multirow{2}{*}{ SDS } & \multirow{2}{*}{15} & 51 & - & 47 \\
\hline 12 & & & & & & & 52 & - & 58 \\
\hline \multirow{3}{*}{13} & $P 1^{f}: P C_{61} B M$ & \multirow{3}{*}{$\mathrm{CHCl}_{3}$} & \multirow{3}{*}{39} & \multirow{3}{*}{$60^{c}$} & \multirow{3}{*}{ SDS } & \multirow{3}{*}{29} & $130^{2}$ & & \\
\hline & $P 2^{f}: \mathrm{PC}_{61} \mathrm{BM}$ & & & & & & $32^{2}$ & - & 49 \\
\hline & $P 3^{f}: P C_{61} B M$ & & & & & & $87^{2}$ & & \\
\hline 14 & PDPP-TNT:PC 71 BM & $\mathrm{CHCl}_{3}$ & 17 & $60^{c}$ & SDS & 0.35 & $113^{1}$ & - & 48 \\
\hline 15 & PBDTTPD:PC 71 BM & $\mathrm{CHCl}_{3}$ & 21 & $40^{c}$ & SDS & 4.0 & $32^{3}$ & - & 45 \\
\hline
\end{tabular}
a: Concentration of active material (AM) in the organic phase (OP).
b: Concentration of nanoparticles in the aqueous dispersion (prior to concentration of the nanoparticles).
c: Concentration of nanoparticle dispersions after concentration step (centrifugation, etc.).
$\mathrm{d}$ : Nanoparticle diameter measured by DLS, except ${ }^{1}$ measured by SEM, ${ }^{2}$ by SAXS, ${ }^{3}$ by TEM.
e: Corresponding to the polymer molar mass $(\mathrm{Mw})$ of $\mathrm{P} 3 \mathrm{HT}$, in $\mathrm{g} \cdot \mathrm{mol}^{-1}$
$\mathrm{f}$ : Chemical formulae shown in Figure 7. 


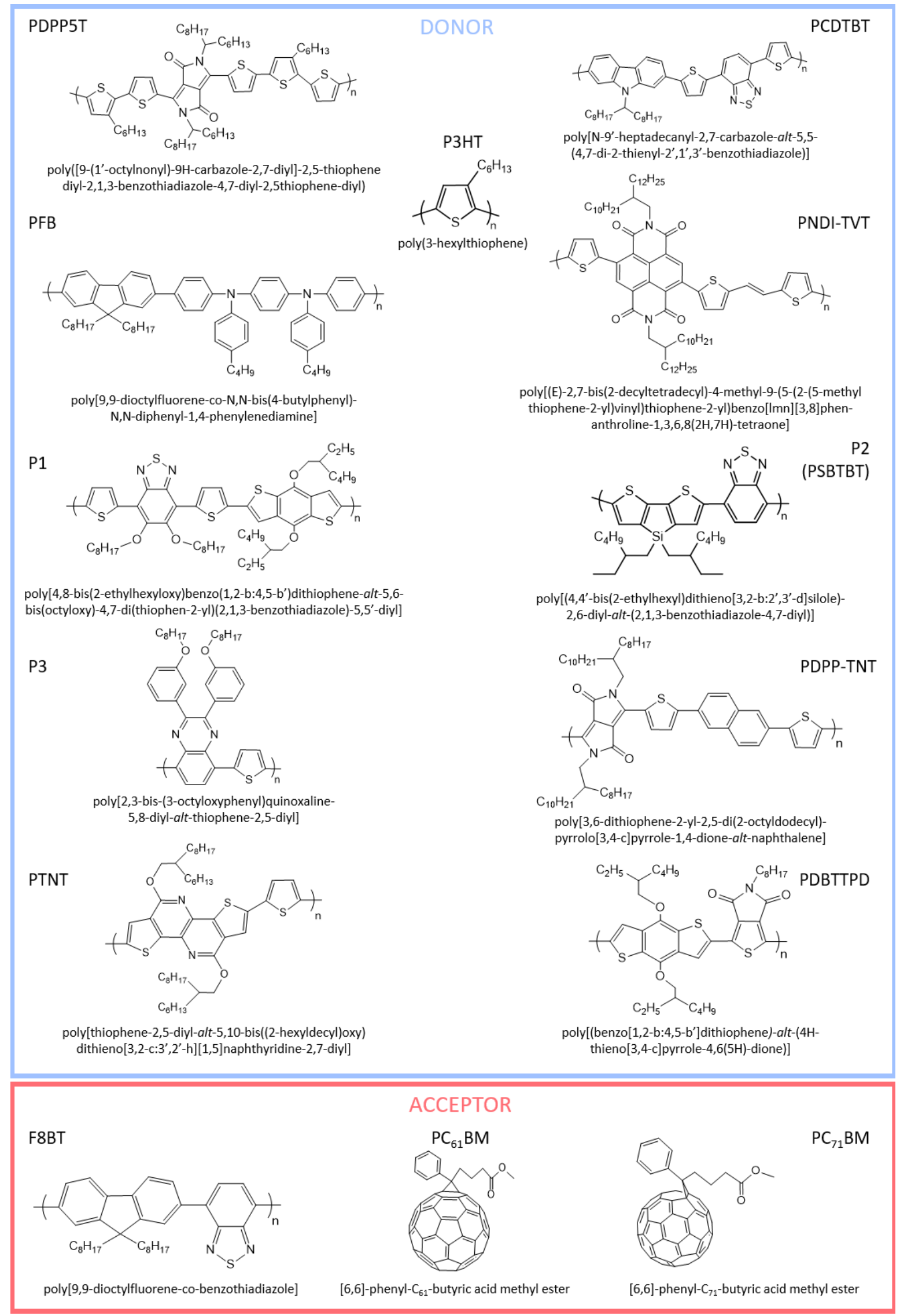

Figure 7. Chemical formulae of the main active materials used for the elaboration of aqueous nanoparticle dispersions by miniemulsion. 
During the solvent evaporation step, nanodroplets of organic solutions of semiconductors are slowly reduced to form solid nanoparticles of semiconductors. According to Asua et al., high sonication power offers more strength to break up droplets into nanodroplets. ${ }^{51}$ Their study was related to miniemulsion polymerization, however, it can be compared to post-polymerization miniemulsion, since the size of a nanodroplet (before the solvent evaporation step) influences the concentration of organic semiconductors in one droplet, thus influencing the final nanoparticle size. Therefore, among the influencing parameters determining the nanoparticle size, the shear power per volume applied during the miniemulsion process, by using sonifiers or high-pressure homogenizers, is a highly important parameter. Parrenin et al. illustrated that increasing the sonication power leads to smaller nanoparticles..$^{53}$ In their study, composite nanoparticles of PCDTBT:PC ${ }_{71} \mathrm{BM}$ were obtained in water, using miniemulsion. They reported a reduction in the nanoparticle size from 140 to $45 \mathrm{~nm}$ by increasing the sonication power from 150 to $225 \mathrm{~W}$. The same conclusion was reported by Pras et al. for PFFO nanoparticles. ${ }^{59}$ The sonication power applied in the literature for the preparation of conjugated polymer nanoparticles for OPV mainly varies from 30 to $350 \mathrm{~W},{ }^{48,60}$ and even to $1000 \mathrm{~W}$ in the case of large batches of NP ink, ${ }^{49}$ with an average sonication power around $240 \mathrm{~W} \cdot{ }^{45,47,61}$

Similarly, increasing the sonication time enables the formation of smaller nanoparticles. ${ }^{62-64}$ Parrenin et al. reported that increasing the sonication time resulted in smaller NPs (from $140 \mathrm{~nm}$ for $2 \mathrm{~min}$ to $50 \mathrm{~nm}$ for $5 \mathrm{~min}$, by applying a sonication power of $150 \mathrm{~W}) .{ }^{53}$ In the OPV literature, the sonication time varies between 1 and 5 minutes, ${ }^{55,65} 10$ minutes in the case of large batches, ${ }^{49}$ and an average sonication time of 2 minutes..$^{37,48,61}$ In the case of ultrasound homogenization, only a small portion of the fluid is passing through the sonication region, depending on the tip geometry, power, and volume. Additional stirring may be required to submit the entire volume to ultrasound, as well as a specific exposure time. ${ }^{66}$ 
The initial organic semiconductor (donor and/or acceptor) solution concentration, i.e. the initial organic solution, also has a strong impact on the size of the nanoparticles formed, as shown in Table 1, entries 1 and 2. Xie et al. reported the increase of the active material (poly(diketopyrrolopyrrolequinquethiophene) low band gap alternating copolymer (PDPP5T) and phenyl- $\mathrm{C}_{71}$-butyric acid methyl ester $\left.\left(\mathrm{PC}_{71} \mathrm{BM}\right)\right)$ concentration from 15 to $40 \mathrm{mg} \cdot \mathrm{mL}^{-1}$ leading to an increase in the nanoparticle size from 5 to $107 \mathrm{~nm} .{ }^{41}$ Parrenin et al. reported the same trend in waterborne nanoparticle dispersion size, with a diameter ranging from 30 to $330 \mathrm{~nm}$ for initial solution concentration from 5 to $50 \mathrm{mg} \cdot \mathrm{mL}^{-}$ ${ }^{1}$, respectively..$^{53}$ Satapathi et al. suggested that this evolution could be explained by the presence of more active material (polymer chains and small molecules) in the polymer solution droplets during the miniemulsion generation, resulting in an increase in the nanoparticle size after organic solvent evaporation. ${ }^{67}$ Depending on the semiconductor used, it is however important to adjust the organic phase concentration as a function of its solubility in the primary organic solvent, in order to avoid aggregation. ${ }^{68}$

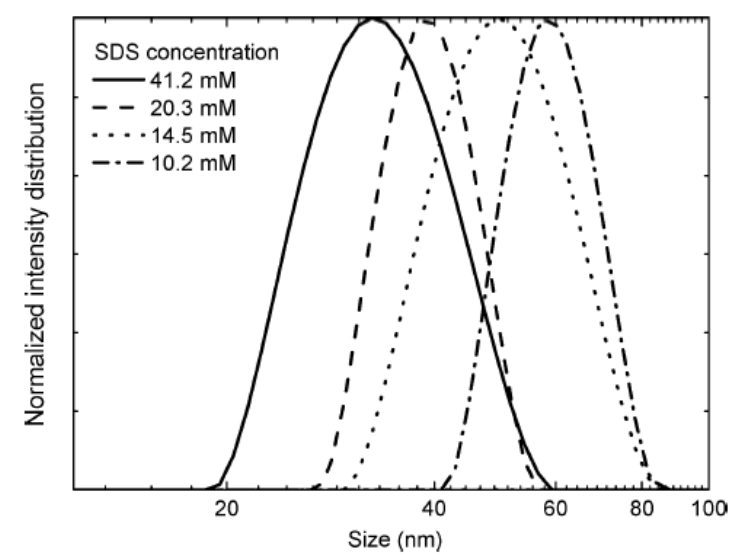

Figure 8. Influence of the surfactant (SDS) concentration on nanoparticle size for PDPP5T:PC 61 BM nanoparticles in aqueous dispersion (measured by DLS). Adapted with permission under a Creative Commons Non-commercial No Derivative Works (CC-BY-NC-ND) Attribution License from ref 44. Copyright 2017 American Chemical Society.

As mentioned above, the influence of the surfactant concentration on the nanoparticle size is well established. ${ }^{44,50,53,67,69}$ Increasing the amount of surfactant leads to a higher surface coverage 
propensity, and thus, to smaller and more numerous nanodroplets stabilized during the emulsion step, influencing at the end the nanoparticle size, after the solvent evaporation step..$^{53}$ As an example, Colberts et al. illustrated the effect of the amount of surfactant when preparing aqueous nanoparticle dispersions of PDPP5T:PC ${ }_{61} \mathrm{BM}$ through miniemulsion. By increasing the SDS concentration from 10 to $40 \mathrm{mM}$, the nanoparticle size, measured by dynamic light scattering (DLS), decreased from 65 to 30 nm (Figure 8 and Table 1, entries 2 and 4). The reduction of the nanoparticle volume is very pronounced at high surfactant concentration until it reaches a threshold limit. ${ }^{51}$ When this limit is reached, the only way to keep decreasing the size of the particles is to increase the applied shear power.

The chemical nature of the surfactant molecule influences its stabilization behavior, and thus the colloidal stability of the dispersion. Surfactants can be classified into two main families: ionic and nonionic. ${ }^{70}$ Ionic surfactants can be subclassified into three categories: i) anionic surfactants, such as SDS (where hydrophilic groups dissociate into anion in aqueous solution), ii) cationic surfactants (dissociation into cation) and iii) amphoteric surfactants (dissociation into cation or anion, depending on external conditions, such as $\mathrm{pH}) .{ }^{70}$ Whereas ionic surfactants stabilize nanoparticles via electrostatic repulsions, non-ionic surfactants stabilize nanoparticles by steric hindering. ${ }^{70-72}$ The emulsification behavior of the surfactant also depends on the hydrophilic/lipophilic balance $(H L B)^{73}$ and can be quantified, according to Griffin's or Davies' theories. ${ }^{74-76}$

Consequently, the surfactant nature has also an influence on the nanoparticle size. If SDS is by far the most used surfactant for the preparation of semiconducting nanoparticle dispersions, research teams have succeeded in tuning the NP size, the NP aggregation, the optical properties, and hole mobility by varying the nature of the surfactant. Tan et al. compared the size of P3HT nanoparticles dispersed in water, stabilized either by SDS, sodium dodecyl benzene sulfate (SDBS), or disodium 4-dodexyl-24'oxydibenzenesulfonate (DOBS), which contain one and two benzene rings, respectively (Figure 9a)..$^{54}$ When these three surfactants were used above their critical micelle concentration (CMC), the size of 
the final nanoparticles slightly increased $(10 \%)$ when using the two aromatic candidates ( $140 \mathrm{~nm}$ ) (Table 1, entry 5). Increasing the hydrophobicity by increasing the number of aromatic rings in the surfactant could lead to an increase in the nanoparticle size.

Cho et al. screened a larger range of surfactants to investigate the most suitable candidate to generate monodisperse populations of nanoparticles of various conjugated polymers..$^{55}$ Non-ionic and large aromatic surfactants were rapidly rejected since they led to micron-sized particles, due to a low colloidal stability. This result is in contradiction with their previous study, where they demonstrated the generation of diketopyrrolopyrrole-based nanoparticle dispersions (NP size $200 \mathrm{~nm}$ diameter) using a non-ionic surfactant from the alkyl-ethoxyethyl family $\left(C_{m} E_{n}\right.$, Figure $\left.9 a\right) .{ }^{77}$ They finally selected two anionic (SDS, SDBS) and two cationic surfactants (dodecyl trimethyl ammonium bromide $\left(\mathrm{C}_{12} \mathrm{TAB}\right.$, Figure 9a) and benzyl dimethyl dodecyl ammonium bromide (BDAB)), and compared the nanoparticle size in each dispersion (Table 1, entry 6 and Figure 9b). Smaller nanoparticles below $100 \mathrm{~nm}$ diameter were obtained using cationic surfactants. The authors also demonstrated that an increase in the alkyl chain length, within the same family of surfactants, leads to an increase in the nanoparticle size (Table 1, entry 6). As it is reported in these studies, the nature of the surfactant molecules influences the final nanoparticle size. However, this influence of surfactant type is not limited to the nanoparticle size, as will be presented in subsections "Crystallinity" and "Surfactant Limitations and Removal". 
a)
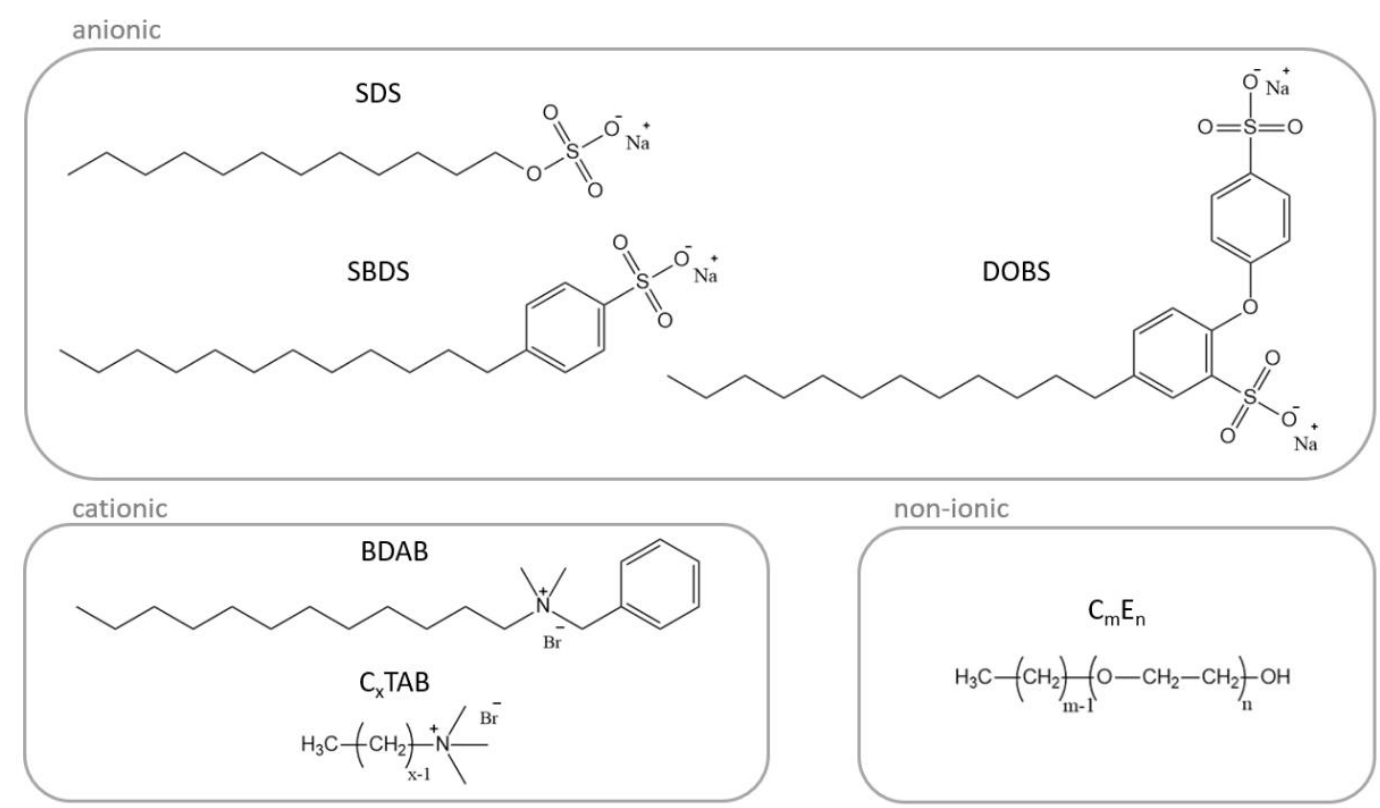

b)
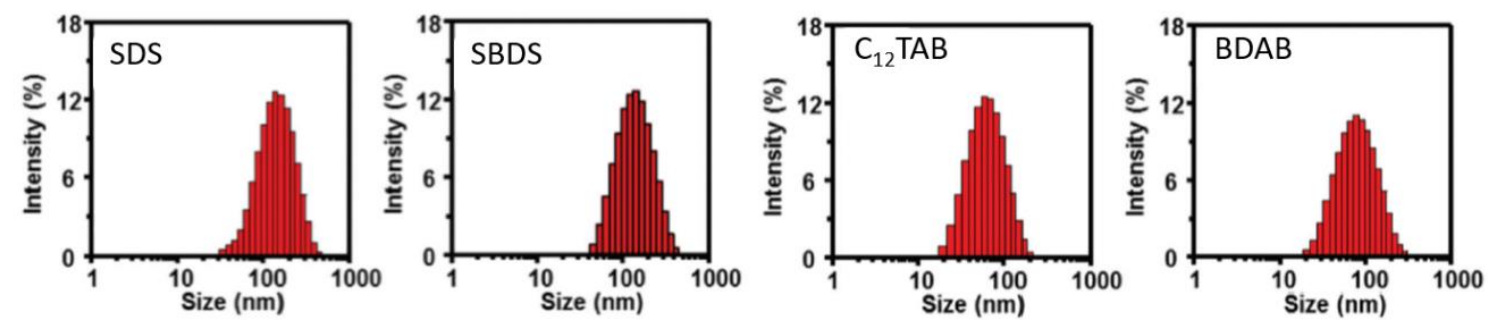

Figure 9. a) Chemical formulae of different kinds of surfactant, classified by family. b) Influence of the surfactant type on the nanoparticle size (measured by DLS) using SDS, SDBS, $\mathrm{C}_{12} \mathrm{TAB}$, and BDAB. Adapted with permission from ref 55. Copyright 2017 Royal Society of Chemistry.

Besides these three main parameters influencing the nanoparticle size when using the miniemulsion technique (i.e. the shear force applied when mixing both phases, the initial concentration of polymer in the organic phase, and the surfactant nature and concentration), other parameters can also have an impact. For example, Xie et al. reported that the oil-to-water volume ratio partially affects the nanoparticle size, mainly for high concentrations of polymer in the primary organic solution $\left(30 \mathrm{mg} \cdot \mathrm{mL}^{-}\right.$ $\left.{ }^{1}\right)$, with a nanoparticle size decreasing from 73 to $36 \mathrm{~nm}$ when the ratio decreased from 0.33 to 0.16 . This effect was however not reported for lower concentrations of active material $\left(15 \mathrm{mg} \cdot \mathrm{mL}^{-1}\right)$. This behavior is similar to the effect of the initial polymer concentration in the organic phase. ${ }^{41}$ 
The organic solvents used are mostly chlorinated, but Pan et al. reported the use of $o$-xylene, which is less detrimental to the environment and human health, and compared it with chloroform. Both solvents emulsified with aqueous solutions of SDS and led to nanoparticle sizes around $30 \mathrm{~nm}$ after solvent evaporation (Table 1, entry 7). ${ }^{56}$ Moreover, although the solvent evaporation time was longer in the case of $o$-xylene (since by comparison chloroform is more volatile), no particle aggregation was observed. The same observation was made by Kietzke et $a l .{ }^{37}$ Therefore, the choice of organic solvent for the miniemulsion is not limited to chlorinated solvents, and non-chlorinated solvents can be considered, without apparent influence on the nanoparticle size.

Holmes et al. reported the preparation of $\mathrm{P} 3 \mathrm{HT}: \mathrm{PC}_{61} \mathrm{BM}$ nanoparticles with different molar masses of $\mathrm{P} \mathrm{HT} .{ }^{34}$ It appeared that the molar mass had little influence over the nanoparticle size. As shown in Table 1, entry 8, the nanoparticle size is relatively constant (around $150 \mathrm{~nm}$ ) for different P3HT molar masses $\left(M_{w}\right)\left(5,9,12,16,44\right.$ and $\left.72 \mathrm{~kg} \cdot \mathrm{mol}^{-1}\right) \cdot{ }^{34}$ Similarly, the donor:acceptor (D:A) ratio in composite nanoparticles did not influence the nanoparticle size. ${ }^{60,78}$

The miniemulsion technique permits the preparation of concentrated dispersions, suitable for different deposition methods, including slot die coating, which will be discussed later in this review. Andersen et al. reported the production of NP ink batches of $100 \mathrm{~mL}$ volume with an active material concentration of $60 \mathrm{mg} \cdot \mathrm{mL}^{-1}{ }^{49}$ The final solids content varies from 1 to $60 \mathrm{mg} \cdot \mathrm{mL}^{-1}$, as reported in Table 1, which is high enough to perform a single deposition of the NP dispersion into a continuous film coating for OPV applications. This point highlights the importance of the use of a surfactant, essential to avoid aggregation of such hydrophobic nanoparticles at high concentration.

The colloidal stability of the nanoparticle dispersions was studied in several articles, as reported in Table 1, which ranged from a few days to half a year. This stability, again, is mainly due to the presence of the surfactant molecules which prevent aggregation of nanoparticles (attributed to the repulsion of negatively charged surfactant headgroups, in the case of SDS). The NP dispersion stability can be studied either by zeta potential analysis, in which a high value, positive or negative, ensures a high 
surfactant coverage and a strong repulsion between particles; ${ }^{44,79}$ or by following the evolution of the nanoparticle size (DLS, SEM or TEM, for example) over time. ${ }^{41}$ For example, if nanoparticle aggregation occurs over time, the size of the object measured by DLS (rather than actual nanoparticle size) increases, or an additional peak corresponding to larger particle aggregates is observed.

Finally, the versatility of the miniemulsion technique has been demonstrated over the last ten years with a large range of active material types, as shown in Figure 7. The miniemulsion technique is therefore a powerful tool to design semiconducting nanoparticles of very different systems, from fullerene derivatives to low band gap polymer-based nanoparticles.

\section{Nanoprecipitation}

As an alternative to the miniemulsion technique, the nanoprecipitation process (also called solvent displacement, reprecipitation technique, or Ouzo process ${ }^{80}$ ) is a general method to generate surfactant-free nanoparticles. It requires the selection of a solvent and a non-solvent for the organic semiconductor that are fully miscible. ${ }^{27}$ As represented in Figure 10, the nanoprecipitation process is simple: the polymer is first dissolved in an organic solvent (typically THF) and then mixed into a large volume of non-solvent (usually water) under stirring (step A, Figure 10). The addition rate (of the organic solvent into water or reverse) is quite important to obtain stable dispersions exhibiting narrow size distributions. ${ }^{81}$ In the literature, the most common approach to form conjugated polymer nanoparticles is to add the organic phase dropwise to water while stirring. ${ }^{26,42,82}$ However, it is worth mentioning that Chambon et al. reported the generation of monomodal nanoparticle dispersions by quickly adding a large amount of water into the organic phase..$^{43,83}$

The formation of nanoparticles occurs during the solvent displacement step (step B, Figure 10). Upon mixing with water, the organic phase containing the polymer becomes greatly supersaturated, which results in the nucleation of polymer solution droplets. ${ }^{80,84-86}$ The organic phase immediately diffuses to the nearest droplet, so that the supersaturation decreases and no further nucleation occurs. When 
the polymer concentration decreases below the critical supersaturation concentration, the growth of the nuclei occurs by accumulation of surrounding polymer chains or small molecules leading to the formation of nanoparticles. The nuclei stop growing when the polymer concentration in the mixture has dropped below the equilibrium saturation concentration. A second growth mechanism, with coagulation of non-stabilized nanoparticles, can occur until the onset of colloidal stability, with absorption of ions or surfactant molecules, for example. Whereas a supersaturation that is too high crosses the spinodal decomposition, leading to phase separation and cluster-cluster aggregation, a low supersaturation leads to stable dispersions through nucleation and growth mechanisms.

Finally, the removal of the organic solvent is performed to obtain nanoparticles dispersed in water (step C, Figure 10). It can be done simply by applying an argon or nitrogen flux, ${ }^{26,42}$ or by rotary/vacuum evaporation..$^{82}$ Unlike the miniemulsion method, a surfactant is not required to achieve the formation of nanoparticles with the nanoprecipitation technique. ${ }^{27,81}$ For surfactant-free nanoprecipitation, no concentration step was further reported.

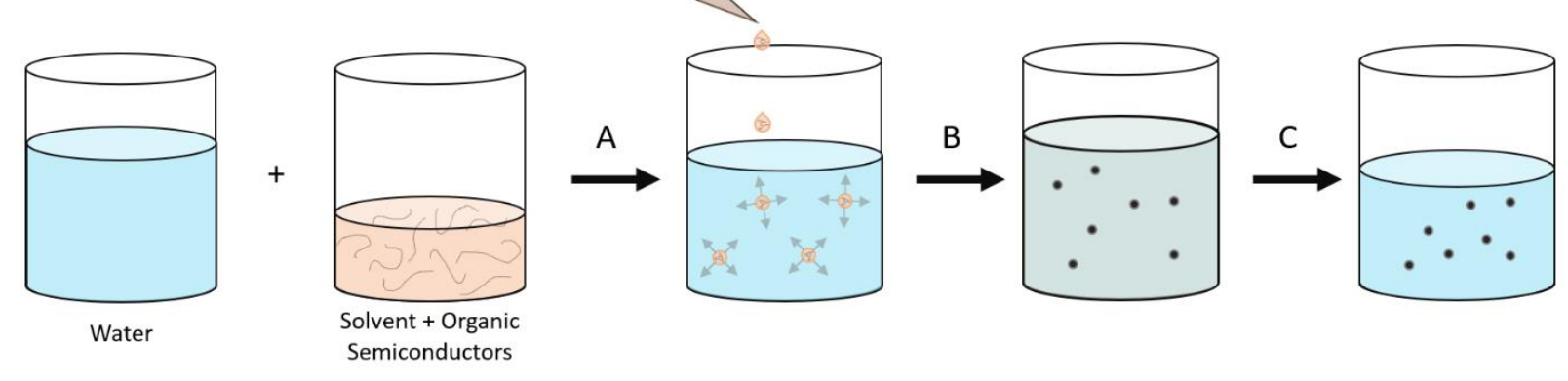

Figure 10. Nanoprecipitation preparation technique: Organic semiconductors dissolved in organic solvent are added dropwise in water under stirring (A). Since the solvent and non-solvent are miscible, a solvent displacement step occurs, resulting in the formation of nanoparticles (through nucleation and growth) (B). Removal of the organic solvent to obtain a dispersion in aqueous media (C).

Based on the theory behind the formation of nanoparticles through nanoprecipitation, the size and size distribution of the nanoparticles depend on the rapid mixing of the two phases, prior to the nucleation step..$^{84,87}$ Therefore, solvents exhibiting high miscibility lead to smaller nanoparticles, since 
homogenization of supersaturation in the media leads to numerous small nuclei (homogenization should occur before nucleation). The use of suitable mixing techniques, which increase the homogenization rate (high-shear and ultra-sonification process), leads to smaller nanoparticles and narrow size distribution..$^{82,88}$ Indeed a higher rate of stirring leads to an enhanced mass transfer, which can induce rapid nucleation, producing smaller nanoparticles. When using mechanical stirring, which is the most reported stirring mode, the stirring rate is a key parameter in tuning the size of the nanoparticles. Prunet and coworkers studied the influence of the stirring rate on PCDTBT:PC ${ }_{71} B M$ nanoparticle size, introducing quickly a small volume of organic solution (THF) into a large volume of aqueous phase. ${ }^{42}$ They observed that a stirring rate which is too high leads to the formation of a vortex resulting in nanoparticle agglomeration, whereas large particles are obtained if the stirring rate is too low.

Other experimental parameters such as the concentration of active material in the organic phase, the solvent/non-solvent volume ratio, and the potential presence of a surfactant, also play a significant role in the nanoparticle size, as summarized in Table 2.

The initial concentration of active material seems to be the most influential parameter on the nanoparticle size, as concluded by multiple research studies. ${ }^{42,81,89}$ This is explained by the presence of more polymer chains in a single nanodroplet, increasing the size of the nanoparticles after the solvent displacement step. Table 2, entry 1, illustrates this increase of the nanoparticle size with the increasing concentration of the starting materials. Additionally, they showed an influence of the polymer molar mass (in the case of P3HT) on the nanoparticle size, with larger nanoparticles for higher molar masses. ${ }^{89}$

The influence of the donor:acceptor ratio on the nanoparticle size has been reported, using $\mathrm{P} 3 \mathrm{HT}: \mathrm{PC}_{61} \mathrm{BM}$ or poly[2-methoxy-5-(2-ethylhexyl-oxy)-p-phenylene-vinylene] (MEH-PPV): $\mathrm{PC}_{61} \mathrm{BM} .^{90-92}$ For MEH-PPV:PC ${ }_{61} \mathrm{BM}$ systems, the size of the nanoparticles varied from 31.2 to $54.8 \mathrm{~nm}$ (measured by 
DLS) when the $\mathrm{PC}_{61} \mathrm{BM}$ loading was increased from 0 to $50 \%$, respectively. This increase in size is reported to correspond to the aggregation of $\mathrm{PC}_{61} \mathrm{BM}$ molecules.

The solvent/non-solvent volume ratio also has an impact on the final nanoparticle size. ${ }^{27,83}$ Prunet $e t$ al. reported an increase in the size of nanoparticles with the increase in solvent/non-solvent volume ratio. ${ }^{42}$ They studied the influence of the final concentration of the active components in water, keeping a fixed initial concentration in THF. They observed that below $0.1 \mathrm{mg} \cdot \mathrm{mL}^{-1}$, the final concentration has a rather low impact on the size of the nanoparticles, however, above $0.1 \mathrm{mg} \cdot \mathrm{mL}^{-1}$ the size increases rapidly from $50 \mathrm{~nm}$ for a concentration of $0.1 \mathrm{mg} \cdot \mathrm{mL}^{-1}$ to $133 \mathrm{~nm}$ for $0.3 \mathrm{mg} \cdot \mathrm{mL}^{-1}$, until the formation of micrometric aggregates at $0.4 \mathrm{mg} \cdot \mathrm{mL}^{-1}$ (Table 2, entry 2).

The main drawbacks of the nanoprecipitation process are the limited stability as well as the low solids content of the final dispersion. Table $\mathbf{2}$ indicates a general lack of colloidal stability over time, with very few stability values reported in the literature, and low concentrations of particles in the final dispersion achieved.

Darwis et al. reported that the colloidal stability of $\mathrm{P} 3 \mathrm{HT}: \mathrm{PC}_{61} \mathrm{BM}$ nanoparticles over time was too low to be considered, so the NP ink should be used immediately after preparation for OPV device fabrication. ${ }^{93}$ However, Palacio Valera et al. reported high zeta potentials for dispersions of $\mathrm{P} 3 \mathrm{HT}: \mathrm{PC}_{61} \mathrm{BM}$ nanoparticles prepared through nanoprecipitation, with a specific core-shell morphology, as will be discussed further in subsection "Donor-Acceptor Morphology". ${ }^{83}$ Without addition of $\mathrm{PC}_{61} \mathrm{BM}, \mathrm{P} 3 \mathrm{HT}$ nanoparticles showed low colloidal stability (zeta potential of $\sim-1.8 \mathrm{mV}$ ) for DMSO dispersions, but with the addition of $\mathrm{PC}_{61} \mathrm{BM}$, the zeta potential of the P3HT NPs increased up to $-29 \mathrm{mV}$ leading to stable dispersions. With the formation of a $\mathrm{PC}_{61} \mathrm{BM}$ shell using a second solvent displacement step in water, the stability increased, reaching a zeta potential up to $-40 \mathrm{mV}$. The authors proposed that this increased stability could be due to the appearance of charges on the nanoparticle surface in water, probably due to the hydrolysis of the ester group into a carboxylate anion. 
A small domain of the polymer/solvent/non-solvent phase diagram, the Ouzo region, between the spinodal and the binodal curves, enables the formation of stable dispersions without additives (concentration of supersaturated material below the spinodal decomposition concentration). ${ }^{94}$ Therefore, stable dispersions mainly present very low solids content, ${ }^{84}$ and rarely exceed $1 \mathrm{mg} \cdot \mathrm{mL}^{-1}$ (Table 2), which is too low for an efficient deposition into an active layer. Successive depositions are therefore required to obtain a suitable thickness. ${ }^{10,42,93}$ Thus, dispersions prepared through nanoprecipitation are limited to low stability and low solids content. Besides, both limitations are linked, since, if the solids content increases, aggregation is more likely to occur.

The addition of a surfactant in the nanoprecipitation process is a way to enhance the stability of the dispersion, and lead to more concentrated inks. As reported in Table 2, entries 5 and 6, the use of a surfactant results in higher stability of the colloidal dispersion over time, ${ }^{95}$ or at high concentration. ${ }^{26}$ Indeed, Xie et al. reached a final nanoparticle concentration of $2.5 \mathrm{mg} \cdot \mathrm{mL}^{-1}$ prior to concentration, using Pluronic F127, a poloxamer and non-ionic surfactant. This surfactant has the advantage of possessing a temperature-sensitive critical micelle concentration (TS-CMC), enabling surfactant stripping to be performed prior to deposition of the nanoparticles into films (further detail on the consideration of surfactants for OPV and the use of such poloxamers are given in the subsection "Surfactant Limitations and Removal" ${ }^{26}$ The authors also reported that higher concentrations of nanoparticles, up to 50 to $80 \mathrm{mg} \cdot \mathrm{mL}^{-1}$, can be reached after centrifugation, which indicates the stabilizing power of the addition of poloxamer surfactant to the dispersion.

Table 2. Experimental conditions of nanoprecipitation techniques for the preparation of aqueous organic semiconductor nanoparticle dispersions.

\begin{tabular}{|c|c|c|c|c|c|c|c|c|c|}
\hline Entry & System & Solvent & $\begin{array}{l}{[\mathrm{AM}]_{\mathrm{OP}}{ }^{\mathrm{a}}} \\
(\mathrm{mg} / \mathrm{mL})\end{array}$ & $\begin{array}{c}{[\mathrm{NPs}]^{\mathrm{b}}} \\
(\mathrm{mg} / \mathrm{mL})\end{array}$ & Surfactant & $\begin{array}{c}\text { Solvent:Water } \\
(\mathrm{v} / \mathrm{v})\end{array}$ & $\begin{array}{l}\text { Diameter } \\
(\mathrm{nm})^{d}\end{array}$ & $\begin{array}{l}\text { Stability } \\
\text { (day) }\end{array}$ & Ref \\
\hline \multirow{3}{*}{1} & \multirow{3}{*}{ PCDTBT:PC ${ }_{71} \mathrm{BM}$} & \multirow{3}{*}{ THF } & 0.1 & 0.01 & \multirow{3}{*}{ No } & 0.06 & 40 & \multirow{3}{*}{$2-3$} & \multirow{3}{*}{42} \\
\hline & & & 0.25 & 0.01 & & 0.02 & 42 & & \\
\hline & & & 0.5 & 0.01 & & 0.01 & 48 & & \\
\hline
\end{tabular}




\begin{tabular}{|c|c|c|c|c|c|c|c|c|c|}
\hline & & & & & \\
\hline & & & 1 & 0.01 & & 0.01 & 81 & & \\
\hline \multirow{3}{*}{2} & & & 0.5 & 0.10 & & 0.20 & 50 & & \\
\hline & & & 0.5 & 0.30 & & 0.60 & 133 & & \\
\hline & & & 0.5 & 0.40 & & 0.80 & aggregates & & \\
\hline \multirow{2}{*}{3} & APFO-3 & \multirow{2}{*}{ THF } & \multirow{2}{*}{0.05} & \multirow{2}{*}{0.01} & \multirow{2}{*}{ No } & \multirow{2}{*}{0.20} & 36 & \multirow{2}{*}{$>10$} & \multirow{2}{*}{82} \\
\hline & PCDTBT & & & & & & 42 & & \\
\hline \multirow{2}{*}{4} & \multirow{2}{*}{ P3HT:PC ${ }_{61} B M$} & THF & 1 & 0.11 & No & 0.11 & $42^{1}$ & - & 92 \\
\hline & & THF & 1 & 0.12 & No & 0.13 & 79 & - & 96 \\
\hline 5 & P3HT & THF & 0.19 & 0.01 & Tween 80 & 0.01 & - & $>60$ & 95 \\
\hline \multirow{3}{*}{6} & P3HT:o-IDTBR & \multirow{3}{*}{ THF } & \multirow{3}{*}{5} & $80^{c}$ & & & 90 & \multirow{3}{*}{$>90$} & \multirow{3}{*}{26} \\
\hline & PBQ-QF:o-IDTBR & & & $50^{c}$ & F127 & 0.50 & 68 & & \\
\hline & PBQ-QF:ITIC & & & $50^{c}$ & & & 77 & & \\
\hline
\end{tabular}
a: Concentration of active material (AM) in the organic phase (OP).
b: Concentration of nanoparticle dispersions in the aqueous dispersion (prior to concentration of the nanoparticles).
c: Concentration of nanoparticle dispersions after concentration step (centrifugation, etc.).
$\mathrm{d}$ : Nanoparticle diameter measured by DLS, except ${ }^{1}$ measured by TEM. 


\section{DONOR}

APFO-3

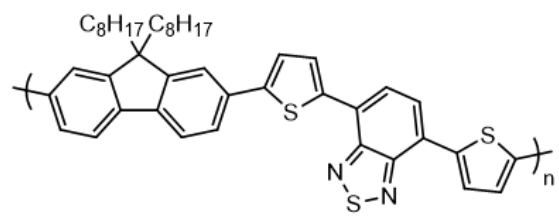

poly[2,7-(9,9-dioctyl-fluorene)-alt-5,5-(4',7'-di-2-thienyl$2^{\prime}, 1^{\prime}, 3^{\prime}$ benzothiadiazole)]

PBQ-QF

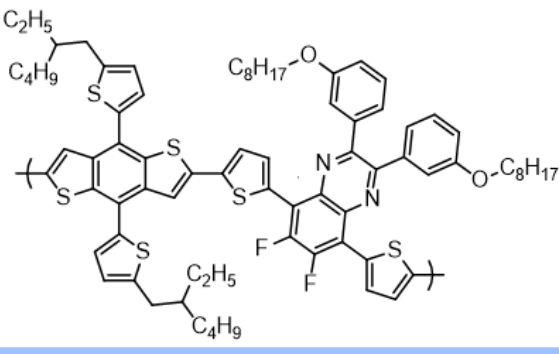

PCDTBT

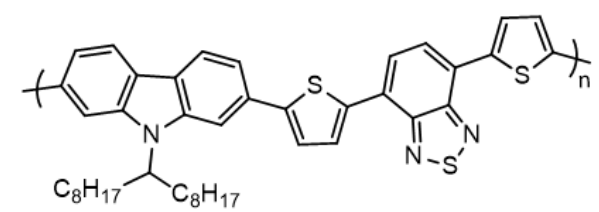

poly[N-9'-heptadecanyl-2,7-carbazole-alt-5,5-(4,7-di-2-thienyl-2', $1^{\prime}, 3^{\prime}-$ benzothiadiazole]

P3HT

\section{ACCEPTOR}

$\mathrm{PC}_{61} \mathrm{BM}$

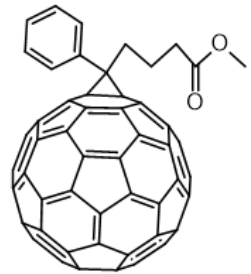

$[6,6]$-phenyl- $\mathrm{C}_{61}$-butyric acid methyl ester

$\mathrm{PC}_{71} \mathrm{BM}$

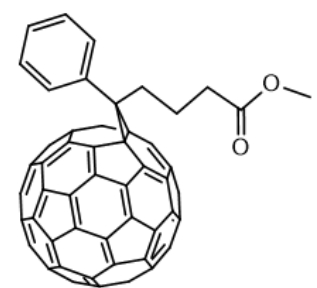

$[6,6]$-phenyl- $C_{71}$-butyric acid methyl este

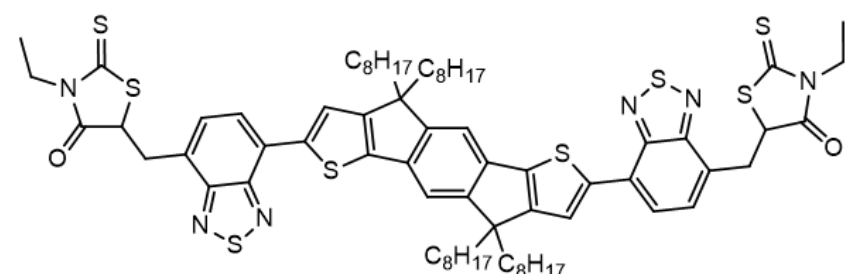

((5Z,5'Z)-5,5'-(((4,4,9,9-tetraoctyl-4,9-dihydro-s-indaceno[1,2-b:5,6- $\left.b^{\prime}\right]$ dithiophene2,7diyl)bis(benzo[c] $[1,2,5]$ thiadiazole-7,4-diyl))bis(methanylylidene))bis(3-ethyl-2thioxothiazolidin-4-one))

ITIC

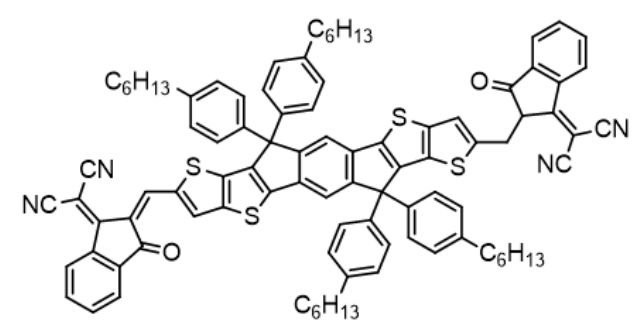

3,9-bis(methylene-(3-(1,1-dicyanomethylene)-indanone))-5,5,11,11tetrakis(4-hexylphenyl)-dithieno[2,3-d:2',3'-d']-s-indaceno[1,2-b:5,6-

$b^{\prime}$ ]dithiophene

Figure 11. Chemical formulae of the main active materials used, of both donor and acceptor type, to prepare aqueous organic semiconductor nanoparticles using the nanoprecipitation process, according to the literature on OPV. 


\section{Conclusions on the Dispersion Techniques}

As detailed in the subsections above, nanoprecipitation and miniemulsion techniques are very versatile for the preparation of aqueous dispersions of organic semiconductor nanoparticles using a large range of organic semiconductor materials (Figure 7 and Figure 11) and with controllable nanoparticle size. Herein we provide a brief comparison of the strengths and weaknesses of these two techniques (Figure 12)

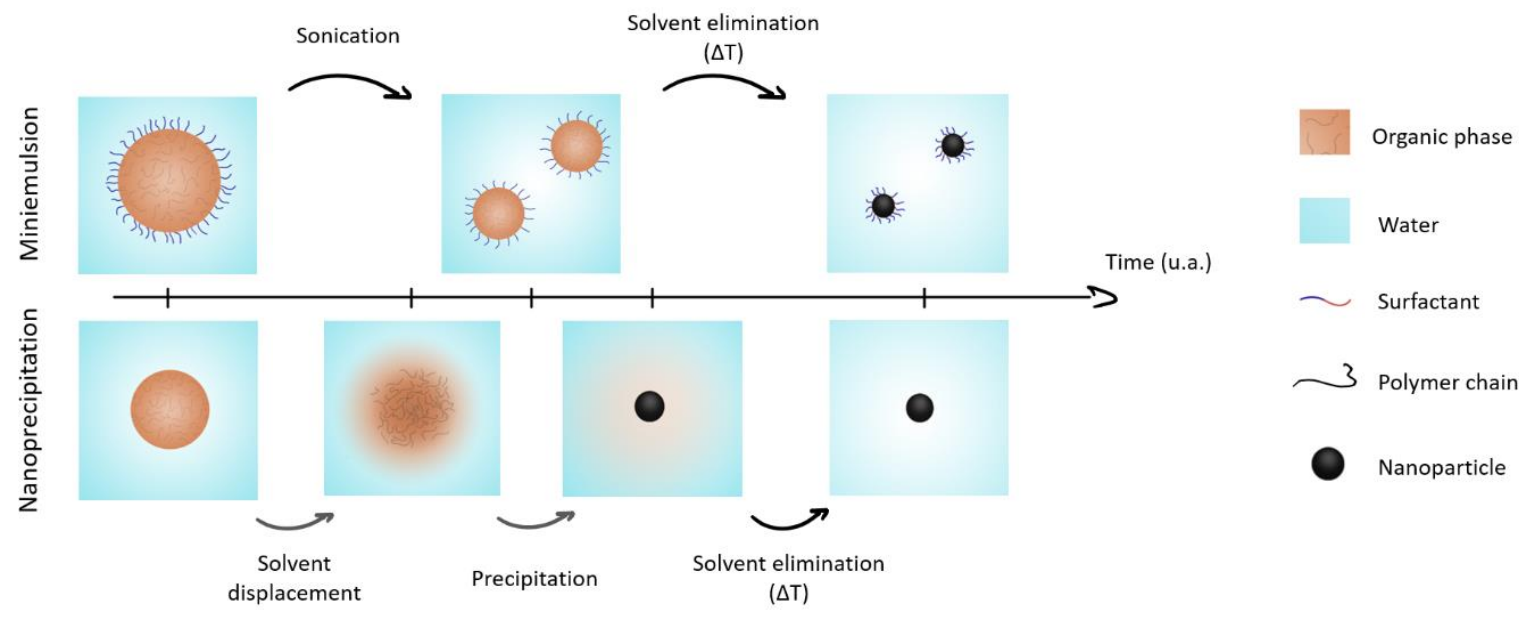

Figure 12. Formation mechanism and timeline of nanoparticles generated through miniemulsion or nanoprecipitation. Mechanisms occurring without external stimuli are represented in grey.

As depicted in Figure 12, the formation mechanism of nanoparticles via miniemulsion or nanoprecipitation is quite different. This difference lies in the degree of miscibility of the polymer solvent and non-solvent. For the miniemulsion route, both are immiscible, the formation of nanoparticles being achieved through external stimuli with, firstly, sonication to create smaller droplets, and then, thermal heating to remove the organic solvent, and the generation of a colloidal dispersion. In the nanoprecipitation route, the miscibility of the polymer solvent and non-solvent leads directly to the formation of nanoparticles, without any external stimuli, with the displacement of the polymer solvent in the non-solvent. External forces, such as mechanical stirring or sonication, can be applied to influence the nanoparticle size. Therefore, the particle formation by nanoprecipitation is 
extremely quick, whereas a long evaporation time is required for miniemulsion preparation to achieve nanoparticles. The removal of the organic solvent also needs to be performed in the nanoprecipitation process, in order to obtain waterborne dispersions, but this step is performed after the formation of the nanoparticles.

In terms of size, smaller nanoparticles are obtained using miniemulsion, with a minimum size of $5 \mathrm{~nm}$ ${ }^{41}$ whereas the smallest size obtained by nanoprecipitation was reported to be $36 \mathrm{~nm} .{ }^{82}$ This size difference is due to the mixing method: mechanical stirring is mainly used in the case of nanoprecipitation, whereas sonication is used for miniemulsion, leading to a more efficient droplet breakdown. Notably, the smallest nanoparticle size reported in the case of nanoprecipitation was obtained using sonication in addition to mechanical stirring. ${ }^{82}$

Miniemulsion enables the preparation of highly stable dispersions, due to the presence of stabilizing surfactant molecules, with colloidal stabilities reported of a few days, weeks, or even months. ${ }^{41,53}$ The colloidal stability of the dispersion in the case of nanoprecipitation is commonly reported to be low, leading to a low suitability for active layer deposition. ${ }^{93}$

Using the miniemulsion route, several teams reached a solids content of the dispersions of up to 60 $\mathrm{mg} \cdot \mathrm{mL}^{-1}$, which is sufficiently high to enable the deposition of an active layer from the dispersion. ${ }^{41,48,49}$ Since the concentration of nanoparticles in the dispersion is directly linked to the colloidal stability, it appears that nanoprecipitation leads to dispersions with very low solids content. This could be explained by the fact that additive-free metastable dispersions can only be achieved in the Ouzo domain, reachable for low concentrations of material and high solvent/non-solvent volume ratios. ${ }^{80,84}$ The main drawback of the miniemulsion technique is the presence of surfactant, which has to be removed prior to the use of the dispersion as an active layer. However, surfactants are required to achieve stable dispersions with high solids content by nanoprecipitation, as reported by Xie and coworkers. ${ }^{26}$ By using Pluronic F127 as a surfactant, the authors were able to reach a concentration for 
the aqueous NP ink of up to $80 \mathrm{mg} \cdot \mathrm{mL}^{-1}$, which is in the range of concentrations reachable by miniemulsion.

The miniemulsion route is more commonly used than the nanoprecipitation route in the OPV community. However, a particular interest in the nanoprecipitation process has arisen during the last few years, especially since the work of Xie et al., who managed to overcome the main drawbacks of nanoprecipitation and reached record efficiencies of $7.5 \%$ in NP-based OPV. ${ }^{26}$

In general, nanoprecipitation and miniemulsion are two efficient techniques providing aqueous dispersions of organic semiconductor nanoparticles, and, with further optimization, they could become a truly viable way to design active materials for OPV.

\section{Nanoparticle Structure}

The internal structure of the nanoparticle plays a significant role over the final performance of the photovoltaic devices, due to its influence on the exciton dissociation efficiency as well as charge transport. One of the main advantages of using the nanoparticle approach lies in the creation of acceptor and donor domains in the size range of the exciton diffusion length ( $10 \mathrm{~nm}){ }^{22,43,61,87,90}$ Conjugated polymers can also be semi-crystalline, and therefore crystallinity is a key feature for photoactive layers, becoming an important parameter to take into account when controlling nanoparticle structure.

The nanoparticle morphology described below is inherent to composite nanoparticles, i.e. nanoparticles containing both donor and acceptor materials, and depends on the material type, the preparation technique, and several preparation parameters.

\section{Donor-Acceptor Morphology}

In OPV, interfaces of electron acceptor and donor materials are required to split the exciton and generate free charges. There is a delicate balance between i) mixing on a sufficiently intimate scale to provide a large surface area of contact between both materials for efficient exciton dissociation, and 
ii) mixing on a sufficiently large scale to enable the existence of donor and acceptor nanodomains, in order to provide charge percolation pathways for holes and electrons to their respective collecting electrodes. This section is therefore focused on the origin of the morphology inside composite nanoparticles (prior to deposition as an active layer and any exposure to thermal annealing treatments) as well as the influence of experimental parameters. The final morphology in OPV devices is susceptible to evolution upon thermal treatment, but this will be described in detail in section "Incorporation in Solar Cells".

Influence of the technique

Kietzke et al. $^{37}$ reported in 2003 the presence of phase separation inside nanoparticles of poly $(9,9-$ bis(2-ethylhexyl)fluorene-2,7-diyl)(PF2/6) and Me-LPPP prepared by miniemulsion, according to photoluminescence (PL) measurements, since they reported a relatively low quenching of PL. Therefore, the authors concluded that the morphology inside the nanoparticle was not finely mixed and hence different to the classic bulk heterojunction, but no indication of the nature of the phase separation was proposed. ${ }^{37}$ They presumed that the size of the domains is determined by the nanoparticle size, since the PL quenching for nanoparticles presenting a diameter of $69 \mathrm{~nm}$ was stronger than the PL quenching for nanoparticles with a diameter of $143 \mathrm{~nm}$. The following year, the same phase separation was reported using PFB:F8BT nanoparticles prepared by miniemulsion.${ }^{97}$ Snaith et al. also reported the preparation of PFB:F8BT nanoparticles through miniemulsion and built devices from the NP dispersion. The authors mentioned that the poor device performance observed could be related to a core-shell morphology, but with no further evidence of such morphology. ${ }^{98} \mathrm{~A}$ few years after, Kietzke et al. proposed a Janus-like morphology (also known as biphasic) to describe PFB:F8BT nanoparticles, extrapolating results obtained for nanoparticles composed of polystyrene and poly(propylene carbonate)..$^{99}$

However, thanks to the appearance of high-resolution microscopy techniques with chemical sensitivity such as scanning transmission X-ray microscopy (STXM), Burke et al. demonstrated that the 
predominant morphology of PFB:F8BT nanoparticles, prepared via miniemulsion, was core-shell, with a F8BT-rich core. ${ }^{100}$ This core-shell morphology soon became the main morphology obtained for nanoparticles of organic semiconductors prepared through miniemulsion. This morphology results from thermodynamically-driven self-assembly of the two active materials and has since 2011 been reported by many research teams. ${ }^{40,93,101}$ A summary of the core-shell nanoparticle morphology measured by synchrotron-based STXM for several material systems is provided in Figure $13 .{ }^{48,69,78}$ Color contrast scale bars are included on the STXM composition maps, where light colors correspond to higher component concentrations.

a) P3HT $\mathrm{PC}_{61} \mathrm{BM}$
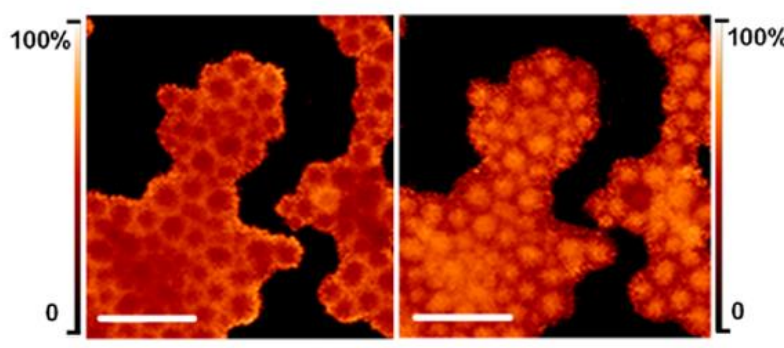

b)

TQ1 $\mathrm{PC}_{71} \mathrm{BM}$
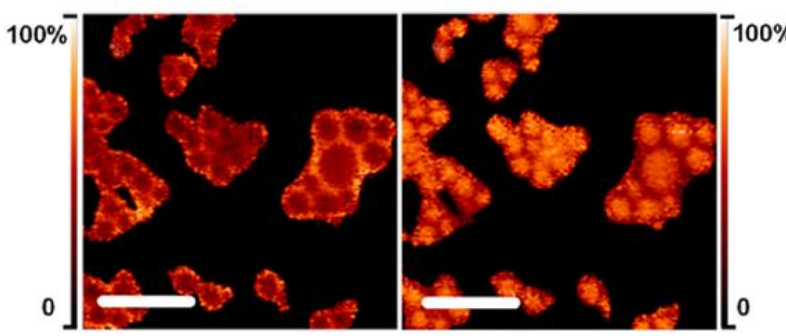

c)

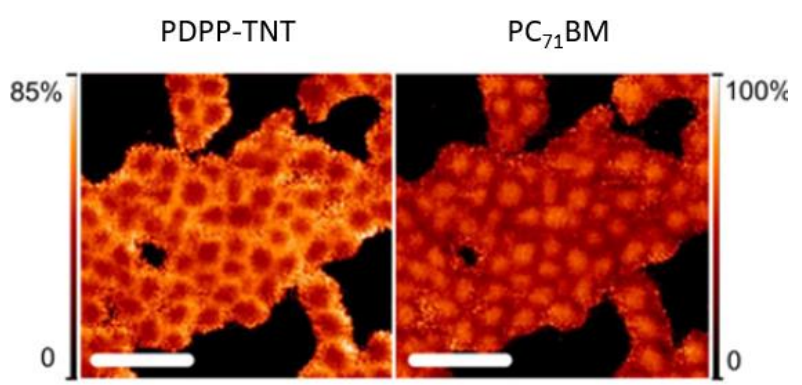

Figure 13. STXM maps of nanoparticles of different D:A material systems prepared by the miniemulsion technique. The left column corresponds to the polymer donor fractional composition and the right column to the fullerene acceptor fractional composition. Scale bars are $600 \mathrm{~nm}$ for all maps. Panel a) adapted with permission from ref 78. Copyright 2015 Elsevier. Panel b) adapted with permission from ref 69. Copyright 2016 Elsevier. Panel c) adapted with permission from ref 48. Copyright 2017 Materials Research Society. 
The core-shell morphology is a consequence of the duration of solvent evaporation from colloidal droplets during the miniemulsion process. While the oil-phase solvent is removed, nanodroplets are slowly reduced to form nanoparticles, therefore, both organic semiconductor components inside a nanodroplet start to rearrange to minimize unfavorable interfacial interactions. ${ }^{40}$ Similarly to the standard BHJ morphology, the miscibility of both materials, linked to their surface energy, plays an important role in the morphology formation, ${ }^{102,103}$ and here, in the morphology of nanoparticles more specifically. As it has been reported for various material systems, the material showing the lowest surface energy (in general conjugated polymers in comparison to fullerene derivatives) migrates to the outer surface of the miniemulsion droplets to minimize total energy during the solvent evaporation step. ${ }^{34,53,69,104}$ According to this theory, Dam and coworkers reported that the morphology of PSBTBT and $\mathrm{P} 3 \mathrm{HT}$ blended with $\mathrm{PC}_{61} \mathrm{BM}$ could be predicted by the knowledge of their surface energy (both donors had a predicted surface energy lower than that of $\left.\mathrm{PC}_{61} \mathrm{BM}\right)$. The morphology of PSBTBT:PC $61 \mathrm{BM}$ and $\mathrm{P} 3 \mathrm{HT}: \mathrm{PC}_{61} \mathrm{BM}$ nanoparticles was then measured by STXM and confirmed to be core-shell, with a polymer-rich shell. ${ }^{105}$ More recently, Al-Mudhaffer et al. reported that the core-shell morphology can be modulated by using active materials with higher miscibilities, such as $\mathrm{P} 3 \mathrm{HT}$ : indene $\mathrm{C}_{60}$ bisadduct (ICBA). ${ }^{106}$

Pan et al. observed higher PL intensities using $o$-xylene as an organic solvent for the preparation of nanoparticles through miniemulsion, in comparison to dispersions using chloroform as an organic solvent. They concluded that the use of $o$-xylene led to the formation of more segregated domains within the nanoparticle. ${ }^{56} \mathrm{D}^{\prime}$ Olieslaeger et al. reported a highly intermixed morphology for PCDTBT:PC ${ }_{71} \mathrm{BM}$ nanoparticles with no evidence of a core-shell structure, ${ }^{46}$ in contradiction with the work of Parrenin et al. on the same system. ${ }^{53}$ However, they did not explore the reason for such a different morphology. One can hypothesize that the organic solvent selection influences the final morphology, by modifying the interfacial interactions and behaviors of both components. 
The surfactant nature could also influence the nanoparticle morphology, since Subianto et al. reported, for $\mathrm{P} 3 \mathrm{HT}: \mathrm{PC}_{61} \mathrm{BM}$ nanoparticles, a morphology that is not core-shell but instead comprised of mixed pure sub-domains of donor and acceptor, while using 2-(3-thienyl)ethyloxybutylsulfonate sodium salt (TEBS) as a surfactant. This observation was made according to neutron scattering data. ${ }^{107}$ Also, Kosco et al. reported similar observations for poly([2,6'-4,8-di(5-ethylhexylthienyl)benzo(1,2- $b ; 3,3-$ b]dithiophene]\{3-fluoro-2[(2-ethylhexyl)carbon-yl]thieno[3,4-b]thiophenediyl\}) (PTB7-Th):eh-IDTBR nanoparticles, with a more intermixed morphology using TEBS instead of SDS as a surfactant for miniemulsion preparation. ${ }^{108}$ Subianto and coauthors hypothesized that the core-shell morphology obtained using SDS was linked to the affinity of P3HT with SDS (due to the long aliphatic tail of SDS), but by using TEBS, the affinity of the surfactant to $\mathrm{P} 3 \mathrm{HT}$ and $\mathrm{PC}_{61} \mathrm{BM}$ was almost equal. Therefore, the phase segregation within the particle was no longer thermodynamically favored.

Holmes et al. reported that the molar mass of $\mathrm{P} 3 \mathrm{HT}$ in a $\mathrm{P} 3 \mathrm{HT}: \mathrm{PC}_{61} \mathrm{BM}$ system has little influence over the morphology of the nanoparticles. ${ }^{34}$ For a molar mass ranging from 9 to $72 \mathrm{~kg} \cdot \mathrm{mol}^{-1}\left(\mathrm{M}_{\mathrm{w}}\right), \mathrm{PC}_{61} \mathrm{BM}-$ rich cores and P3HT-rich shells are identified in every case. In the case of nanoparticles prepared from low molar mass $\mathrm{P} 3 \mathrm{HT}\left(5 \mathrm{~kg} \cdot \mathrm{mol}^{-1}\right)$, no evidence of the nanoparticle shape was reported after deposition on a substrate (necessary to conduct STXM analysis), attributed to the very short polymer chain length. Increasing the loading of $\mathrm{PC}_{61} \mathrm{BM}$ in $\mathrm{P} 3 \mathrm{HT}: \mathrm{PC}_{61} \mathrm{BM}$ nanoparticles was reported to increase the $\mathrm{PC}_{61} \mathrm{BM}-$ rich core size by keeping the same core composition. The proportion of $\mathrm{PC}_{61} \mathrm{BM}$ in the shell is increased as well, as reported by Holmes et al., with an increase from 18 to $33 \%$ of $\mathrm{PC}_{61} \mathrm{BM}$ in the P3HT-rich shell for 1:0.5 to $1: 2$ donor:acceptor ratios. ${ }^{78}$

The core-shell morphology, and hence the phase separation of both components, can lead to superior thermal stability of the nanoparticles, as reported by Holmes et al. for PDPP-TNT:PC ${ }_{71} B M$ nanoparticles. Since both components are not intimately mixed, their respective $T_{g} s$ remain separated (rather than a system possessing a single blend $\mathrm{T}_{\mathrm{g}}$ ), ${ }^{109}$ leading to a higher activation threshold (the temperature of the higher $\mathrm{T}_{\mathrm{g}}$ material) for any morphological evolution in the nanoparticle film. Also, 
the presence of more crystalline domains in the nanoparticle shell (linked to a lower concentration of $\mathrm{PC}_{71} \mathrm{BM}$ in the polymer-rich shell) increases the temperature required to thermally modify the nanoparticle shape and morphology. ${ }^{48}$ Therefore, the core-shell morphology is advantageous in order to extend the lifetime of devices by increasing their thermal stability, as the utilization temperatures for OPV can reach $85^{\circ} \mathrm{C}$ under solar exposure. ${ }^{110}$

It is known that for OPV, the blend ratio between the donor and the acceptor plays a significant role on the final performance. Therefore, the presence of two different domains in core-shell nanoparticles (and so two different blend ratios) is important to consider, as evidenced by Dam et al. ${ }^{105}$ Composite nanoparticles of $\mathrm{PSBTBT}: \mathrm{PC}_{61} \mathrm{BM}$ and $\mathrm{P} 3 \mathrm{HT}: \mathrm{PC}_{61} \mathrm{BM}$ (diameter $\sim 24 \mathrm{~nm}$ ), were prepared via miniemulsion. They both presented a core-shell morphology with a polymer-rich shell showing similar composition (69 and $67 \%$ of donor material, respectively). However, the $\mathrm{PC}_{61} \mathrm{BM}$-rich core was richer in $\mathrm{PC}_{61} \mathrm{BM}$ for $\mathrm{P} 3 \mathrm{HT}: \mathrm{PC}_{61} \mathrm{BM}$ nanoparticles $(80 \%)$ in comparison to that of the PSBTBT:PC ${ }_{61} \mathrm{BM}$ system (60\%). Therefore, despite PSBTBT being a much higher performing low band gap material, OPV devices exhibited similar efficiencies, since the optimized ratio for $\mathrm{P} 3 \mathrm{HT}: \mathrm{PC}_{61} \mathrm{BM}(1: 0.8)$ was located in the shell region (80\% of the nanoparticle volume) and the optimized ratio for PSBTBT:PC ${ }_{61} \mathrm{BM}$ (1:1.5) was located in the core of the nanoparticles ( $18 \%$ of the nanoparticle volume). Consequently, the composition of the shell, which dominates charge generation and transport, should be optimized in priority. ${ }^{105}$

Nanoprecipitation, in contrast to miniemulsion, leads to the formation of nanoparticles presenting a more blended morphology, ${ }^{93}$ as represented in Figure 14. Darwis et al. attribute this morphology to the fact that the preparation does not require a long solvent removal step to form the nanoparticles, and that the mechanism of solvent displacement is fast enough to "freeze" the distribution of both components in the nanoparticle, which results in highly intermixed domains. This morphology was further attested by Prunet et al. on PCDTBT:PC $71 \mathrm{BM}$ nanoparticles, where no core-shell morphology is 
observed by STXM, ${ }^{42}$ in contrast to their previous work reporting a core-shell morphology for the same system prepared via miniemulsion..$^{53}$

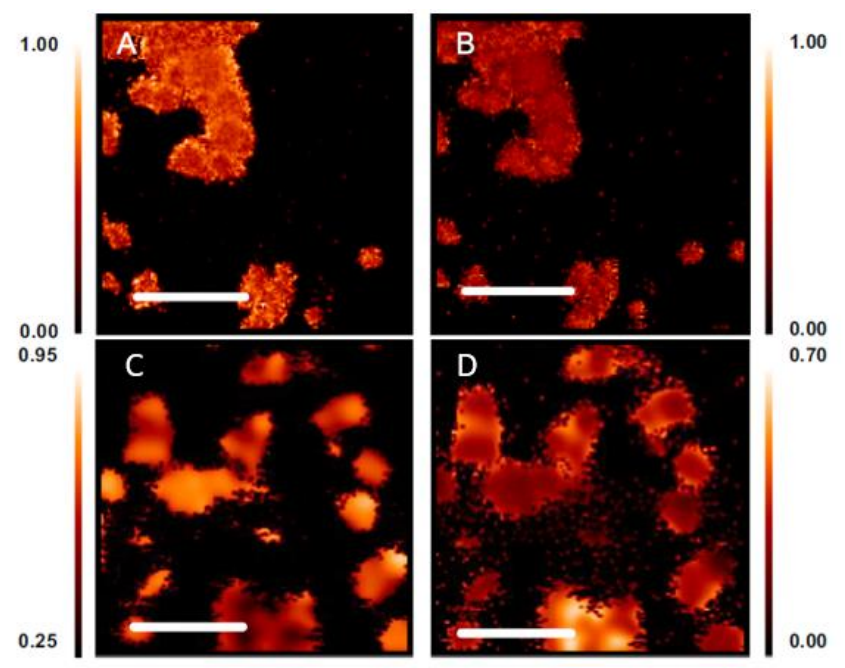

Figure 14. STXM maps of $\mathrm{P} 3 \mathrm{HT}: \mathrm{PC}_{61} \mathrm{BM}$ nanoparticles prepared via miniemulsion $(\mathrm{A}, \mathrm{B})$ and nanoprecipitation (C,D) with $\mathrm{P} 3 \mathrm{HT}$ composition $(\mathrm{A}, \mathrm{C})$ and $\mathrm{PC}_{61} \mathrm{BM}$ composition $(\mathrm{B}, \mathrm{D})$. Scale bars are fixed at $500 \mathrm{~nm}$. Adapted with permission from ref 93. Copyright 2014 Elsevier.

It is worth mentioning that, playing on the principle of nanoprecipitation, Chambon et al. performed successive solvent displacements to create $\mathrm{P} 3 \mathrm{HT}: \mathrm{PC}{ }_{61} \mathrm{BM}$ core-shell nanoparticles (Figure 15). ${ }^{43}$ The first solvent displacement from THF to dimethyl sulfoxide (DMSO) led to the precipitation of P3HT, with $\mathrm{PC}_{61} \mathrm{BM}$ molecules still soluble in the solution (for concentrations below the solubility threshold in DMSO). Then, through a second solvent displacement step from the mixture THF/DMSO to water, $\mathrm{PC}_{61} \mathrm{BM}$ precipitates preferentially on the $\mathrm{P} 3 \mathrm{HT}$ nanoparticles, forming a $\mathrm{PC}_{61} \mathrm{BM}$ shell (observed by an increase in the nanoparticle size after the second displacement step ) ${ }^{43,83}$ Therefore the core-shell morphology is not exclusive to preparation via miniemulsion and can be achieved through nanoprecipitation. 


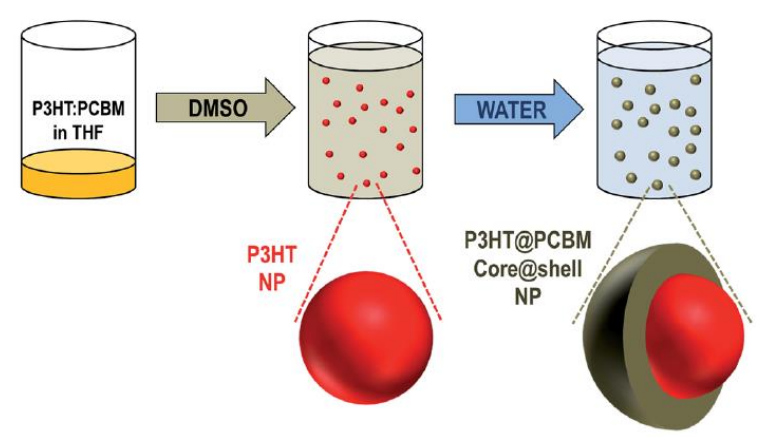

Figure 15. Nanoprecipitation using successive solvent displacements to create a core-shell structure. Adapted with permission from ref 43. Copyright 2014 Royal Society of Chemistry.

As evidenced by Clafton et al. for a $\mathrm{P} 3 \mathrm{HT}: \mathrm{PC}_{61} \mathrm{BM}$ system, increasing the $\mathrm{PC}_{61} \mathrm{BM}$ proportion in the blend leads to larger domains of $\mathrm{PC}_{61} \mathrm{BM}$ and a decrease in the $\mathrm{P} 3 \mathrm{HT}$ domain size, leading to an increase in bimolecular recombination (when the proportion of $\mathrm{PC}_{61} \mathrm{BM}$ is too high), rather than geminate recombination. ${ }^{111}$ This increase in bimolecular recombination was linked to the formation of larger $\mathrm{PC}_{61} \mathrm{BM}$ aggregates instead of numerous small aggregates in the nanoparticles. Also, the crystallinity of regio-regular $\mathrm{P} 3 \mathrm{HT}$ is reported to constrain the diffusion of $\mathrm{PC}_{61} \mathrm{BM}$, whereas amorphous regiorandom $\mathrm{P} 3 \mathrm{HT}$ appears to produce a more homogeneous distribution of $\mathrm{PC}_{61} \mathrm{BM}$ into the nanoparticle, since molecules of $\mathrm{PC}_{61} \mathrm{BM}$ diffuse through amorphous $\mathrm{P} 3 \mathrm{HT}$ domains but not crystalline $\mathrm{P} 3 \mathrm{HT}$ domains. ${ }^{112-114}$

Morphology limitations

Thus, a fundamental difference between the morphology of nanoparticles prepared via miniemulsion and nanoprecipitation was collectively accepted, as represented schematically in Figure 16. Therefore, studies to determine the best morphology were proposed by various teams. 


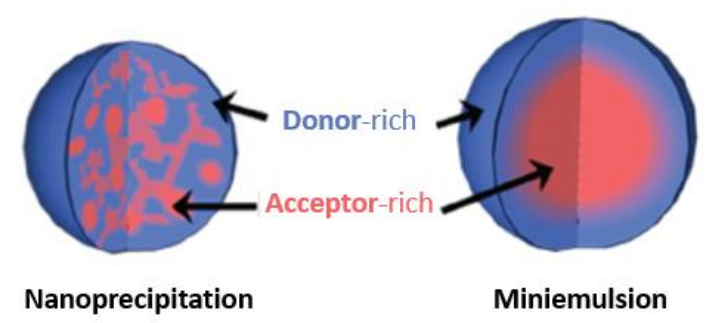

Figure 16. Schematic representation of the morphology of nanoparticles prepared via nanoprecipitation or miniemulsion. Adapted with permission from ref 96. Copyright 2015 Royal Society of Chemistry.

Richards et al. reported the influence of the component distribution inside a nanoparticle over the charge generation and transport, for a $\mathrm{P} 3 \mathrm{HT}: \mathrm{PC}_{61} \mathrm{BM}$ system. ${ }^{40}$ As expected, a core-shell morphology was reported for nanoparticles prepared by miniemulsion whereas nanoparticles prepared with another technique (made from organogel) ${ }^{39}$ presented a blended morphology (similar to the morphology reached by nanoprecipitation). Charge transport properties of nanoparticles prepared via miniemulsion seemed to be limited by the core-shell morphology, leading to a hindrance in the transport of free charges, especially out of the $\mathrm{PC}_{61} \mathrm{BM}$ core. Therefore, the authors identified the blended morphology as the most desired option for optimizing charge generation and transport. ${ }^{40}$ The trapping effect of the core-shell morphology was also reported by Yamamoto et al., limiting conduction pathways for free charges. ${ }^{61}$

Al-Mudhaffer et al. investigated the origin of the performance limitations observed for nanoparticlebased OPV devices (nanoparticles of $\sim 40 \mathrm{~nm}$ diameter prepared via miniemulsion, hence presenting a core-shell morphology) in comparison to standard BHJ OPV. ${ }^{115}$ They demonstrated that the main photocurrent loss mechanism was the poor charge generation yields which appeared to be a result of the morphology of donor and acceptor domains, i.e. the core-shell morphology. The presence of acceptor- or donor-rich domains decreases the probabilities for an exciton encountering an interface, and dissociating. This conclusion was also proposed by other teams ${ }^{68}$ and by Schwarz et al., who conducted steady-state absorption and sub-picosecond transient absorption spectroscopy. ${ }^{96}$ In the 
NP-based OPV community, it was therefore hypothesized that the core-shell structure of nanoparticles was unsuitable for reaching an optimal OPV active layer morphology.

However, the nanoparticle size could be optimized, since by decreasing the size of the nanoparticle, the size of both acceptor- and donor-rich domains is expected to decrease. Colberts et al. experimentally observed an increase in PCE (from $1.05 \%$ and $1.73 \%$ ) by decreasing the size of PDPP5T:PC 61 BM nanoparticles (from 60 and $44 \mathrm{~nm}$ ). ${ }^{44} \mathrm{An}$ optimized structure (feature size and particle size) could overcome the current limitations. For instance, Feron et al. reported through dynamic Monte Carlo simulations and real experiments, made on $\mathrm{P} 3 \mathrm{HT}: \mathrm{PC}_{61} \mathrm{BM}$ nanoparticles, that the optimal nanoparticle size was $\sim 30 \mathrm{~nm} .{ }^{116}$ The core-shell morphology offers a powerful tool for controlling the size of each domain in accordance with the exciton diffusion length, accessible by customizing the nanoparticle size. By playing on experimental parameters, the morphology of nanoparticles prepared via miniemulsion can be modulated and potentially the current limitations linked to the core-shell morphology can be overcome. As will be presented later in this review (subsection "Thermal Treatment of the Active Layer"), thermal treatment of the nanoparticles can in some cases overcome the limitations of a core-shell morphology leading to an enhancement of the final OPV performance, with for example, the diffusion of ICBA in the P3HT-rich domain during drying or annealing, ${ }^{104}$ or the creation of nano-pathways between neighboring $\mathrm{PC}_{71} \mathrm{BM}$-rich cores. ${ }^{69}$

Furthermore, Marks et al. reported the preparation of more intermixed domains through miniemulsion. ${ }^{57}$ The authors compared two different techniques for the removal of the organic solvent for $\mathrm{P} 3 \mathrm{HT}: \mathrm{PC}_{61} \mathrm{BM}$ nanoparticles: through heating (commonly used, $3+$ hours), or through rotary evaporation under vacuum, leading to a faster removal of the organic solvent (few seconds). The removal by rotary evaporation led to more intermixed domains, confirmed by STXM measurements, since a shorter time is available during the nanoparticle formation phase to reach the thermodynamic equilibrium morphology. The presence of more intermixed donor-acceptor domains led to an increase in exciton dissociation efficiency to $50 \%$ in comparison to $\mathrm{P} 3 \mathrm{HT}: \mathrm{PC}_{61} \mathrm{BM}$ nanoparticles presenting a 
standard core-shell morphology (standard evaporation). However, even though a clear improvement in the exciton dissociation efficiency was achieved, final OPV performance was similar to that of OPV devices prepared with nanoparticles of a typical core-shell morphology, which is still far from the performance reached in standard BHJ OPV. The authors concluded that morphology was not the only limiting factor, and other parameters such as the presence of free-surfactant molecules should also be considered..$^{57}$

\section{Crystallinity}

The influence of crystallinity on charge transport is well known in standard BHJ OPV devices, with a higher charge carrier mobility in crystalline domains. ${ }^{117}$ Also, crystalline domains show an increased exciton diffusion length. Thus, crystallinity enhances the exciton dissociation efficiency as well. ${ }^{118,119}$ Crystallinity of conjugated polymers is hence an important parameter to consider, in order to improve the final performance of NP OPV devices. As the morphology of the active layer processed from nanoparticles is highly dependent on the initial morphology of the nanoparticles, the crystallinity of the active layer is related to the initial crystallinity in the nanoparticles. Moreover, thermal treatments are known to facilitate crystalline domain growth, but their influence over the active layer morphology will be later described in the subsection "Thermal Treatment of the Active Layer". As previously discussed for morphology, the influence of the preparation technique, as well as several experimental parameters, are expected to modify crystallinity inside a nanoparticle before any post-treatment. Its evolution only concerns semi-crystalline polymers such as P3HT, ${ }^{48,100}$ PDPP-TNT, ${ }^{120}$ PDPP5T, ${ }^{41,44}$ and therefore, this sub-section is not relevant to amorphous polymer studies such as $\mathrm{PFB}^{121}$ or TQ1. ${ }^{69}$

P3HT-based systems were mainly investigated in the case of nanoparticles prepared by miniemulsion, and the presence of both crystalline and amorphous regions in nanoparticles was confirmed by numerous teams, usually by the observation of vibronic features marked by a red-shift in UV-visible absorbance spectra associated with crystalline P3HT domains. ${ }^{78,104,119,122,123}$ Labastide et al. reported 
the presence of non-uniformly oriented crystalline domains of P3HT by high-resolution transmission electron microscopy (TEM) inside a nanoparticle. ${ }^{124}$

Since miniemulsion requires a surfactant, some groups studied the effect of the surfactant nature on the crystallinity of nanoparticles. Cho et al. reported that the alkyl chain length of the surfactant affects the crystallinity of PNDI-TVT-based nanoparticles, by screening surfactants from the $C_{x} T A B$ family. ${ }^{55} A$ longer alkyl chain resulted in higher intermolecular packing of the semiconducting materials, and an ordered morphology was obtained. Tan et al. reported the influence of the presence of aromatic group(s) in the molecular structure of the surfactant over the degree of crystallinity in P3HT nanoparticles. ${ }^{54}$ By increasing the number of aromatic groups (from SDS to DOBS), they observed redshifted vibrational peaks in the UV-visible absorbance spectra (Figure 17a), due to a possible $\pi$-stacking of $\mathrm{P} 3 \mathrm{HT}$ chains with the surfactant.

Nagarjuna et al. investigated the influence of the solvent on the uniformity and structural order of P3HT nanoparticles prepared via miniemulsion. ${ }^{125}$ Three types of solvents were used: chloroform (good solvent), toluene (marginal solvent), and a mixture between both. During the evaporation step, the polymer chains started to aggregate inside toluene droplets (lower precipitation threshold due to the lower solubility). Therefore, the authors concluded that a solvent annealing effect occurred, resulting in more time for polymer chains to reorganize, increasing the final degree of crystallinity of P3HT. 


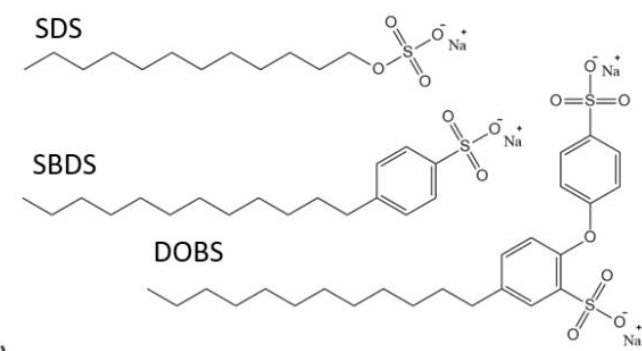

b)

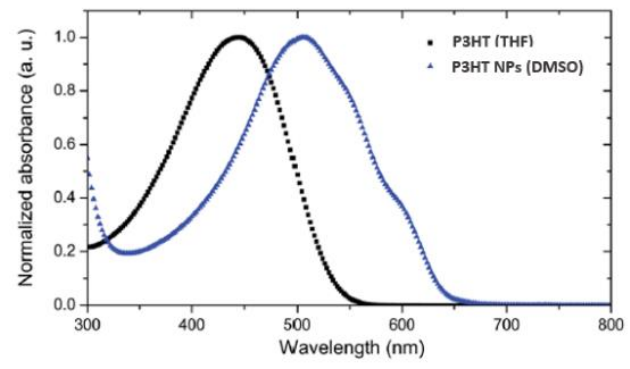

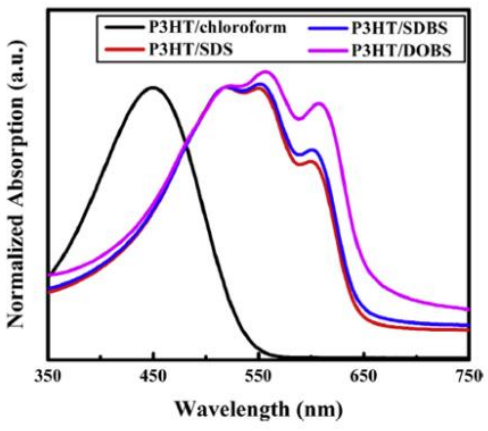

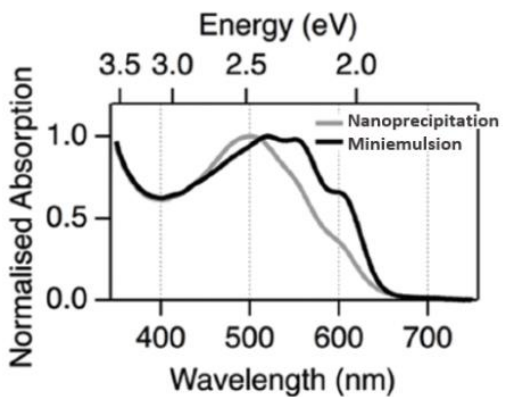

Figure 17. UV-Vis absorption spectra of a) P3HT colloids prepared via miniemulsion using different surfactants (with an increasing number of aromatic rings) and corresponding chemical formulae. b) of P3HT dissolved in THF and $\mathrm{P} 3 \mathrm{HT}$ nanoparticles after solvent displacement from THF to DMSO, c) P3HT:PC ${ }_{61} \mathrm{BM}$ nanoparticles prepared via nanoprecipitation or miniemulsion. Panel a) adapted with permission from ref 54. Copyright 2016 Elsevier. Panel b) adapted with permission from ref 43. Copyright 2014 Royal Society of Chemistry. Panel c) adapted with permission from ref 96. Copyright 2015 Royal Society of Chemistry.

For nanoparticles prepared by nanoprecipitation, a bathochromic shift was directly observed after the nanoparticle formation in UV-visible spectroscopy indicating an increase in the ordering of polymeric chains, after chloroform evaporation, as shown in Figure 17b. ${ }^{43,89,92}$ The increased inter-chain interactions can also be identified by a red-shift in photoluminescence spectra. ${ }^{82,90}$ Shimizu et al. reported that the initial polymer concentration (P3HT in THF) influences the inter-chain packing inside a nanoparticle, observing also a red-shift in UV-visible absorbance. ${ }^{89}$ The authors proposed that a higher number of precipitated polymeric chains at high concentration led to a stronger chain packing and larger crystals in the nanoparticle structure. However, they also observed an increase in the NP 
size with increasing concentration. The higher conformational freedom given by larger NP diameters can also explain the improved interchain packing structure.

A reduction in the $\mathrm{P} 3 \mathrm{HT}$ crystalline domains by increasing the $\mathrm{PC}_{61} \mathrm{BM}$ concentration was reported by Pedersen et al. for nanoparticles prepared through miniemulsion, with X-ray studies of the dispersion. ${ }^{126}$ The same observation was made by Hu et al., who reported a blue-shift in the absorbance spectra when increasing the $\mathrm{PC}_{61} \mathrm{BM}$ loading. ${ }^{92} \mathrm{Hu}$ et al. also identified the presence of two types of $\mathrm{P} 3 \mathrm{HT}$ crystals: Type I (showing a shorter $\pi$-stacking distance, backbones spaced by approximatively $3.8 \AA$ ) and Type II (longer $\pi$-stacking distance, approx. $4.5 \AA$ ) ; ${ }^{127,128}$ since they reported that the formation of highly aligned structures such as $\mathrm{H}$-aggregates, were unlikely in blended materials. The $\mathrm{PC}_{61} \mathrm{BM}$ loading influenced the preferential formation of Type I P3HT crystals, leading to a closer $\pi-\pi$ stacking between the thiophene units. ${ }^{90,92}$

Finally, Schwarz et al. compared the crystallinity of nanoparticles from miniemulsion and nanoprecipitation techniques. As illustrated in Figure 17c, nanoparticles prepared via miniemulsion presented a higher degree of crystallinity, with a stronger red-shift in comparison to those prepared through nanoprecipitation. The crystalline proportions of P3HT were estimated at $57 \%$ and $45 \%$ for miniemulsion-based and nanoprecipitation-based nanoparticles, respectively, through steady-state absorption spectroscopy. This study was carried out on particles with almost the same size, and the same donor:acceptor ratio. ${ }^{96}$

However, this difference in crystallinity could be partially related to the difference in structure of each nanoparticle (core-shell for miniemulsion and heterojunction-like for nanoprecipitation). As previously evidenced by other teams, the presence of $\mathrm{PC}_{61} \mathrm{BM}$ led to a decrease in the $\mathrm{P} 3 \mathrm{HT}$ crystalline domain size. ${ }^{92,126}$ Marks et al. reported a lower crystallinity for more intermixed nanoparticles prepared through miniemulsion (in the case of quick evaporation of chloroform (few seconds), through rotary evaporation under vacuum), in comparison with standard core-shell nanoparticles (evaporation of 
chloroform over $3+$ hours) ${ }^{57}$ The authors attributed this decrease in crystallinity to the reduced time available for polymer chains to reorganize.

Thus, a more intermixed internal morphology of nanoparticles prepared via nanoprecipitation impedes the crystallization of $\mathrm{P} 3 \mathrm{HT}$, whereas nanoparticles presenting a core-shell structure can develop larger crystalline domains in the polymer phase.

\section{Incorporation in Solar Cells}

From the design of nanoparticles for OPV to the processing of solar cells, numerous steps are still required, particularly the active layer casting from the nanoparticle dispersion. Many parameters influence the final performance of solar cells, such as the type of nanoparticles used, their size, the type of surfactant and its concentration, but also parameters related to the formation of the active layer, such as thermal treatment, surface energy of the substrate, choice of electrode material, etc. An understanding of the influence of each parameter is mandatory in enabling the design of optimized devices showing high efficiency. Finally, the up-scaling techniques used to process the nanoparticle dispersion into solar cells will be discussed in this section.

In order to characterize the efficiency of the solar cell, four main parameters are considered in this review, the PCE, the short-circuit current density $\left(\mathrm{J}_{\mathrm{sc}}\right)$, the open-circuit voltage $\left(\mathrm{V}_{\mathrm{OC}}\right)$ and the fill factor (FF). ${ }^{129} \mathrm{~V}_{\mathrm{oc}}$ is mainly driven by the energy gap between the HOMO (highest occupied molecular orbital) of the donor and the LUMO (lowest unoccupied molecular orbital) of the acceptor, but will also be impacted by different kinds of recombination (radiative, non-radiative) in devices as well as the presence of pinholes in the various device layers. ${ }^{130}$ The morphology and microstructure of the active layer greatly influence these parameters. An increase in the donor:acceptor interfacial area, leading to more intermixed domains, results in an enhanced $V_{o c}$ while crystalline and/or aggregated domains decrease it. ${ }^{131-133} \mathrm{~J}_{\mathrm{SC}}$ is driven by the absorption profile of the system, but will be limited by the geminate recombination if donor:acceptor domains are larger than the exciton diffusion length and by the free-charge mobility. FF corresponds to the ratio between the maximum output and the $J_{S C} * V_{O C}$ 
product. This ideality factor is linked to the competition between charge recombination and charge transport in the system. ${ }^{129}$ The PCE corresponds to the ratio between the maximum output power of the device and the incident power (from sunlight).

\section{Active Layer Formation and Composition}

Layer Deposition

Going from the nanoparticle dispersion in ink to the formation of the active layer is a complex process. Depending on the preparation technique used (miniemulsion or nanoprecipitation), the first deposition step differs. Nanoparticles prepared via nanoprecipitation were mainly reported with low stability, resulting in dispersions with low solids content, leading to non-uniform layers after one single deposition (spin-coating step). Consequently, various deposition steps are required to form a uniform, homogeneous active layer. ${ }^{10,19,93}$ In the case of miniemulsion-based nanoparticle inks, only one deposition step leads to a sufficiently homogeneous active layer, due to the use of concentrated and stable dispersions. ${ }^{26,57}$ Besides, it was found that the number of depositions has an influence over the final OPV performance, tuning the film thickness and roughness. Stapleton et al. reported in 2012 that a stacking of five layers made from PFB:F8BT nanoparticles led to the best performance with $0.39 \%$ PCE, reaching even higher efficiencies than their homologous standard $\mathrm{BHJ}(0.2 \% \mathrm{PCE}) .{ }^{58}$ However, a total of five layers was reported as the limit to avoid the appearance of cracks on the active layer surface.

Vaughan et al. also reported better efficiencies for NP-based devices in comparison to their BHJ counterparts, for PFB:F8BT (0.82 \% and $0.36 \%$ PCE respectively) ${ }^{134}$ and PDPP-TNT:PC ${ }_{70} \mathrm{BM}_{\text {sMstems }}$ (1.99\% and $1.05 \%$ PCE respectively). ${ }^{120}$ They proposed that higher efficiencies resulted from a finer distribution of the acceptor and donor domains, more in the range of the exciton diffusion length, leading to an enhanced exciton dissociation. This hypothesis was further confirmed by Yamamoto et al. for PTBT-DPP:ICBA systems, as presented in Figure 18, with atomic force microscopy (AFM) 
images. ${ }^{61}$ The authors reported a PCE of $2.63 \%$ for NP-based devices vs $0.44 \%$ for standard BHJ devices. Thus, a real advantage of nanoparticles lies in the ability to optimize the morphology of the active layer during the nanoparticle preparation, which was maintained during the deposition process, whereas in the case of standard $\mathrm{BHJ}$, the active layer morphology is controlled by deposition conditions..$^{15,48,123,135}$

a)

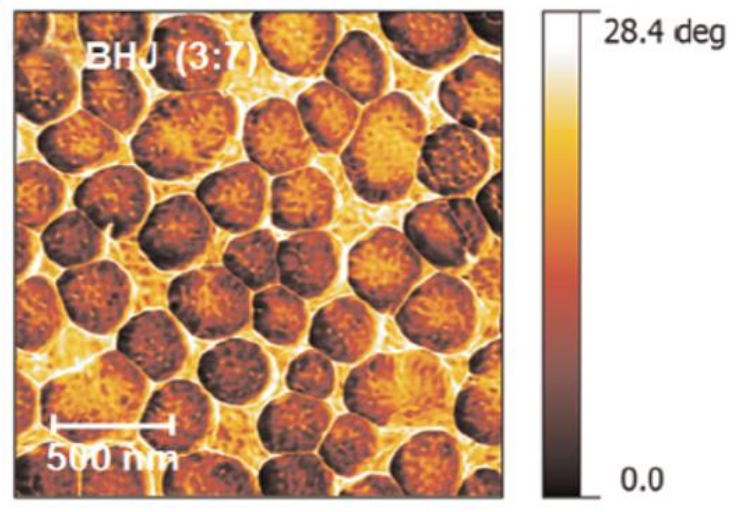

b)

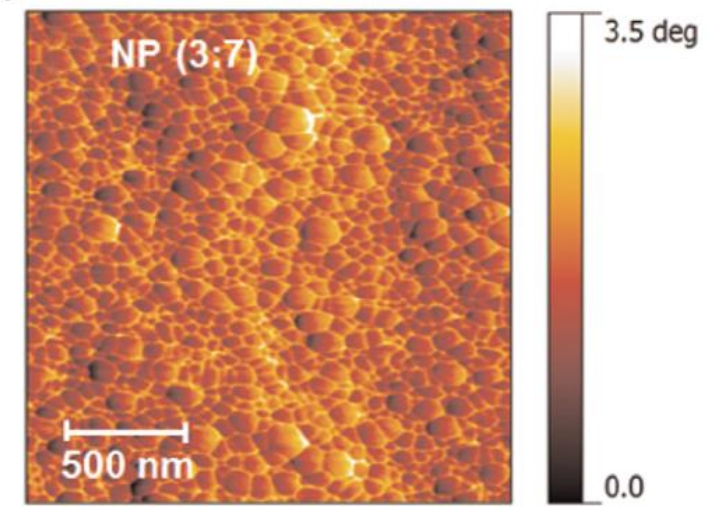

Figure 18. AFM phase contrast images of a) standard PTBT-DPP:ICBA BHJ and b) NP-based films, nanoparticle size $\sim 85 \mathrm{~nm}$. Adapted with permission from ref 61. Copyright 2015 Elsevier.

During the deposition step, the nanoparticle size has an influence over the final OPV performance. Very large particles are undesirable for OPV, since a large size limits the film to 1 or 2 particle layers stacked (since the active layer thickness is $\sim 100 \mathrm{~nm}$ ), and can lead to an increase in the potential shortcircuits and heterogeneities on the active layer surface. ${ }^{65}$ Vaughan et al. reported that small nanoparticles ( $30 \mathrm{~nm}$ in their study) led to densely packed films (presenting a hexagonal packing structure) ${ }^{47}$ which is more suited for the deposition of OPV active layers. In the case of singlecomponent nanoparticles, Satapathi et al. reported that the size of the particles should be in the range of the exciton diffusion length, in order to have a high exciton dissociation efficiency. ${ }^{67}$

The influence of the nanoparticle size for composite nanoparticles on the final OPV device performance is also partially linked to the good intermixing of both active materials, which can be 
investigated by performing PL spectroscopy. For nanoparticles of PFB:F8BT prepared via miniemulsion, Kietzke et al. reported that the PL quenching of nanoparticles presenting a diameter of $45 \mathrm{~nm}$ was higher than that of those with a diameter of $96 \mathrm{~nm} .{ }^{97}$ Reduction of both domain sizes is expected to enhance exciton dissociation, especially for nanoparticles presenting a core-shell structure, which in the end, can enhance the final OPV device performance. ${ }^{44,78}$ Colberts et al. showed that the enhanced exciton dissociation in smaller composite nanoparticles (below $45 \mathrm{~nm}$ ) was correlated to optimized OPV device performance. ${ }^{44}$ However, this trend is not general and OPV devices presenting the best performance do not always follow the same tendency. For instance, Gehan et al. reported better efficiencies for composite and single-component $\mathrm{P} 3 \mathrm{HT}: \mathrm{PC}_{61} \mathrm{BM}$ nanoparticles presenting a diameter of $80 \mathrm{~nm}$ (study considering nanoparticles from 70 to $115 \mathrm{~nm}$ ). ${ }^{123}$ Therefore, not only a good exciton dissociation efficiency (which can be attested through PL) is necessary when optimizing the nanoparticle size, other parameters, such as charge transport, should also be investigated.

\section{Single-Component vs Composite Nanoparticles}

Two key approaches can be considered to prepare the active layer: the deposition of nanoparticles combining the donor and the acceptor inside the same nanoparticle (composite nanoparticles) or the use of a combination of pure nanoparticles, creating a donor:acceptor nanoparticle blend (singlecomponent nanoparticles). Many research teams have tried to identify the best approach in order to optimize the solar cell fabrication process.

Kietzke et al. reported that better efficiencies can be obtained by using composite nanoparticles of PFB:F8BT, according to the higher incident photon to converted electron efficiency (IPCE), when integrated into solar cells. ${ }^{97}$ Gehan et al. proposed a comprehensive study on a P3HT:PC ${ }_{61} \mathrm{BM}$ system, with nanoparticles of almost the same size in both cases (around $80 \mathrm{~nm}$ diameter). By looking first to conducting AFM images of the active layer, they reported highly intermixed domains for composite nanoparticles throughout the film, whereas larger domains were observed for the single-component nanoparticle-based active layer. This result suggested that the exciton dissociation could be less 
efficient for single-component nanoparticles, which was confirmed by the performance of both devices, with reported PCE of $2.15 \%$ and $1.84 \%$ for composite and single-component nanoparticles, respectively. ${ }^{123}$ In the case of composite nanoparticles, a higher $V_{\text {oc }}$ was observed (Figure 19), whereas $\mathrm{J}_{\mathrm{sc}}$ was similar in both cases. The authors attributed the difference in performance for these two morphologies to the degree of intermixing of the donor and acceptor domains, lower in the case of single-component nanoparticles, affecting both $\mathrm{V}_{\mathrm{Oc}}$ and FF.

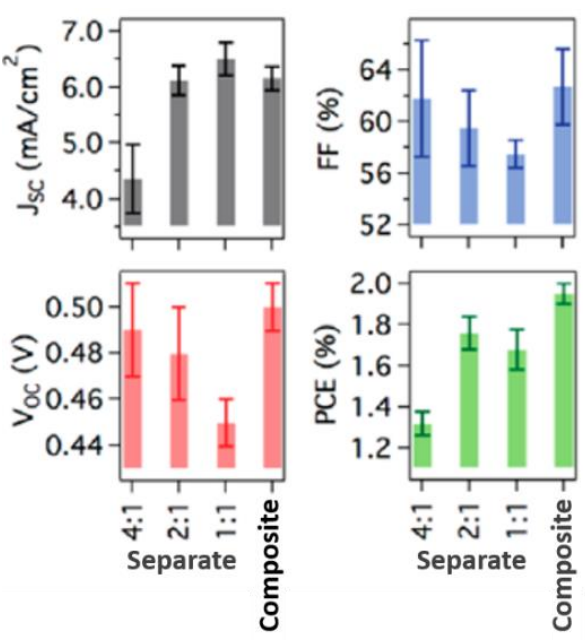

Figure 19. OPV device characteristics for mixtures of single-component nanoparticles (referred to as separate) and composite nanoparticles. 4:1, 2:1 and 1:1 correspond to the different weight ratio of P3HT NPs to $\mathrm{PC}_{61} \mathrm{BM}$ NPs. Adapted with permission from ref 123. Copyright 2014 American Chemical Society.

Xie et al. proposed a study of the microstructure of the active layer prepared from nanoparticle inks. For devices made from a blend of single-component nanoparticles (13.5 nm for PDPP5T-2 and $42.1 \mathrm{~nm}$ for $\mathrm{PC}_{71} \mathrm{BM}$ nanoparticles) or composite nanoparticles $(4.6 \mathrm{~nm})$, the best PCE obtained after thermal treatments were $2.32 \%$ and $3.38 \%$ respectively. ${ }^{41}$ The authors identified that the loss mechanism in the nanoparticle-based OPV devices was mainly attributed to bimolecular recombination due to the low and unbalanced mobilities which resulted in weak charge mobility and lifetime, determined by photo-induced charge carrier extraction by linearly increasing voltage (photo-CELIV). They attributed these poor electronic characteristics to the non-optimal phase separation (absence of collection 
pathways due to the core-shell morphology) evidenced by photoluminescence, STXM and AFM analysis. They proposed the representation of the active layer morphology in Figure $\mathbf{2 0}$ before and after annealing in each case (also compared with a standard BHJ morphology deposited from chlorinated solvent). The higher performance of composite nanoparticles (bNPs) compared to singlecomponent nanoparticles (bpNPs) was, therefore, attributed to a higher degree of domain intermixing and the formation of collection pathways for charge collection which resulted in reduced charge trapping and non-geminate recombination in comparison to single-component nanoparticles. ${ }^{41}$ However, the mobility-lifetime product (product between the charge mobility and lifetime in $\mathrm{cm}^{2} / \mathrm{V}$ ) were found to be lower than in $\mathrm{BHJ}$ films deposited from chlorinated solvent, suggesting that the collection pathways are not optimally formed, even with composite nanoparticle-based active layers. The lack of conduction pathways in comparison to BHJ could be linked to the initial NP morphology.

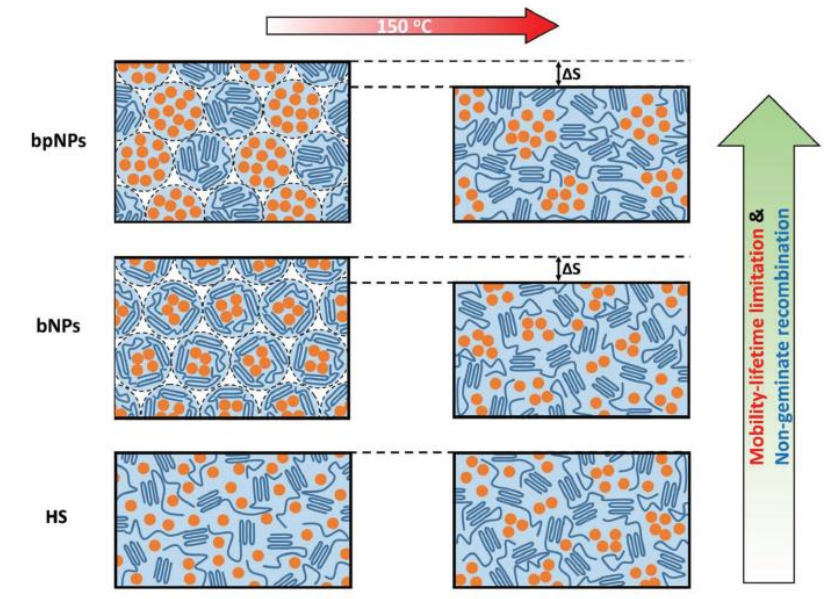

Figure 20. Schematic representation of the morphology of an active layer made from a blend of pure nanoparticles (bpNPs), composites nanoparticles (bNPs) or a standard BHJ (HS), before (left) and after (right) thermal treatment. Adapted with permission from ref 41. Copyright 2018 John Wiley and Sons.

Thus, composite nanoparticles are depicted as a better approach than single-component nanoparticles since more intermixed domains are obtained, for the same NP size. ${ }^{41,123}$ However, not only the exciton 
dissociation efficiency must be considered in OPV, one should also consider the transport of free charges. Conduction pathways are necessary in order to efficiently extract free charges. Charge carrier mobility is higher in pure domains (pure domains of acceptor or donor materials) than in intermixed domains, thus, a compromise between both should be considered in order to optimize the overall OPV device performance. Also, in all of these studies, the size of the single-component nanoparticles was generally larger than the exciton diffusion length (few nanometers), limiting the comparison between both approaches. Until now, the use of composite nanoparticles seemed to be the best alternative, but further studies making the comparison between single-component and composite nanoparticles could be useful. Holmes et al. reported that the use of single-component nanoparticles can lead, after annealing, to the presence of three domains: pure donor (for high hole conduction), pure acceptor (high electron conduction) and an intermixed phase (for high exciton dissociation); which is an elegant optimization of the system in order to create three kinds of domains, one aiming for the efficient dissociation of excitons and the others, for optimal charge transport. ${ }^{119}$ It seems therefore too soon to conclude that composite nanoparticles are the one and only viable alternative for nanoparticle-based OPVs.

Finally, Vaughan et al. built on the solvent orthogonality of the colloidal inks and developed in 2016 a vertical engineering approach to the active layer morphology by using both composite and singlecomponent nanoparticles. ${ }^{47}$ As presented in Figure 21, this gradient approach used pure P3HT or $\mathrm{PC}_{61} \mathrm{BM}$ nanoparticles next to the PEDOT:PSS and aluminum layers, respectively, and a concentration gradient of each component for composite nanoparticles. In this way, conduction pathways are expected, leading to an easier and more efficient charge collection. The authors developed the same strategy for PFB:F8BT nanoparticles. Whereas for PFB:F8BT, slightly better performance was obtained by using the gradient approach ( $0.39 \%$ vs $0.27 \%$ for NP-based and $\mathrm{BHJ}$, respectively), for $\mathrm{P} 3 \mathrm{HT}: \mathrm{PC}_{61} \mathrm{BM}$ nanoparticles, a limitation in $\mathrm{J}_{\mathrm{Sc}}$ was reported, leading to lower efficiencies for the gradient approach (2.34 \% for BHJ and champion of $0.41 \%$ for NP-based devices). The low performance was attributed to the non-optimal interparticle morphology and connectivity. The use of gradient nanoparticles 
seemed to lead to a reduction in the recombination rate, as higher values of $V_{\text {oc }}$ were obtained in comparison to standard NP-based devices. By optimizing annealing conditions, the authors managed to increase the $\mathrm{J}_{\mathrm{SC}}$ while maintaining a high $\mathrm{V}_{\mathrm{OC}}$ for devices with a vertical gradient and finally increased the final OPV device performance. Although the PCEs achieved were low ( $0.5 \%$ for the hero cell), the multilayer deposition approach is an interesting strategy in order to have good control over the vertical morphology profile of the active layer.

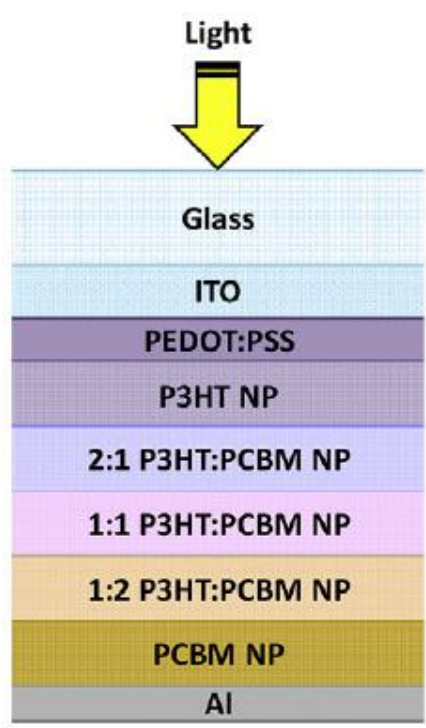

Figure 21. Device architecture for $\mathrm{P} 3 \mathrm{HT}: \mathrm{PC}_{61} \mathrm{BM}$ nanoparticle-based $\mathrm{OPV}$ devices with the graded nanoparticle layer strategy. Adapted with permission from ref 47. Copyright 2016 Elsevier.

\section{Thermal Treatment of the Active Layer}

Water Removal and Nanoparticle Sintering

Annealing is performed after deposition of the nanoparticles on a substrate in order to sinter the nanoparticles, as represented in Figure 22. Annealing allows the enhancement of OPV device efficiency by improving interparticle connectivity and hence charge transport, and also modifies the nanoscale morphology of the active layer. ${ }^{42,58,60,97,120}$ 

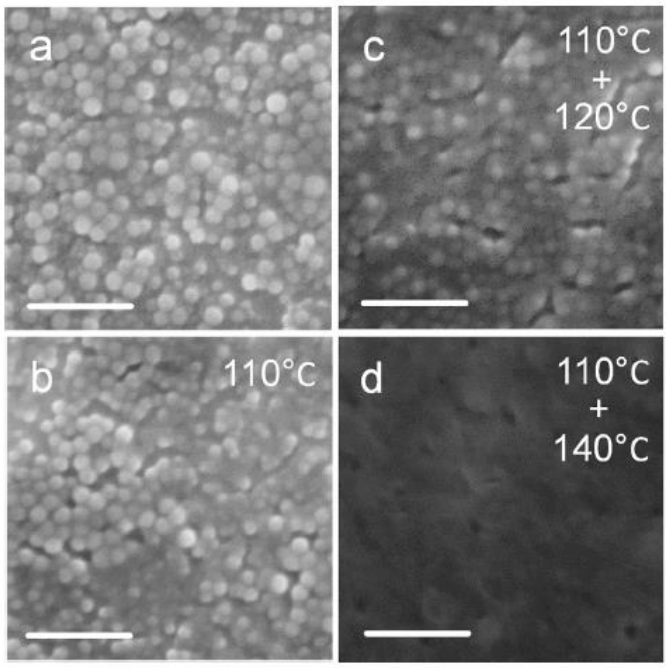

Figure 22. Scanning electron microscopy (SEM) images of TQ1:PC $\mathrm{C}_{71} \mathrm{BM}$ nanoparticles as cast (a), after drying at $110{ }^{\circ} \mathrm{C}$ for 4 minutes (b), after drying at $110^{\circ} \mathrm{C}$ for 4 minutes and annealing at $120^{\circ} \mathrm{C}$ for 5 minutes (c) and after drying at $110{ }^{\circ} \mathrm{C}$ for 4 minutes and annealing at $140{ }^{\circ} \mathrm{C}$ for 5 minutes (d). Scale bars are $200 \mathrm{~nm}$. Adapted with permission from ref 69. Copyright 2016 Elsevier.

Another thermal treatment, a drying step (prior to annealing step, and softer), can be performed directly after deposition of the nanoparticle ink over the substrate, in order to remove the presence of residual water and initiate the formation of a more continuous active layer from nanoparticle assembly, before the deposition of electrodes. ${ }^{69,78,104,120}$ If the drying temperature is above the $T_{g}$ of the polymer, sintering of the nanoparticles can also be observed. Another way to remove water from the active layer is to perform the deposition at high temperature, in order to evaporate water directly during the deposition step. ${ }^{42}$ The drying step is not always performed if annealing conditions are applied right after the deposition of the active layer. ${ }^{26}$

Holmes et al. reported that an increase in the drying temperature, from $90{ }^{\circ} \mathrm{C}$ to $140{ }^{\circ} \mathrm{C}$, led in an increase in device performance for TQ1:PC 71 BM systems. ${ }^{69}$ Drying temperatures of $110{ }^{\circ} \mathrm{C}$ and $120^{\circ} \mathrm{C}$, which are above the $T_{g}$ of TQ1, led to the sintering of the nanoparticles, but the discrete particle shape can still be distinguished (in SEM) and the device performance remained below $1 \%$. However, when the drying step was increased to $140^{\circ} \mathrm{C}$, a smoother film surface was obtained, with no evidence of 
nanoparticle shape or phase separation, and optimum OPV performance with an average PCE of 1.72 $\%$ (2.23\% maximum) was achieved. The authors studied the influence of the application of a second thermal treatment, annealing post-cathode deposition (which was performed after the deposition of the top electrode). It led to a further improvement of the efficiency, up to $2.1 \%$ ( $2.54 \%$ maximum), for a device where the active layer was already dried at $140{ }^{\circ} \mathrm{C}$. However, when the drying step was performed below $140{ }^{\circ} \mathrm{C}$, a decrease in efficiency was observed after the annealing step. The authors proposed that the remaining presence of water in the active layer for low drying temperatures (below $140^{\circ} \mathrm{C}$ ) could explain this decrease in performance. ${ }^{69}$

\section{Nano-Morphology Control}

Annealing is also expected to induce in some cases phase separation and an increase in the conjugated polymer crystalline domains in the active layer. ${ }^{104,136}$ By using a temperature above the $T_{g}$, the polymer chain mobility increases, leading to local aggregation and the creation of conduction pathways for free charges. ${ }^{69}$ Lee et al. attested that annealing led to larger crystalline domain size for P3HT domains, by using wide angle X-ray diffraction. ${ }^{60}$ Vaughan et al. explained that the improvement in charge transport upon annealing could be linked to the increase in crystallinity of the polymer rich-domain in PDPP-TNTbased systems. ${ }^{120}$

In the case of devices built from a blend of single-component nanoparticles, thermal treatment was reported by Holmes and co-workers to improve the exciton dissociation efficiency. ${ }^{119}$ For instance, in a $\mathrm{P} 3 \mathrm{HT}: \mathrm{PC}_{61} \mathrm{BM}$ system, thermal annealing of the nanoparticle film led to the formation of three distinct domains: i) pure $\mathrm{P} 3 \mathrm{HT}$ domain, ii) pure $\mathrm{PC}_{61} \mathrm{BM}$ domain and iii) a blend of $\mathrm{P} 3 \mathrm{HT}$ and $\mathrm{PC}_{61} \mathrm{BM}$. Directly following the deposition of single-component nanoparticles, the donor:acceptor interface was limited to the contact area of the nanoparticles (Figure 23a, b), leading to a poor exciton dissociation efficiency (34\%). Upon annealing, two mechanisms occur: sintering of nanoparticles (Figure 23c, d), and diffusion of a fraction of $\mathrm{PC}_{61} \mathrm{BM}$ into the amorphous $\mathrm{P} 3 \mathrm{HT}$ domains (Figure 23e). An intermixed phase is formed and an increase in the exciton dissociation yield (64 \%) is reported. 


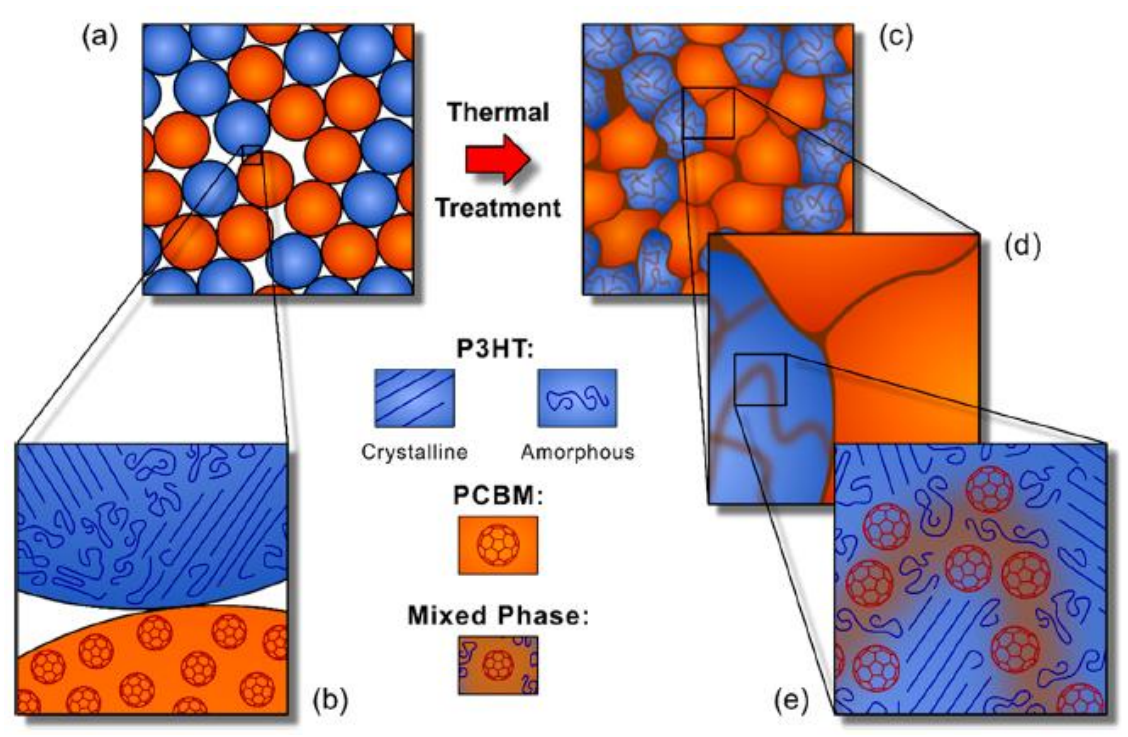

Figure 23. Active layer comprised of pure $\mathrm{P} 3 \mathrm{HT}$ and pure $\mathrm{PC}_{61} \mathrm{BM}$ nanoparticles (a), with interfaces for exciton dissociation limited to the regions of nanoparticle contact (b). After annealing (c), contact between the particles increases leading to more interfaces (d), and also to the diffusion of $\mathrm{PC}_{61} \mathrm{BM}$ into the amorphous domains of P3HT, resulting in an intermixed phase (e). Adapted with permission from ref 119. Copyright 2018 American Chemical Society.

The influence of thermal treatment on the film morphology is non-negligible for composite nanoparticles, especially for those presenting a core-shell morphology. Annealing can lead to higher mobility of polymer chains and small molecule diffusion, which potentially enables interconnections between the donor and acceptor domains, but can also provoke a phase separation, depending on thermal treatment conditions (temperature and/or time). Numerous teams working on core-shell nanoparticles reported an important phase separation upon annealing, leading to a decrease in the OPV final performance, especially when the conditions are not appropriate, ${ }^{34,101,104,120}$ as presented in Figure 24 . 
a
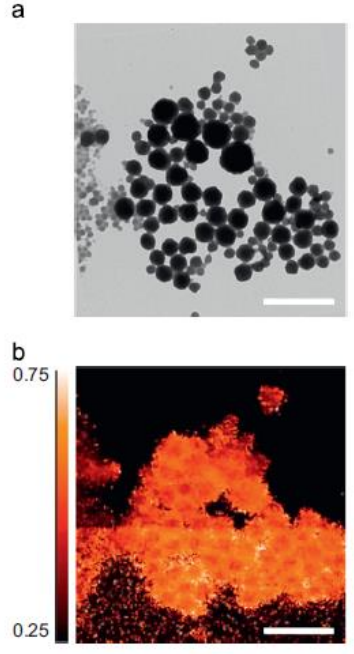

C

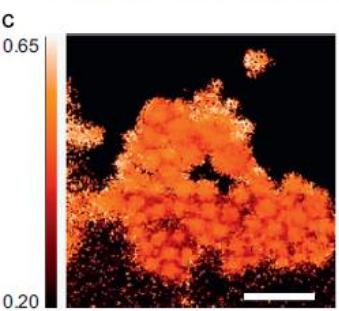

d
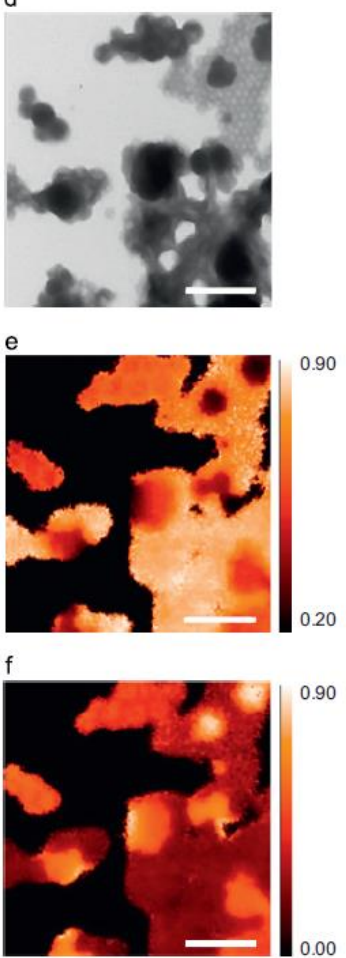

Figure 24. TEM images $(a, d)$ and $S T X M(b, c, e, f)$ of $P 3 H T: P C_{61} B M$ NP films before $(a, b, c)$ and after annealing (d,e,f), with $\mathrm{P} 3 \mathrm{HT}$ composition $(\mathrm{b}, \mathrm{e})$ and $\mathrm{PC}_{61} \mathrm{BM}$ composition $(\mathrm{c}, \mathrm{f})$. All scale bars are $1 \mu \mathrm{m}$. Adapted with permission from ref 101. Copyright 2013 Elsevier.

However, Vaughan et al. reported the evolution of efficiency for devices based on PDPP-TNT:PC ${ }_{71} B M$ composite nanoparticles upon thermal treatment. The as-spun PCE was $\sim 0.05 \%$, and strongly increased, up to $1.99 \%$, after 10 minutes of thermal treatment at $130{ }^{\circ} \mathrm{C}$, but decreased to 0.78 and $0.70 \%$ after the treatment time was extended to 30 and 60 minutes, respectively. ${ }^{120}$ This decrease is likely due to the aggregation of $\mathrm{PC}_{71} \mathrm{BM}$ upon thermal treatment. Feron et al. reported that, in comparison to their $\mathrm{BHJ}$ counterparts, the core-shell morphology of nanoparticles in $\mathrm{P} 3 \mathrm{HT}: \mathrm{PC}_{61} \mathrm{BM}$ systems limited the molecular diffusion of $\mathrm{PC}_{61} \mathrm{BM}$ upon thermal treatment and so, phase segregation, for the same annealing conditions. ${ }^{137}$ Holmes et al. reported that an increase in $\mathrm{PC}_{61} \mathrm{BM}$ loading in $\mathrm{P} 3 \mathrm{HT}: \mathrm{PC}_{61} \mathrm{BM}$ NPs led to less phase separation after annealing, with PCE of 0.40 and $1.00 \%$ for $\mathrm{D}: \mathrm{A}$ ratios of $1: 0.5$ and $1: 2$, respectively. ${ }^{78}$ 
The authors also studied, in another work, the influence of the polymer molar mass on phase separation. ${ }^{34}$ They coated thin films of $\mathrm{P} 3 \mathrm{HT}: \mathrm{PC}_{61} \mathrm{BM}$ composite nanoparticles prepared through miniemulsion, using P3HT of different molar masses $\left(M_{w}\right): 5,9,12,16,44$ and $72 \mathrm{~kg} \mathrm{~mol}^{-1}$. Upon thermal annealing ( $140{ }^{\circ} \mathrm{C}$ for $4 \mathrm{~min}$ ), $\mathrm{PC}_{61} \mathrm{BM}$ molecules contained in the $\mathrm{PC}_{61} \mathrm{BM}$-rich cores diffused through amorphous domains of $\mathrm{P} 3 \mathrm{HT}$, leading to an intermixing of both phases. However, a second diffusion mechanism was identified for low molar masses of P3HT (5-12 kg.mol$\left.{ }^{-1}\right)$ involving the diffusion and coalescence of $\mathrm{PC}_{61} \mathrm{BM}$ cores. As a result, large phase separation was evidenced in the low molar mass samples whereas less phase segregation was reported in high molar mass P3HT (Figure 25). The morphological changes upon annealing are linked to the diffusion of $\mathrm{PC}_{61} \mathrm{BM}$ molecules causing aggregates. The occurrence of the two mechanisms is highly dependent on P3HT molar mass. By increasing the molar mass, only diffusion of molecular $\mathrm{PC}_{61} \mathrm{BM}$ is observed, leading to the formation of joined-shell rather than large phase segregation. In a following study, the same team reported that the domain composition and the device performance were driven by the $\mathrm{PC}_{61} \mathrm{BM}$ diffusion in the nanoparticle structure. ${ }^{138}$ 


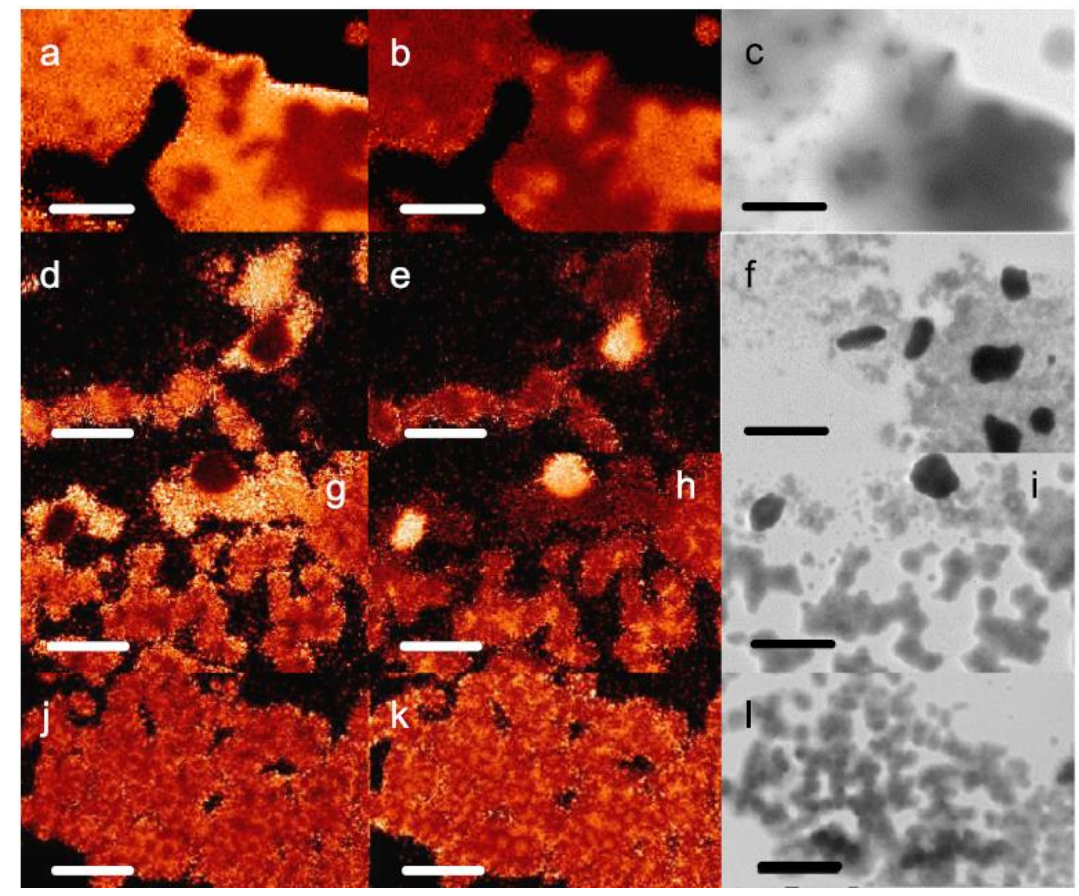

Figure 25. STXM images of composition maps showing P3HT concentration (first column), $\mathrm{PC}_{61} \mathrm{BM}$ concentration (second column) and corresponding position-matched TEM images (third column) for annealed P3HT:PC ${ }_{61} \mathrm{BM}$ nanoparticles prepared from P3HT of molar mass $\left(\mathrm{Mw}_{\mathrm{w}}\right) 5(\mathrm{a}-\mathrm{c}), 9(\mathrm{~d}-\mathrm{f}), 12(\mathrm{~g}-\mathrm{i})$ and $16(\mathrm{j}-\mathrm{l}) \mathrm{kg} \cdot \mathrm{mol}^{-1}$. Scale bars are $1 \mu \mathrm{m}$. Adapted with permission from ref 34. Copyright 2013 Elsevier.

Ulum et al. reported the influence of thermal treatment on P3HT:ICBA NP films. ${ }^{104}$ While a typical coreshell morphology was initially reported, with a low fraction of ICBA in the shell ( 23\%), thermal annealing led to the increase of ICBA proportion in the shell (up to 34\%). The evolution of the nanoparticle morphology upon thermal treatment can be shown in Figure 26. Using Flory-Huggins theory, the authors showed that ICBA is miscible in amorphous P3HT at all weight fractions, even after the growth of $\mathrm{P} 3 \mathrm{HT}$ crystalline domains upon annealing. As a consequence, thermal annealing provokes the diffusion of ICBA molecules in $\mathrm{P} 3 \mathrm{HT}$, resulting in more intermixed domains, and they reported a maximum PCE of $2.5 \%$ after thermal treatment of OPV devices. 


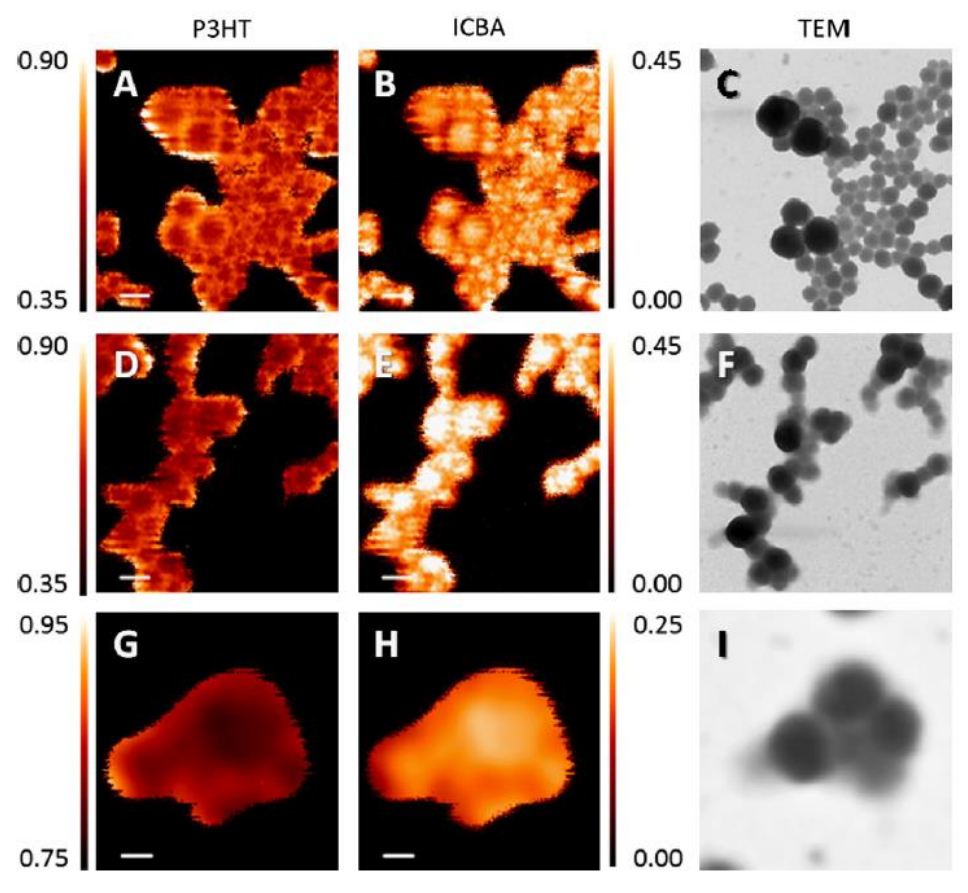

Figure 26. STXM compositional maps of P3HT concentration (first column), ICBA concentration (second column) and corresponding position-matched TEM images (third column) of nanoparticle films as-spun (A-C), after drying (4 minutes at $\left.110^{\circ} \mathrm{C}\right)(\mathrm{D}-\mathrm{F})$ and after annealing ( 3 minutes at $\left.150^{\circ} \mathrm{C}\right)(\mathrm{G}-\mathrm{I}) .2 \mu \mathrm{m} \times 2 \mu \mathrm{m}(\mathrm{A}-\mathrm{F})$ and $1 \mu \mathrm{m} \times 1 \mu \mathrm{m}(\mathrm{G}-$ I) images, and scales bars are $200 \mathrm{~nm}(\mathrm{~A}, \mathrm{~B}, \mathrm{D}, \mathrm{E})$ and $100 \mathrm{~nm}(\mathrm{G}, \mathrm{H})$. Adapted with permission from ref 104. Copyright 2013 Elsevier.

Holmes et al. reported the behavior of $\mathrm{TQ1}: \mathrm{PC}_{71} \mathrm{BM}$ composite nanoparticles prepared through miniemulsion, upon thermal treatment. ${ }^{69}$ The low miscibility of TQ1 (non-crystalline polymer) and $\mathrm{PC}_{71} \mathrm{BM}$ led to two different $\mathrm{T}_{\mathrm{g}} \mathrm{s}$ rather than a blend $\mathrm{T}_{\mathrm{g}}$, respectively, for both materials. The authors observed that annealing at $140{ }^{\circ} \mathrm{C}$ for 5 min led to the sintering of the nanoparticles (as the thermal treatment temperature is above the $\mathrm{T}_{\mathrm{g}}$ of TQ1 $\left.\approx 100^{\circ} \mathrm{C}\right)$, without large phase segregation, and also to the appearance of nano-pathways between the $\mathrm{PC}_{71} \mathrm{BM}$ cores, as schematized in Figure 27. The creation of nano-pathways was reported due to the motion of the molecules of $\mathrm{PC}_{71} \mathrm{BM}$ present in the TQ1-rich shells. Indeed, as $\mathrm{PC}_{71} \mathrm{BM}$ and $\mathrm{TQ1}$ have a tendency to phase segregate, $\mathrm{PC}_{71} \mathrm{BM}$ will form connecting pathways between the $\mathrm{PC}_{71} \mathrm{BM}$-rich cores. Annealing between 140 and $160{ }^{\circ} \mathrm{C}$ led to the sintering of the TQ1-rich shells and the creation of an interconnected donor network, where the 
$\mathrm{PC}_{71} \mathrm{BM}$ cores kept their shape, without moving or aggregating. This hypothesis was confirmed by the fact that, for higher annealing temperatures $\left(>160{ }^{\circ} \mathrm{C}\right)$, above the $\mathrm{T}_{\mathrm{g}}$ of $\mathrm{PC}_{71} \mathrm{BM}\left(\approx 163^{\circ} \mathrm{C}\right)$, a gross phase segregation was observed by STXM and TEM analysis, due to the easier motion of the $\mathrm{PC}_{71} \mathrm{BM}$ molecules through the TQ1-rich domains, both materials being in a viscous state. ${ }^{69}$ Thus, by optimizing the annealing conditions, the authors reported an improved morphology which facilitated charge extraction thanks to the percolation paths of the $\mathrm{PC}_{71} \mathrm{BM}$-rich cores and the TQ1-rich network, leading to a champion PCE of $2.54 \%$. Xie et al. tried to reproduce the formation of nano-pathways with PDPP5T-2:PC ${ }_{71} \mathrm{BM}$ nanoparticles upon annealing. ${ }^{41}$ However, they only observed sintering of the nanoparticles and no morphological changes such as conduction pathways. They hypothesized that different morphological behaviors occurred after annealing in comparison to the system TQ1:PC ${ }_{71} B M$, linked to the differences in the Flory-Huggins interaction parameters.

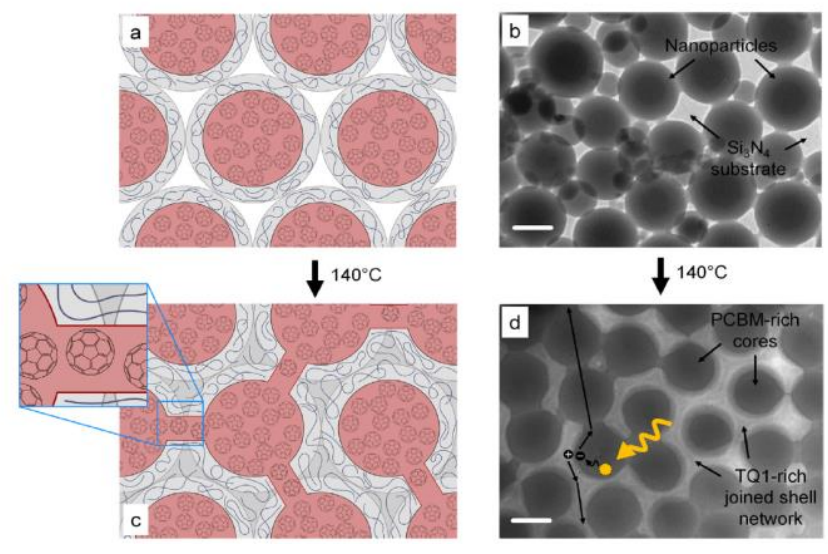

Figure 27. Schematic representation of TQ1:PC $\mathrm{7}_{11} \mathrm{BM}$ nanoparticles creating nano-pathways after annealing with a) schematic b) TEM images of the film as cast, and c) schematic, d) TEM images of film after annealing at $140{ }^{\circ} \mathrm{C}$. Scale bars fixed at $100 \mathrm{~nm}$. Adapted with permission from ref 69. Copyright 2016 Elsevier.

In the case of composite nanoparticles prepared via nanoprecipitation and presenting a more blended morphology, no modification of the morphology was identified upon soft and mild thermal treatment yet but this could be due to the lack of studies, in comparison to those on miniemulsion-based 
nanoparticles. An increase in final performance was reported, mainly by improving the contact between particles, the homogeneity of the film and the crystallinity of the polymer domains. ${ }^{19,42,46}$ For instance, Prunet et al. reported that as-spun films reached a PCE $<0.01 \%$ whereas after annealing at $160{ }^{\circ} \mathrm{C}$, a PCE of $0.33 \%$ was achieved. However, they also reported the appearance of large pure domains when annealing conditions were too strong (high temperature and/or treatment time), leading to a dramatic fall in the OPV device performance, for annealing over $180^{\circ} \mathrm{C}$, with a PCE of 0.02 $\%{ }^{42}$

\section{Surfactant Limitations and Removal}

During the preparation of colloidal dispersions by miniemulsion, or in some cases by nanoprecipitation (to ensure a stability sufficiently high for deposition of the active layer), a surfactant is required. Among the hypotheses to explain the limitations in the performance of nanoparticulate-based OPV devices in comparison to standard BHJ homologs, the insulating character of surfactant molecules was discussed as a limiting factore. ${ }^{98}$ In the NP-based OPV horizon, almost exclusively sodium dodecyl sulfate (SDS) was used, which is a non-conjugated surfactant presenting an anionic charge and a cationic counter ion. However, the presence of the sulfate group and its sodium counter ion can act as charge traps and decrease the charge mobility in films. ${ }^{53}$ Furthermore, even when a non-ionic surfactant is used, as in the case of Pluronic F127, the presence of residual free surfactant molecules in the dispersion inhibits charge transport between the donor and acceptor in the film, as reported by Xie et al. ${ }^{26}$ The presence of surfactant in the active layer was also reported to generate more defects, resulting in higher charge trapping, according to a numerical simulation performed by Han et al. ${ }^{139}$ Therefore, the removal of the excess surfactant was reported by many teams through washing steps, dialysis or centrifugal dialysis. ${ }^{41,44,57}$ Post deposition thermal treatment was also investigated as a surfactant removal technique by Cho et al., where annealing at $270{ }^{\circ} \mathrm{C}$ was performed on poly[2,5-bis(3- 
tetradecylthiophen-2-yl)thieno[3,2-b]thiophene] (PBTTT) nanoparticles (PBTTT showing a high $T_{\mathrm{g}}$ ) stabilized by SDS, in order to degrade efficiently the excess of surfactant. ${ }^{140}$

Therefore, the presence of free-molecules of surfactant in the active layer or still bound to the nanoparticle surface has been identified to be a limiting factor, and the efficient reduction of the freeand bound surfactant concentration before deposition appears to be the best solution.

Cho et al. reported the use of non-ionic surfactants from the alkyl-ethoxyethyl $\left(C_{m} E_{n}\right)$ family (Figure 28a), which are amphiphilic oligomers, in order to overcome the limitations due to the classic use of SDS, leading to charge trapping and the formation of a very dense shell of surfactant around the nanoparticles due to its poor hydrophilic/lipophilic balance (HLB). ${ }^{77}$ They reported that the surfactant excess can be efficiently removed by post-deposition washing in ethanol, leading to highly ordered films, increasing the final charge transport properties up to $2.51 \mathrm{~cm}^{2} \mathrm{~V}^{-1} \mathrm{~s}^{-1}$ for $\mathrm{C}_{16} \mathrm{E}_{10}$-based polymer field-effect transistor (PFET) films compared to $10^{-3} \mathrm{~cm}^{2} \mathrm{~V}^{-1} \mathrm{~s}^{-1}$ for SDS-based devices, using PDPP-SVS as the active material (Figure $\mathbf{2 8 b}$ ). Cho et al. proposed four criteria that surfactants should fulfill in order to be used in organic electronics, including OPV: i) ability to form a stable emulsion, ii) minimum quantity of surfactant for stabilization of the emulsion, iii) efficient removal of the surfactant excess and iv) generation of highly crystalline domains. ${ }^{55}$ Among the large range of surfactants tested (SDS, SDBS, BDAB, etc.) they reported that the alkyl trimethyl ammonium bromide ( $\left.C_{x} T A B\right)$ surfactant family (Figure 28a) was the most suited for the preparation of colloidal dispersions, with a large range of organic semiconductors. PFET devices were prepared with $\mathrm{C}_{16} \mathrm{TAB}$-stabilized nanoparticles, and a charge mobility up to $2.7 \mathrm{~cm}^{2} \mathrm{~V}^{-1} \mathrm{~s}^{-1}$ was reported, using nanoparticles of PDPP-SVS. The efficient removal of excess surfactant, through washing with ethanol in the case of $C_{x} T A B$, appears again as a key-point to enhance performance of organic devices. ${ }^{55}$ 
a)

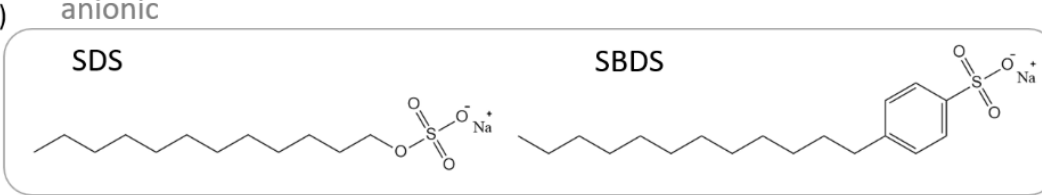

cationic

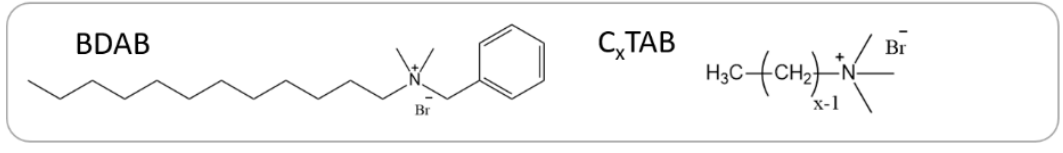

non-ionic

$C_{m} E_{n}$

$\mathrm{H}_{3} \mathrm{C}-\left(\mathrm{CH}_{2}\right) \underset{\mathrm{m}-\mathrm{I}}{(\mathrm{O}}-\mathrm{CH}_{2}-\mathrm{CH}_{2}-\mathrm{OH}$

\section{Pluronic F127}

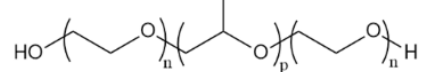

b)

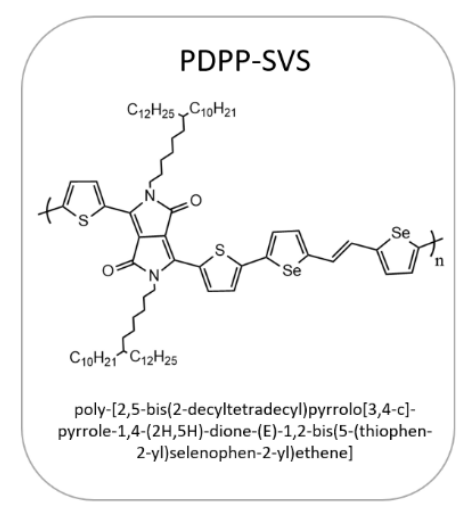

Figure 28. a) Chemical structure of surfactants used for nanoparticle-based organic semiconducting colloidal dispersions. b) Chemical structure of conjugated polymer achieving the best charge mobilities reported with various surfactant in the work of Cho et al..$^{55,77}$

More recently, Xie et al. reported the comparison of a polymeric surfactant, an amphiphilic tri-block copolymer (Pluronic F127) (Figure 28a) and SDS, and demonstrated that the excess of surfactant must be removed in order to optimize the efficiency of solar cells. ${ }^{26}$ Pluronic F127 surfactant exhibits a temperature-sensitive critical micelle concentration (TS-CMC), which enables the variation of the CMC value as a function of the dispersion temperature. By lowering the temperature of the dispersion to around $0{ }^{\circ} \mathrm{C}$, micelles formed of Pluronic F127 disassemble into single molecules and partly leave the nanoparticle surface, leading to an easier removal of the surfactant excess by centrifugal dialysis, as shown in Figure 29. For instance, whereas the residual quantity of SDS was more than $13 \%$ after ten washings, the residual quantity of Ppluronic F127 was around $2 \%$ of the original amount after three washings at $0{ }^{\circ} \mathrm{C} .{ }^{26}$ Thus, solar cells made with dispersions using either SDS or Pluronic F127 were realized, and a strong increase in the final OPV performance was observed using the poloxamer F127, as shown in Table 3. Xie et al. highlighted the use of a TS-CMC surfactant and showed that efficient and environmentally-friendly solar cells can be processed by using an aqueous dispersion, with the current record in PCE for OPV devices made from nanoparticles achieving a PCE of $7.50 \%$ for the PBQQF:ITIC system, whereas a PCE of $4.42 \%$ was achieved using SDS as a surfactant. ${ }^{26}$ Also, a strong 
increase in $\mathrm{J}_{\mathrm{sc}}$ is observed when using Pluronic F127 as a surfactant, which confirms that removal of surfactant excess limits charge trapping effects.

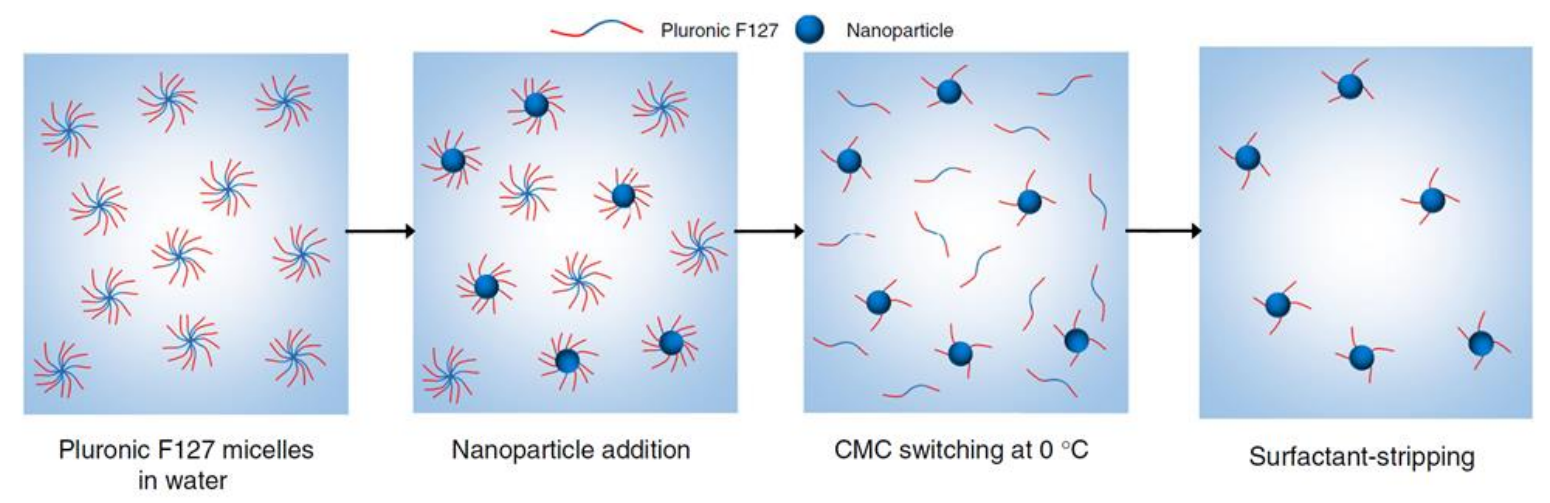

Figure 29. Removal of a temperature sensitive surfactant (Pluronic F127) during the nanoparticle preparation, before deposition of the active layer. Adapted with permission under a Creative Commons Attribution 4.0 International License from ref 26. Copyright 2018 Springer Nature.

Table 3. Performance of OPV devices using SDS or Pluronic F127 as surfactant. THF refers to the standard BHJ device. Record PCE for each are shown between brackets. Adapted with permission under a Creative Commons Attribution 4.0 International License from ref 26. Copyright 2018 Springer Nature.

\begin{tabular}{|c|c|c|c|c|c|}
\hline Material & Solvent (surfactant) & $\mathrm{V}_{\mathrm{OC}}(\mathrm{V})$ & $J_{s c}\left(m A \cdot c^{-2}\right)$ & $\mathrm{FF}(\%)$ & PCE (\%) \\
\hline \multirow{3}{*}{ P3HT:o-IDTBR } & THF & $0.74 \pm 0.02$ & $8.38 \pm 0.40$ & $48.9 \pm 2.5$ & $3.11 \pm 0.34(3.45)$ \\
\hline & Water (SDS) & $0.75 \pm 0.01$ & $7.45 \pm 0.31$ & $45.2 \pm 2.1$ & $2.53 \pm 0.20(2.73)$ \\
\hline & Water (F127) & $0.76 \pm 0.01$ & $10.36 \pm 0.39$ & $62.9 \pm 2.0$ & $4.95 \pm 0.32(5.23)$ \\
\hline \multirow{2}{*}{ PCE10:o-IDTBR } & Water (SDS) & $0.97 \pm 0.03$ & $9.20 \pm 0.32$ & $40.7 \pm 2.9$ & $3.61 \pm 0.48(4.12)$ \\
\hline & Water (F127) & $0.97 \pm 0.03$ & $12.01 \pm 0.43$ & $42.4 \pm 2.0$ & $4.94 \pm 0.25(5.19)$ \\
\hline \multirow{2}{*}{ PBQ-QF:o-IDTBR } & Water (SDS) & $0.92 \pm 0.04$ & $9.79 \pm 0.80$ & $38.3 \pm 2.0$ & $3.45 \pm 0.57(4.02)$ \\
\hline & Water (F127) & $0.95 \pm 0.03$ & $13.09 \pm 0.41$ & $47.9 \pm 4.3$ & $5.96 \pm 0.58(6.52)$ \\
\hline \multirow{2}{*}{ PBQ-QF:ITIC } & Water (SDS) & $0.84 \pm 0.01$ & $10.31 \pm 0.32$ & $46.0 \pm 3.1$ & $3.98 \pm 0.49(4.42)$ \\
\hline & Water (F127) & $0.85 \pm 0.02$ & $14.87 \pm 0.30$ & $52.7 \pm 2.9$ & $6.97 \pm 0.53(7.50)$ \\
\hline
\end{tabular}

Not only the charge transport is limited by the excess of free unbound surfactant molecules, but also the packing density of nanoparticles in the active layer, leading to the formation of cracks or de-wetting areas. $^{65,141}$ For instance, Colberts et al. reported that the control of the free and surface-bound surfactant concentration, using SDS in their work, affected the de-wetting or aggregate formation during the active layer deposition step. ${ }^{44}$ Free and surface-bound surfactant concentration can be 
tracked by conductivity and Zeta-potential measurements, respectively. Whereas a concentration of surfactant that is too high led to the formation of holes in the films, a concentration that is too low led to aggregation of NPs, causing non-homogeneous films and pin-holes in the active layer, resulting in electrical short-circuits (Figure 30). Therefore, the free and surface-bound surfactant concentration should be controlled in order to achieve efficient and reproducible deposition of the nanoparticle dispersion into an active layer. Almyahi et al. reported a balance between the charge-trapping effect when the concentration of surfactant is too high (using SDS in their work as well) and poor film formation due to insufficient wetting when the concentration is too low. ${ }^{65}$ Therefore, if no additional treatment is applied to enhance the wettability, the concentration of surfactant is a key-parameter to improve the final OPV device performance.
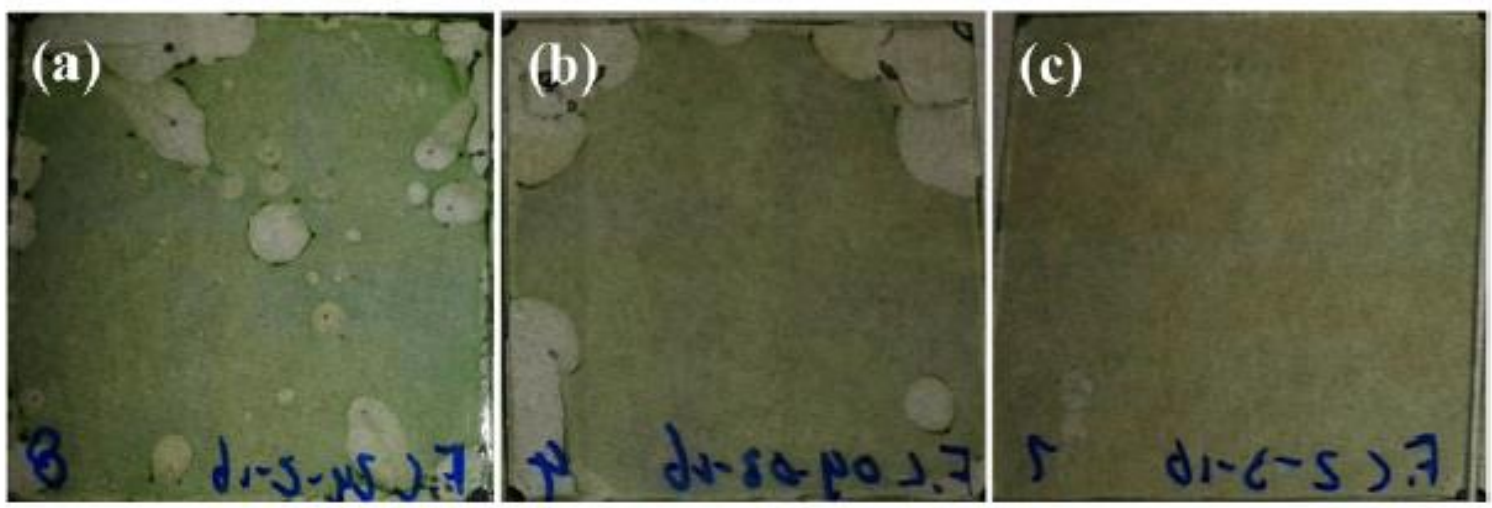

Figure 30. Images of spin coated active layer with a) high concentration, b) low concentration and c) medium concentration of SDS. Adapted with permission under a Creative Commons Non-commercial No Derivative Works (CC-BY-NC-ND) Attribution License from ref 44. Copyright 2017 American Chemical Society.

\section{Efficiency Enhancement and Upscaling Process}

The performance of nanoparticle-based solar cells can be drastically improved by various parameters, as reported above (experimental parameters during the nanoparticle synthesis, nanoparticle size, thermal treatment, removal of surfactant excess, etc). However, the optimization of OPV device 
performance is not limited to the direct modification of the active layer, but is also linked to the use of specific treatments over the substrate before deposition of the active layer, the choice of materials for the electrodes, and the technique used to print/process solar cells.

Vaughan et al. reported the influence of the cathode material on the OPV device performance. ${ }^{134}$ Active layers were fabricated from PFB:F8BT nanoparticle dispersions and a standard chlorinated solvent. They investigated the influence of two different electron transporting electrodes, $\mathrm{Ca} / \mathrm{Al}$ and Al-based. For Ca/Al-based electrodes, a thin layer of calcium is first deposited (20-30 nm) prior to an aluminum layer $(80-100 \mathrm{~nm})$, which prevents at the end the oxidation of the calcium. ${ }^{142,143} \mathrm{Using} \mathrm{Ca} / \mathrm{Al}$ electrodes, the device performance increased two-fold, for both nanoparticle and BHJ devices, with higher performance reached by nanoparticle-based solar cells (PCE: $0.82 \%$ for NP vs PCE: $0.36 \%$ for $\mathrm{BHJ})$. The authors proposed a model to explain the increase in performance, involving the diffusion of Ca to the nanoparticle, creating a calcium doped-polymer interface, as presented in Figure $\mathbf{3 1}$. This doping was suggested to create interband gap states in PFB, which would enhance the rapid quenching of excitons and reduce the recombination in the active layer. 

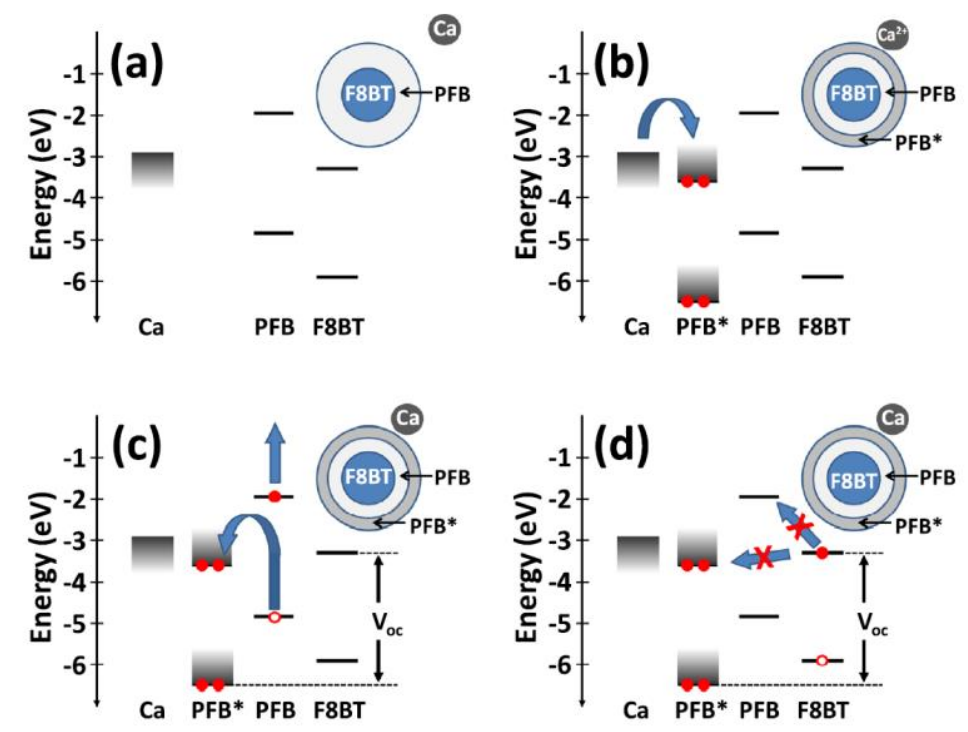

Figure 31. Energy level diagrams for PFB:F8BT nanoparticles in the presence of calcium. (a) Calcium diffuses to nanoparticle surface. (b) Calcium dopes PFB-rich shell producing gap states. Electron transfer occurs from calcium producing filled gap states. (c) An exciton generated on PFB approaches the doped PFB material (PFB*) and a hole transfers to the filled gap state producing a more energetic electron. (d) Electron transfer from an exciton generated on F8BT to either the higher energy PFB LUMO or the filled lower energy PFB* LUMO is hindered. Adapted from Vaughan, B.; Stapleton, A.; Xue, B.; Sesa, E.; Zhou, X.; Bryant, G.; Belcher, W.; Dastoor, P. Effect of a Calcium Cathode on Water-Based Nanoparticulate Solar Cells. Appl. Phys. Lett. 2012, 101 (5), 053901 , with the permission of AIP Publishing.

Feron et al. also reported enhanced OPV performance using $\mathrm{Ca} / \mathrm{Al}$ electrodes in comparison to Al electrodes for $\mathrm{P} 3 \mathrm{HT}: \mathrm{PC}_{61} \mathrm{BM}$ nanoparticles (PCE: $1.0 \%$ vs $0.23 \%$ after thermal treatment, respectively). ${ }^{137}$ According to their observations, the main explanation relied in the migration of $\mathrm{PC}_{61} \mathrm{BM}$ molecules towards the calcium layer interface upon thermal treatment, leading to the formation of percolation pathways, increasing the overall charge extraction and optimizing the vertical morphology. This migration of $\mathrm{PC}_{61} \mathrm{BM}$ was not reported in the case of the devices without a calcium interlayer. 
Incorporation of ethanol in the aqueous dispersion was reported by several teams to enhance the overall performance of solar cells. ${ }^{123}$ Bag et al. reported that the incorporation of $20 \%$ ethanol in the aqueous miniemulsion-based dispersion enhances the $\mathrm{J}_{\mathrm{SC}}$ and the PCE, from 4.69 to $6.38 \mathrm{~mA} \cdot \mathrm{cm}^{-2}$ and $1.58 \%$ to $2.15 \%$, respectively. ${ }^{136}$ In fact, addition of ethanol decreased the surface tensionof the dispersion, resulting in the formation of a more homogeneous film. ${ }^{61}$ However, Colberts et al. highlighted that a disruption in the dispersion stability upon addition of ethanol can lead to aggregation of the nanoparticles, so, addition of ethanol to water prior to deposition should be done gently and carefully. ${ }^{44}$

Bag et al. reported several optimizations of the fabrication process in order to significantly improve the OPV device performance. Firstly, to increase the surface wettability, the PEDOT:PSS substrate was exposed to UV-O ${ }_{3}$ for a few minutes, resulting in a good wettability of the nanoparticle dispersion over the substrate surface. ${ }^{136}$ The authors also showed that the use of a $\mathrm{PC}_{61} \mathrm{BM}$ buffer electron transport layer, spin coated from a dichloromethane solution on top of the nanoparticle active layer, enabled better charge extraction as well as a reduced surface roughness between the active layer and the cathode. Finally, addition of $20 \%$ ethanol and the use of a Ca/Al-based cathode enabled performances almost 5 times superior to be reached for the optimized fabrication process $(2.15 \%)$ in comparison to the initial fabrication procedure $(0.46 \%) .{ }^{136}$

Colberts et al. identified that the active layer thickness influenced OPV performance. By varying the spin coating speed, they managed to form active layers of different thicknesses ${ }^{44}$ For PDPP5T:PC 61 BM (and PDPP5T:PC $71 \mathrm{BM}$ ), the best performances were achieved using an active layer thickness between 60 and $70 \mathrm{~nm}$ (and 67 to $50 \mathrm{~nm}$ ). They also reported that storing (or ageing) the nanoparticle dispersion was a key step in order to increase the OPV device performance. Interestingly, by storing the dispersion for one day, a better nanoparticle deposition and more homogeneous film formation was observed, leading to a slight increase of the performance (from $1.54 \%$ to $2.03 \%$ ) as well as the reproducibility of the solar cell fabrication. This enhancement was attributed to changes in the surface charge, 
measured by Zeta-potential, which decreased from $-39 \mathrm{mV}$ to $-30 \mathrm{mV}$ after one day of aging. The authors attributed this change to a stabilization time, necessary for the dispersion to reach the balance between free and bound surfactant molecules. ${ }^{44}$

The optimization of the fabrication process can lead to non-negligible improvements in PCE. However, these improvements should not be limited to the laboratory scale, and efforts have already been made by several teams to upscale the fabrication process of either nanoparticle dispersion preparation or solar cell processing, in order to reach industrial requirements. The first step for upscaling the solar cell production is the increase of the nanoparticle ink preparation volume, which should not be limited to a few $\mathrm{mL}$ per preparation.

Almyahi et al. reported the preparation of $\mathrm{P} 3 \mathrm{HT}$ :Indene- $\mathrm{C}_{60}$ multiadduct (ICXA) nanoparticles in a large quantity, and also proposed the use of a low-cost acceptor material (ICXA), in order to decrease the final cost of solar cells. ${ }^{68}$ The cost of the devices is important to consider, even at the laboratory scale, since OPVs should be a low-cost technology. Nanoparticles of P3HT and ICXA were prepared via miniemulsion, in a small batch of $0.5 \mathrm{~mL}$ and in a larger batch of $100 \mathrm{~mL}$, both with a final solids content of $60 \mathrm{mg} \cdot \mathrm{mL}^{-1}$. The mean nanoparticle size of the larger ink batch was similar (a few nanometers larger) to that of the small batch, and the performances reached were also comparable, with a PCE of $0.88 \%$ and $0.87 \%$ for the small and the large ink batches, respectively. Therefore, the authors demonstrated that the upscaling of the preparation volume, in their case by a factor of 200 , did not lead to a decrease in the nanoparticle ink quality or in the final OPV device performance. ${ }^{68}$

In a following study, Almyahi et al. reported the purification steps for small $(2.5 \mathrm{~mL})$ and large $(250 \mathrm{~mL})$ batches of nanoparticles, using centrifugal dialysis and crossflow filtration, respectively. ${ }^{65}$ They reported similar efficiencies for different volumes of purified nanoparticles $(0.5 \mathrm{~mL}$ for the small batch, and $50 \mathrm{~mL}$ for the large batch), with the small and large batches showing a PCE of 0.65 and $0.67 \%$ respectively, thus validating purification processes at the large scale. 
Early in the development of nanoparticle-based solar cells, Andersen et al. reported the use of a rollto-roll system (slot-die coating and screen printing methods) for the fabrication of solar cells from an aqueous ink of low band gap polymer nanoparticles, over flexible substrates ${ }^{49}$ However, the authors reported that the coating of the inks by roll-to-roll methods was first impossible, because of a "catastrophic" de-wetting during deposition over a zinc oxide substrate in the following device architecture: PET/ITO/ZnO/ink/PEDOT:PSS/Ag. In order to overcome this issue, they proposed the addition of a non-ionic fluorosurfactant and the reduction of the coating speed in order to create homogeneous and continuous films in a reproducible way. In the end, the best system used presented a PCE of $0.55 \%$, the poor performances were mainly attributed to the non-optimum morphology.

Almyahi et al. reported that a strategy to ensure a homogeneous deposition of the active layer without addition of additives, is to modify the surface energy of the substrate, here by UV-ozone treatment. ${ }^{144}$ For instance, increasing the concentration of surfactant in the ink led to a better deposition, but the OPV performance is dramatically decreased, and a surfactant concentration that is too low leads to poor film deposition, as reported previously. There is hence a balance to be found between the film formation and the electronic performance. ${ }^{26,53,57}$ Thus, UV-O ${ }_{3}$ treatment of the substrate, the PEDOT:PSS layer in their work, could be an alternative to the use of surfactant in order to improve the film formation. The treatment time should be optimized as well, as a treatment time that is too long (over 5 to 10 minutes) was reported to increase the formation of aggregates. Such surface treatment could be used in a roll-to-roll setup, as a corona treatment, in order to lead to more stable deposition of the active layer, without the necessity of additives. Such pre-treatment showed a great improvement in the device fabrication, with a PCE up to $0.45 \%$ reached for a P3HT:ICXA system, using a roll-to-roll printing technique. ${ }^{144}$ 


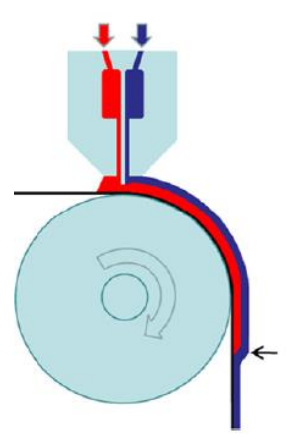

Figure 32. Schematic representation of a double slot-die coating of the active layer (red) and the PEDOT:PSS layer (blue). Adapted with permission from ref 145. Copyright 2012 Elsevier.

Finally, Larsen-Olsen et al. reported the use of a double slot-die coating device, in order to print the active layer (from $\mathrm{P} 3 \mathrm{HT}: \mathrm{PC}_{61} \mathrm{BM}$ nanoparticle dispersion) as well as the PEDOT:PSS layer at the same time (Figure 32). ${ }^{145}$ They reported lower performances using a double slot-die coating in comparison to the deposition layer-by-layer with a standard slot-die coating. However, by optimizing the deposition process, the slot-die coating of several layers at the same time could be an elegant approach to lower the financial and environmental cost of solar cell production and reducing the payback time.

\section{Development in Nanoparticle-Based Solar Cells}

Since the first thought of using organic semiconductor nanoparticles, numerous studies have been performed, showing that this approach could be a strong alternative to the use of chlorinated solvents. As summarized in Table 4, from 2011 to the beginning of 2020, efficiencies have increased from less than $1 \%$ to $7.50 \%$.

It is clear that the main technique presented in the literature is the miniemulsion technique, and a strong increase in the PCE of miniemulsion-based NP OPV devices was observed since 2014, reaching up to $3.8 \%$ in efficiency, attributed to a better understanding of nanoparticle morphology, active layer formation, and influence of external parameters such as surfactant. Even if nanoprecipitation is poorly 
represented in comparison, record efficiencies were reached using this approach, using the poloxamer Pluronic F127.

P3HT was mainly used from 2011 to 2015, but the use of low band-gap polymers has been reported more recently. Concerning the acceptors, while the majority of studies used fullerene derivatives, systems using NFAs were reported more recently, reaching high efficiencies and showing the versatility of such preparation techniques.

Table 4. Evolution of OPV device performance based on active layers of colloidal nanoparticles.

\begin{tabular}{|c|c|c|c|c|c|c|c|c|}
\hline Year & System & Technique & Surfactant & $\begin{array}{l}\text { Voc } \\
\text { (V) }\end{array}$ & $\begin{array}{c}\text { Jsc } \\
\left(\mathrm{mA} \cdot \mathrm{cm}^{-2}\right)\end{array}$ & $\mathrm{FF}$ & $\begin{array}{l}\text { PCE } \\
(\%) \\
\end{array}$ & Ref \\
\hline \multirow{4}{*}{2011} & P3HT:PC ${ }_{61} \mathrm{BM}$ & Nanoprecipitation & - & 0,36 & 0,214 & 0,24 & 0,018 & 21 \\
\hline & $\mathrm{P} 1: \mathrm{PC}_{61} \mathrm{BM}$ & \multirow{3}{*}{ Miniemulsion } & \multirow{3}{*}{ SDS } & 0,24 & 1,1 & 27,5 & 0,07 & \multirow{3}{*}{49} \\
\hline & PSBTBT:PC ${ }_{61} \mathrm{BM}$ & & & 0,47 & 3,99 & 29,3 & 0,55 & \\
\hline & $\mathrm{P} 3: \mathrm{PC}_{61} \mathrm{BM}$ & & & 0,54 & 0,92 & 30,8 & 0,15 & \\
\hline \multirow{3}{*}{2012} & $\mathrm{P} 3 \mathrm{HT} \cdot \mathrm{PC} \mathrm{BM}$ & \multirow{2}{*}{ Miniemulsion } & \multirow{2}{*}{ SDS } & 0,24 & 0,5 & 25 & 0,03 & \multirow{2}{*}{145} \\
\hline & РЗПI:PC61DIVI & & & 0,45 & 1,95 & 33,1 & 0,29 & \\
\hline & PFB:F8BT & Miniemulsion & SDS & 0,77 & 1,81 & 28 & 0,39 & 58 \\
\hline \multirow{2}{*}{2013} & $\mathrm{P} 3 \mathrm{HT}: \mathrm{PC}_{61} \mathrm{BM}$ & Miniemulsion & SDS & 0.52 & 5.45 & 47.0 & 1.31 & 101 \\
\hline & P3HT:ICBA & Miniemulsion & SDS & 0.79 & 5.57 & 57.0 & 2.50 & 104 \\
\hline \multirow{5}{*}{2014} & PDPPTNT:PC ${ }_{71} B M$ & Miniemulsion & SDS & 0.76 & 6.09 & 43.0 & 1.99 & 120 \\
\hline & \multirow{4}{*}{ P3HT:PC 61 BM } & Nanoprecipitation & - & 0.63 & 4.84 & 36.0 & 1.09 & 93 \\
\hline & & \multirow{3}{*}{ Miniemulsion } & \multirow{3}{*}{ SDS } & 0.51 & 6.38 & 66.2 & 2.15 & 123 \\
\hline & & & & 0.54 & 4.73 & 47.0 & 1.20 & 138 \\
\hline & & & & 0.52 & 6.38 & 67.9 & 2.15 & 136 \\
\hline \multirow{5}{*}{2015} & PSBTBT:PC ${ }_{61} \mathrm{BM}$ & Miniemulsion & SDS & 0.62 & 6.20 & 33 & 1.3 & \multirow{2}{*}{105} \\
\hline & \multirow{3}{*}{ P3HT:PC 61 BM } & \multirow{3}{*}{ Miniemulsion } & \multirow{3}{*}{ SDS } & 0.52 & 5.5 & 47 & 1.3 & \\
\hline & & & & 0.52 & 4.60 & 42.0 & 1.00 & 78 \\
\hline & & & & 0.47 & 4.89 & 50.5 & 1.16 & 126 \\
\hline & P(TBT-DPP):ICBA & Miniemulsion & SDS & 0.44 & 12.73 & 47.0 & 2.63 & 61 \\
\hline 2016 & $\mathrm{TQ1}: \mathrm{PC}_{71} \mathrm{BM}$ & Miniemulsion & SDS & 0.70 & 10.06 & 36.0 & 2.54 & 69 \\
\hline \multirow{4}{*}{2017} & PBDTTPD:PC ${ }_{71} \mathrm{BM}$ & Miniemulsion & SDS & 0.86 & 9.99 & 44.0 & 3.80 & 45 \\
\hline & PDPP5T:PC ${ }_{71} \mathrm{BM}$ & Miniemulsion & SDS & 0.54 & 9.34 & 47.0 & 2.36 & 44 \\
\hline & \multirow{2}{*}{ PCDTBT:PC 71 BM } & Miniemulsion & SDS & 0.57 & 8.69 & 38.0 & 1.90 & 46 \\
\hline & & Miniemulsion & SDS & 0.61 & 3.79 & 30.7 & 0.70 & 53 \\
\hline \multirow{2}{*}{2018} & \multirow{2}{*}{ P3HT:ICXA } & \multirow{2}{*}{ Miniemulsion } & \multirow{2}{*}{ SDS } & 0.59 & 3.81 & 39 & 0.87 & 68 \\
\hline & & & & 0.50 & 3.64 & 51 & 0.73 & 65 \\
\hline
\end{tabular}




\begin{tabular}{|c|c|c|c|c|c|c|c|c|}
\hline & PCDTBT:PC ${ }_{71} \mathrm{BM}$ & Nanoprecipitation & - & 0.48 & 1.65 & 29.0 & 0.19 & 42 \\
\hline & PDPP5T-2:PC 71 BM & Miniemulsion & SDS & 0.54 & 11.59 & 49.0 & 3.38 & 41 \\
\hline & PTNT:PC 71 BM & Miniemulsion & SDS & 0.89 & 4.73 & 39.0 & 1.65 & 56 \\
\hline & P3HT:O-IDTBR & \multirow{4}{*}{ Nanoprecipitation } & F127 & 0.77 & 10.75 & 64.9 & 5.23 & \multirow{4}{*}{26} \\
\hline & PCE10:0-IDTBR & & F127 & 1.00 & 12.44 & 44.4 & 5.19 & \\
\hline & PBQ-QF:O-IDTBR & & F127 & 0.98 & 13.50 & 52.2 & 6.52 & \\
\hline & PBQ-QF:ITIC & & F127 & 0.87 & 15.17 & 55.6 & 7.50 & \\
\hline \multirow{2}{*}{2019} & P3HT:ICXA & Miniemulsion & SDS & 0.58 & 0.44 & 5.91 & 1.51 & 144 \\
\hline & P3HT:PC 61 BM & Miniemulsion & SDS & 0.38 & 7.1 & 44.0 & 1.20 & 57 \\
\hline
\end{tabular}

\section{Conclusion and Perspectives}

In this review, we have provided a complete overview of the evolution of nanoparticle-based OPV during the last 20 years, from preparation techniques to the formation of the active layer from colloidal dispersions. It is clear that the use of nanoparticles to deposit the active layer is an efficient and appealing approach, since, in less than 20 years, the efficiency record underwent a twenty-fold increase (from 0.39 to $7.50 \%$ ). Switching from organic solvent (chlorinated, aromatic and even alcoholic) to water for manufacturing organic solar cells would lead to environmentally friendly and safer conditions.

Miniemulsion and nanoprecipitation are the two main techniques used for the preparation of nanoparticle dispersions and have been thoroughly investigated in the literature, with a particular focus on the experimental parameters influencing the nanoparticle size. The morphology inside a nanoparticle was also of great interest, since the distribution of donor and acceptor domains drives the charge generation and charge transport efficiencies. Depending on the technique used, the morphology inside a nanoparticle will vary, with a core-shell morphology reported for nanoparticles prepared via miniemulsion and a heterojunction-like morphology reported for nanoparticles prepared via nanoprecipitation. Here, there is still research to be undertaken to understand the relationship between structure and properties, especially concerning small nanoparticles, in the scale of 5 to 30 $\mathrm{nm}$. The presence of crystalline domains was reported inside nanoparticles, directly following their 
preparation, showing the good ordering of polymer chains within the nanoparticles and resulting in an enhancement of charge mobility.

The transition between the aqueous dispersion and the formation of the active layer is a key-step in nanoparticle-based OPV devices. Two approaches can be considered: the deposition of composite nanoparticles or a blend of single-component nanoparticles. It is still too early to state which option is superior, since only few comparative studies have been performed, and not always in comparative conditions (according to the size of the nanoparticles). Thermal treatments are also reported as key steps for the formation of the active layer. Annealing is a powerful tool to influence the morphology of the active layer, and not only by provoking a sintering of nanoparticles but also by enabling an optimization of the thin film morphology. Other treatments like ozone-treatment, deposition of a buffer layer, modification of the electrode material, etc., can enhance the final OPV performance. However, further improvement needs to be achieved in order to reach efficiencies currently obtained from "classical" conjugated polymer solutions.

Another important point highlighted is the charge trapping effect of the free and surface bound molecules of surfactant, used during the preparation of nanoparticles, resulting in a decrease in the final performance of solar cells. Solutions to overcome this limitation can be the modification of the surfactant used, the removal of the surfactant excess, or both strategies at the same time. Xie et al. presented the use of a non-ionic and temperature-sensitive CMC surfactant, Pluronic F127, reaching the highest efficiencies achieved for nanoparticle-based OPV to date, with a maximum PCE of $7.50 \%$ for the PBQ-QF:ITIC system, due to the more efficient surfactant removal step. ${ }^{26}$ Other approaches can also be considered, like Ferreti et al., who used a conjugated amphiphilic block copolymer, acting as a surfactant via miniemulsion. ${ }^{146}$

Finally, since the design of nanoparticles for OPV is still reduced to the lab-scale, upscaling of the nanoparticle production as well as the preparation of solar cells via printing or roll-to-roll methods are necessary for industrialization. Hence, some research teams reported the upscaling of the ink with the 
preparation of large batches of nanoparticles and the upscaling of the solar cell production, with printing techniques.

\section{Acknowledgements}

This work was made possible thanks to the financial support of E2S (Energy and Environment Solutions) of the Université de Pau et Pays de l'Adour.

This work was performed within the framework of IRP NextPV-II, with support from CNRS (INC and INSIS) and RCAST/University of Tokyo.

This work was performed in part at the Materials Node (Newcastle) of the Australian National Fabrication Facility (ANFF), which is a company established under the National Collaborative Research Infrastructure Strategy (NCRIS) to provide nano- and microfabrication facilities for Australia's researchers.

\section{References}

(1) International Energy Agency. World Energy Balances: An Overview. World Energy Balances 2019. 2019.

(2) International Energy Agency. Renewable Information 2019: Overview. Renewable Information 2019. 2019.

(3) Mazzio, K. A.; Luscombe, C. K. The Future of Organic Photovoltaics. Chem. Soc. Rev. 2015, 44 (1), 78-90.

(4) Darling, S. B.; You, F. The Case for Organic Photovoltaics. RSC Adv. 2013, 3 (39), 17633.

(5) Hedley, G. J.; Ruseckas, A.; Samuel, I. D. W. Light Harvesting for Organic Photovoltaics. Chem. Rev. 2017, 117 (2), 796-837.

(6) Espinosa, N.; García-Valverde, R.; Urbina, A.; Krebs, F. C. A Life Cycle Analysis of Polymer Solar Cell Modules Prepared Using Roll-to-Roll Methods under Ambient Conditions. Solar Energy Materials and Solar Cells 2011, 95 (5), 1293-1302.

(7) Du, X.; Heumueller, T.; Gruber, W.; Classen, A.; Unruh, T.; Li, N.; Brabec, C. J. Efficient Polymer Solar Cells Based on Non-Fullerene Acceptors with Potential Device Lifetime Approaching 10 Years. Joule 2019, 3 (1), 215-226.

(8) Yip, H.-L.; Jen, A. K.-Y. Recent Advances in Solution-Processed Interfacial Materials for Efficient and Stable Polymer Solar Cells. Energy Environ. Sci. 2012, 5 (3), 5994. 
(9) Liu, Q.; Jiang, Y.; Jin, K.; Qin, J.; Xu, J.; Li, W.; Xiong, J.; Liu, J.; Xiao, Z.; Sun, K.; Yang, S.; Zhang, X.; Ding, L. 18\% Efficiency Organic Solar Cells. Science Bulletin 2020, 65 (4), 272-275.

(10) Zhou, X.; Belcher, W.; Dastoor, P. Solar Paint: From Synthesis to Printing. Polymers 2014, 6 (11), 2832-2844.

(11) Ma, Z.; Zhao, B.; Gong, Y.; Deng, J.; Tan, Z. Green-Solvent-Processable Strategies for Achieving Large-Scale Manufacture of Organic Photovoltaics. J. Mater. Chem. A 2019, 7 (40), 22826-22847.

(12) Lee, S.; Jeong, D.; Kim, C.; Lee, C.; Kang, H.; Woo, H. Y.; Kim, B. J. Eco-Friendly Polymer Solar Cells: Advances in Green-Solvent Processing and Material Design. ACS Nano 2020, 14 (11), 14493-14527.

(13) Zhang, S.; Ye, L.; Zhang, H.; Hou, J. Green-Solvent-Processable Organic Solar Cells. Mater. Today 2016, 19 (9), 533-543.

(14) Holmes, N. P.; Munday, H.; Barr, M. G.; Thomsen, L.; Marcus, M. A.; Kilcoyne, A. L. D.; Fahy, A.; van Stam, J.; Dastoor, P. C.; Moons, E. Unravelling Donor-Acceptor Film Morphology Formation for Environmentally-Friendly OPV Ink Formulations. Green Chem. 2019, 21 (18), 5090-5103.

(15) Subianto, S.; Dutta, N.; Andersson, M.; Choudhury, N. R. Bulk Heterojunction Organic Photovoltaics from Water-Processable Nanomaterials and Their Facile Fabrication Approaches. Advances in Colloid and Interface Science 2016, 235, 56-69.

(16) Duan, C.; Zhang, K.; Zhong, C.; Huang, F.; Cao, Y. Recent Advances in Water/Alcohol-Soluble $\pi$-Conjugated Materials: New Materials and Growing Applications in Solar Cells. Chem. Soc. Rev. 2013, 42 (23), 9071.

(17) Sankaran, S.; Glaser, K.; Gärtner, S.; Rödlmeier, T.; Sudau, K.; Hernandez-Sosa, G.; Colsmann, A. Fabrication of Polymer Solar Cells from Organic Nanoparticle Dispersions by Doctor Blading or Ink-Jet Printing. Organic Electronics 2016, 28, 118 122.

(18) Xie, C.; Tang, X.; Berlinghof, M.; Langner, S.; Chen, S.; Späth, A.; Li, N.; Fink, R. H.; Unruh, T.; Brabec, C. J. Robot-Based High-Throughput Engineering of Alcoholic Polymer: Fullerene Nanoparticle Inks for an Eco-Friendly Processing of Organic Solar Cells. ACS Appl. Mater. Interfaces 2018, 10 (27), 23225-23234.

(19) Gärtner, S.; Christmann, M.; Sankaran, S.; Röhm, H.; Prinz, E.-M.; Penth, F.; Pütz, A.; Türeli, A. E.; Penth, B.; Baumstümmler, B.; Colsmann, A. Eco-Friendly Fabrication of 4\% Efficient Organic Solar Cells from Surfactant-Free P3HT:ICBA Nanoparticle Dispersions. Adv. Mater. 2014, 26 (38), 6653-6657.

(20) Millstone, J. E.; Kavulak, D. F. J.; Woo, C. H.; Holcombe, T. W.; Westling, E. J.; Briseno, A. L.; Toney, M. F.; Fréchet, J. M. J. Synthesis, Properties, and Electronic Applications of Size-Controlled Poly(3-Hexylthiophene) Nanoparticles. Langmuir 2010, 26 (16), 13056-13061.

(21) Darwis, D.; Elkington, D.; Sesa, E.; Cooling, N.; Bryant, G.; Zhou, X.; Belcher, W.; Dastoor, P.; Iskandar, F.; Abdullah, M. Surfactant Free P3HT / PCBM Nanoparticles for Organic Photovoltaics (OPV). AIP Conf. Proc. 2011, 1415, 120-123.

(22) Nagai, M.; Huang, J.; Cui, D.; Wang, Z.; Huang, W. Two-Step Reprecipitation Method with Size and Zeta Potential Controllability for Synthesizing Semiconducting Polymer Nanoparticles. Colloid Polym Sci 2017, 295 (7), 1153-1164.

(23) Darwis, D.; Sesa, E.; Ulum, S.; Holmes, N. P.; Feron, K.; Thameel, M.; Chowdhury, R.; Farhamsah, D.; Tegg, L.; Zhou, X.; Dastoor, P. C.; Belcher, W. J. Role of Morphology of Surfactant-Free Nanoparticles in Organic Photovoltaics. Journal of Elec Materi 2020, 49 (7), 4168-4179. 
(24) Gärtner, S.; Clulow, A. J.; Howard, I. A.; Gilbert, E. P.; Burn, P. L.; Gentle, I. R.; Colsmann, A. Relating Structure to Efficiency in Surfactant-Free Polymer/Fullerene Nanoparticle-Based Organic Solar Cells. ACS Appl. Mater. Interfaces 2017, 9 (49), 42986-42995.

(25) Xu, X.; Yu, L.; Yan, H.; Li, R.; Peng, Q. Highly Efficient Non-Fullerene Organic Solar Cells Enabled by a Delayed Processing Method Using a Non-Halogenated Solvent. Energy Environ. Sci. 2020, 13 (11), 4381-4388.

(26) Xie, C.; Heumüller, T.; Gruber, W.; Tang, X.; Classen, A.; Schuldes, I.; Bidwell, M.; Späth, A.; Fink, R. H.; Unruh, T.; McCulloch, I.; Li, N.; Brabec, C. J. Overcoming Efficiency and Stability Limits in Water-Processing Nanoparticular Organic Photovoltaics by Minimizing Microstructure Defects. Nat Commun 2018, 9 (1), 5335.

(27) Rao, J. P.; Geckeler, K. E. Polymer Nanoparticles: Preparation Techniques and SizeControl Parameters. Prog Polym Sci 2011, 36 (7), 887-913.

(28) Vert, M.; Doi, Y.; Hellwich, K.-H.; Hess, M.; Hodge, P.; Kubisa, P.; Rinaudo, M.; Schué, F. Terminology for Biorelated Polymers and Applications (IUPAC Recommendations 2012). Pure and Applied Chemistry 2012, 84 (2), 377-410.

(29) Pecher, J.; Mecking, S. Nanoparticles of Conjugated Polymers. Chem. Rev. 2010, 110 (10), 6260-6279.

(30) Hittinger, E.; Kokil, A.; Weder, C. Synthesis and Characterization of Cross-Linked Conjugated Polymer Milli-, Micro-, and Nanoparticles. Angew. Chem. Int. Ed. 2004, 43 (14), 1808-1811.

(31) Kuehne, A. J. C.; Gather, M. C.; Sprakel, J. Monodisperse Conjugated Polymer Particles by Suzuki-Miyaura Dispersion Polymerization. Nat Commun 2012, 3 (1), 1088.

(32) Virgili, T.; Botta, C.; Mróz, M. M.; Parrenin, L.; Brochon, C.; Cloutet, E.; Pavlopoulou, E.; Hadziioannou, G.; Geoghegan, M. Size-Dependent Photophysical Behavior of Low Bandgap Semiconducting Polymer Particles. Front. Chem. 2019, 7, 409.

(33) Groenendaal, L. "Bert"; Jonas, F.; Freitag, D.; Pielartzik, H.; Reynolds, J. R. Poly(3,4Ethylenedioxythiophene) and Its Derivatives: Past, Present, and Future. Advanced Materials 2000, 12 (7), 481-494.

(34) Holmes, N. P.; Burke, K. B.; Sista, P.; Barr, M.; Magurudeniya, H. D.; Stefan, M. C.; Kilcoyne, A. L. D.; Zhou, X.; Dastoor, P. C.; Belcher, W. J. Nano-Domain Behaviour in P3HT:PCBM Nanoparticles, Relating Material Properties to Morphological Changes. Solar Energy Materials and Solar Cells 2013, 117, 437-445.

(35) Ramírez-Aparicio, J.; Pathiranage, T. M. S. K.; Nguyen, H. Q.; Stefan, M. C.; Samaniego-Benítez, J. E.; Salinas-Bravo, V. M.; Ramírez-Bon, R. Synthesis of P3HT Base Semiconducting Hybrid Films and Their Photocatalytic Properties. J Coat Technol Res 2019, 16 (4), 1065-1075.

(36) Bhatt, M. P.; Magurudeniya, H. D.; Sista, P.; Sheina, E. E.; Jeffries-EL, M.; Janesko, B. G.; McCullough, R. D.; Stefan, M. C. Role of the Transition Metal in Grignard Metathesis Polymerization (GRIM) of 3-Hexylthiophene. J. Mater. Chem. A 2013, 1 (41), 12841.

(37) Kietzke, T.; Neher, D.; Landfester, K.; Montenegro, R.; Güntner, R.; Scherf, U. Novel Approaches to Polymer Blends Based on Polymer Nanoparticles. Nature Mater 2003, 2 (6), 408-412.

(38) Tuncel, D.; Demir, H. V. Conjugated Polymer Nanoparticles. Nanoscale 2010, 2 (4), 484.

(39) Richards, J. J.; Weigandt, K. M.; Pozzo, D. C. Aqueous Dispersions of Colloidal Poly(3-Hexylthiophene) Gel Particles with High Internal Porosity. Journal of Colloid and Interface Science 2011, 364 (2), 341-350. 
(40) Richards, J. J.; Whittle, C. L.; Shao, G.; Pozzo, L. D. Correlating Structure and Photocurrent for Composite Semiconducting Nanoparticles with Contrast Variation Small-Angle Neutron Scattering and Photoconductive Atomic Force Microscopy. ACS Nano 2014, 8 (5), 4313-4324.

(41) Xie, C.; Classen, A.; Späth, A.; Tang, X.; Min, J.; Meyer, M.; Zhang, C.; Li, N.; Osvet, A.; Fink, R. H.; Brabec, C. J. Overcoming Microstructural Limitations in Water Processed Organic Solar Cells by Engineering Customized Nanoparticulate Inks. $A d v$. Energy Mater. 2018, 8 (13), 1702857.

(42) Prunet, G.; Parrenin, L.; Pavlopoulou, E.; Pecastaings, G.; Brochon, C.; Hadziioannou, G.; Cloutet, E. Aqueous PCDTBT:PC 71 BM Photovoltaic Inks Made by Nanoprecipitation. Macromol. Rapid Commun. 2018, 39 (2), 1700504.

(43) Chambon, S.; Schatz, C.; Sébire, V.; Pavageau, B.; Wantz, G.; Hirsch, L. Organic Semiconductor Core-Shell Nanoparticles Designed through Successive Solvent Displacements. Mater. Horiz. 2014, 1 (4), 431-438.

(44) Colberts, F. J. M.; Wienk, M. M.; Janssen, R. A. J. Aqueous Nanoparticle Polymer Solar Cells: Effects of Surfactant Concentration and Processing on Device Performance. ACS Appl. Mater. Interfaces 2017, 9 (15), 13380-13389.

(45) D’Olieslaeger, L.; Pirotte, G.; Cardinaletti, I.; D’Haen, J.; Manca, J.; Vanderzande, D.; Maes, W.; Ethirajan, A. Eco-Friendly Fabrication of PBDTTPD:PC71BM Solar Cells Reaching a PCE of $3.8 \%$ Using Water-Based Nanoparticle Dispersions. Organic Electronics 2017, 42, 42-46.

(46) D’Olieslaeger, L.; Pfannmöller, M.; Fron, E.; Cardinaletti, I.; Van Der Auweraer, M.; Van Tendeloo, G.; Bals, S.; Maes, W.; Vanderzande, D.; Manca, J.; Ethirajan, A. Tuning of PCDTBT:PC71BM Blend Nanoparticles for Eco-Friendly Processing of Polymer Solar Cells. Solar Energy Materials and Solar Cells 2017, 159, 179-188.

(47) Vaughan, B.; Stapleton, A.; Sesa, E.; Holmes, N. P.; Zhou, X.; Dastoor, P. C.; Belcher, W. J. Engineering Vertical Morphology with Nanoparticulate Organic Photovoltaic Devices. Organic Electronics 2016, 32, 250-257.

(48) Holmes, N. P.; Vaughan, B.; Williams, E. L.; Kroon, R.; Anderrson, M. R.; Kilcoyne, A. L. D.; Sonar, P.; Zhou, X.; Dastoor, P. C.; Belcher, W. J. DiketopyrrolopyrroleBased Polymer:Fullerene Nanoparticle Films with Thermally Stable Morphology for Organic Photovoltaic Applications. MRC 2017, 7 (1), 67-73.

(49) Andersen, T. R.; Larsen-Olsen, T. T.; Andreasen, B.; Böttiger, A. P. L.; Carlé, J. E.; Helgesen, M.; Bundgaard, E.; Norrman, K.; Andreasen, J. W.; Jørgensen, M.; Krebs, F. C. Aqueous Processing of Low-Band-Gap Polymer Solar Cells Using Roll-to-Roll Methods. ACS Nano 2011, 5 (5), 4188-4196.

(50) Landfester, K. Semiconducting Polymer Nanosphere in Aqueous Dispersion Prepared by a Miniemulsion Process. Adv. Mater. 2002, 14 (9), 651.

(51) Asua, J. M. Miniemulsion Polymerization. Progress in Polymer Science 2002, 27 (7), 1283-1346.

(52) Piok, T.; Gamerith, S.; Gadermaier, C.; Plank, H.; Wenzl, F. P.; Patil, S.; Montenegro, R.; Kietzke, T.; Neher, D.; Scherf, U.; Landfester, K.; List, E. J. W. Organic LightEmitting Devices Fabricated from Semiconducting Nanospheres. Adv. Mater. 2003, 15 (10), 800-804.

(53) Parrenin, L.; Laurans, G.; Pavlopoulou, E.; Fleury, G.; Pecastaings, G.; Brochon, C.; Vignau, L.; Hadziioannou, G.; Cloutet, E. Photoactive Donor-Acceptor Composite Nanoparticles Dispersed in Water. Langmuir 2017, 33 (6), 1507-1515.

(54) Tan, B.; Li, Y.; Palacios, M. F.; Therrien, J.; Sobkowicz, M. J. Effect of Surfactant Conjugation on Structure and Properties of Poly(3-Hexylthiophene) Colloids and Field Effect Transistors. Colloid Surface A 2016, 488, 7-14. 
(55) Cho, J.; Yoon, S.; Min Sim, K.; Jin Jeong, Y.; Eon Park, C.; Kwon, S.-K.; Kim, Y.-H.; Chung, D. S. Universal Selection Rule for Surfactants Used in Miniemulsion Processes for Eco-Friendly and High Performance Polymer Semiconductors. Energy Environ. Sci. 2017, 10 (11), 2324-2333.

(56) Pan, X.; Sharma, A.; Gedefaw, D.; Kroon, R.; Diaz de Zerio, A.; Holmes, N. P.; Kilcoyne, A. L. D.; Barr, M. G.; Fahy, A.; Marks, M.; Zhou, X.; Belcher, W.; Dastoor, P. C.; Andersson, M. R. Environmentally Friendly Preparation of Nanoparticles for Organic Photovoltaics. Organic Electronics 2018, 59, 432-440.

(57) Marks, M.; Holmes, N. P.; Sharma, A.; Pan, X.; Chowdhury, R.; Barr, M. G.; Fenn, C.; Griffith, M. J.; Feron, K.; Kilcoyne, A. L. D.; Lewis, D. A.; Andersson, M. R.; Belcher, W. J.; Dastoor, P. C. Building Intermixed Donor-Acceptor Architectures for WaterProcessable Organic Photovoltaics. Phys. Chem. Chem. Phys. 2019, 21 (10), 57055715.

(58) Stapleton, A.; Vaughan, B.; Xue, B.; Sesa, E.; Burke, K.; Zhou, X.; Bryant, G.; Werzer, O.; Nelson, A.; David Kilcoyne, A. L.; Thomsen, L.; Wanless, E.; Belcher, W.; Dastoor, P. A Multilayered Approach to Polyfluorene Water-Based Organic Photovoltaics. Sol. Energy Mater. Sol. Cells 2012, 102, 114-124.

(59) Pras, O.; Chaussy, D.; Stephan, O.; Rharbi, Y.; Piette, P.; Beneventi, D. Photoluminescence of 2,7-Poly(9,9-Dialkylfluorene- Co -Fluorenone) Nanoparticles: Effect of Particle Size and Inert Polymer Addition. Langmuir 2010, 26 (18), 1443714442.

(60) Lee, Y.; Lee, S. H.; Kim, K.; Lee, J. W.; Han, K.-Y.; Kim, J.; Joo, J. Single Nanoparticle of Organic P-Type and $n$-Type Hybrid Materials: Nanoscale Phase Separation and Photovoltaic Effect. J. Mater. Chem. 2012, 22 (6), 2485-2490.

(61) Yamamoto, N. A. D.; Payne, M. E.; Koehler, M.; Facchetti, A.; Roman, L. S.; Arias, A. C. Charge Transport Model for Photovoltaic Devices Based on Printed Polymer: Fullerene Nanoparticles. Sol. Energy Mater. Sol. Cells 2015, 141, 171-177.

(62) Landfester, K.; Bechthold, N.; Tiarks, F.; Antonietti, M. Formulation and Stability Mechanisms of Polymerizable Miniemulsions. Macromolecules 1999, 32 (16), 52225228.

(63) Huang, H.; Zhang, H.; Li, J.; Cheng, S.; Hu, F.; Tan, B. Miniemulsion Copolymerization of Styrene and Butyl Acrylate Initiated by Redox System at Lower Temperature-Preparation and Polymerizaton of Miniemulsion. J. Appl. Polym. Sci. 1998, 68 (12), 2029-2039.

(64) Rodriguez, V. S.; El-Aasser, M. S.; Asua, J. M.; Silebi, C. A. Miniemulsion Copolymerization of Styrene-Methyl Methacrylate. J. Polym. Sci. A Polym. Chem. 1989, 27 (11), 3659-3671.

(65) Almyahi, F.; Andersen, T. R.; Cooling, N. A.; Holmes, N. P.; Griffith, M. J.; Feron, K.; Zhou, X.; Belcher, W. J.; Dastoor, P. C. Optimisation of Purification Techniques for the Preparation of Large-Volume Aqueous Solar Nanoparticle Inks for Organic Photovoltaics. Beilstein J. Nanotechnol. 2018, 9, 649-659.

(66) Mason, T. J.; Lorimer, J. P. Sonochemistry (Theory, Applications and Uses of Ultrasound in Chemistry). Berichte der Bunsengesellschaft für physikalische Chemie 1989, 93 (10), 1150-1151.

(67) Satapathi, S.; Gill, H. S.; Li, L.; Samuelson, L.; Kumar, J.; Mosurkal, R. Synthesis of Nanoparticles of P3HT and PCBM for Optimizing Morphology in Polymeric Solar Cells. Applied Surface Science 2014, 323, 13-18.

(68) Almyahi, F.; Andersen, T. R.; Cooling, N.; Holmes, N. P.; Fahy, A.; Barr, M. G.; Kilcoyne, D.; Belcher, W.; Dastoor, P. C. Optimization, Characterization and Upscaling 
of Aqueous Solar Nanoparticle Inks for Organic Photovoltaics Using Low-Cost Donor:Acceptor Blend. Org. Electron. 2018, 52, 71-78.

(69) Holmes, N. P.; Marks, M.; Kumar, P.; Kroon, R.; Barr, M. G.; Nicolaidis, N.; Feron, K.; Pivrikas, A.; Fahy, A.; Mendaza, A. D. de Z.; Kilcoyne, A. L. D.; Müller, C.; Zhou, X.; Andersson, M. R.; Dastoor, P. C.; Belcher, W. J. Nano-Pathways: Bridging the Divide between Water-Processable Nanoparticulate and Bulk Heterojunction Organic Photovoltaics. Nano Energy 2016, 19, 495-510.

(70) Nakama, Y. Surfactants. In Cosmetic Science and Technology, $1^{\text {st }}$ edition, Elsevier, Amsterdam, The Nederland, 2017; pp 231-244.

(71) Kosswig, K. Surfactants. In Ullmann's Encyclopedia of Industrial Chemistry; WileyVCH Verlag GmbH \& Co. KGaA, Ed.; Wiley-VCH Verlag GmbH \& Co. KGaA: Weinheim, Germany, 2000; p a25_747.

(72) Holmberg, K.; Jönsson, B.; Kronberg, B.; Lindman, B. Surfactants and Polymers in Aqueous Solution - Chapter 21 - Emulsions and Emulsifiers; John Wiley \& Sons, Ltd: Chichester, UK, 2002.

(73) Rosen, M. J.; Kunjappu, J. T. Surfactants and Interfacial Phenomena - Chapter 8: Emulsification by Surfactants; John Wiley \& Sons, Inc.: Hoboken, NJ, USA, 2012.

(74) Griffin, W. L. Classification of Surface-Active Agents by HLB. Journal of the Society of Cosmetic Chemists 1949, 1 (5), 311-326.

(75) Davies, J. T. A Quantitative Kinetic Theory of Emulsion Type. I. Physical Chemistry of the Emulsifying Agent. Proc. 2nd Int. Congr. Surface Activity, Butterworths, London 1957, $1,426-438$.

(76) Nollet, M.; Boulghobra, H.; Calligaro, E.; Rodier, J. -D. An Efficient Method to Determine the Hydrophile-Lipophile Balance of Surfactants Using the Phase Inversion Temperature Deviation of $\mathrm{C}_{\mathrm{i}} \mathrm{E}_{\mathrm{j}} / \mathrm{n}$-octane/Water Emulsions. Int J Cosmet Sci 2019, 41 (2), 99-108.

(77) Cho, J.; Cheon, K. H.; Ahn, H.; Park, K. H.; Kwon, S.-K.; Kim, Y.-H.; Chung, D. S. High Charge-Carrier Mobility of $2.5 \mathrm{Cm}^{2} \mathrm{~V}^{-1} \mathrm{~s}^{-1}$ from a Water-Borne Colloid of a Polymeric Semiconductor via Smart Surfactant Engineering. Adv. Mater. 2015, 27 (37), 5587-5592.

(78) Holmes, N. P.; Nicolaidis, N.; Feron, K.; Barr, M.; Burke, K. B.; Al-Mudhaffer, M.; Sista, P.; Kilcoyne, A. L. D.; Stefan, M. C.; Zhou, X.; Dastoor, P. C.; Belcher, W. J. Probing the Origin of Photocurrent in Nanoparticulate Organic Photovoltaics. Sol. Energy Mater. Sol. Cells 2015, 140, 412-421.

(79) Kumar, A.; Dixit, C. K. 3 - Methods for Characterization of Nanoparticles. In Advances in Nanomedicine for the Delivery of Therapeutic Nucleic Acids; Woodhead Publishing, Elsevier, United Kingdom, 2017; pp 43-58.

(80) Aubry, J.; Ganachaud, F.; Cohen Addad, J.-P.; Cabane, B. Nanoprecipitation of Polymethylmethacrylate by Solvent Shifting:1. Boundaries. Langmuir 2009, 25 (4), 1970-1979.

(81) Dwivedi, P.; Karumbaiah, K. M.; Das, R. Nano-Size Polymers via Precipitation of Polymer Solutions. In Nano-Size Polymers; Fakirov, S., Ed.; Springer International Publishing: Cham, 2016; pp 251-282.

(82) Wang, S.; Singh, A.; Walsh, N.; Redmond, G. Surfactant-Free, Low Band Gap Conjugated Polymer Nanoparticles and Polymer:Fullerene Nanohybrids with Potential for Organic Photovoltaics. Nanotechnology 2016, 27 (24), 245601.

(83) Palacio Valera, A.; Schatz, C.; Ibarboure, E.; Kubo, T.; Segawa, H.; Chambon, S. Elaboration of PCBM Coated P3HT Nanoparticles: Understanding the Shell Formation. Front. Energy Res. 2019, 6, 146. 
(84) Schubert, S.; Delaney, Jr, J. T.; Schubert, U. S. Nanoprecipitation and Nanoformulation of Polymers: From History to Powerful Possibilities beyond Poly(lactic Acid). Soft Matter 2011, 7 (5), 1581-1588.

(85) Lepeltier, E.; Bourgaux, C.; Couvreur, P. Nanoprecipitation and the "Ouzo Effect": Application to Drug Delivery Devices. Advanced Drug Delivery Reviews 2014, 71, 8697.

(86) Martínez Rivas, C. J.; Tarhini, M.; Badri, W.; Miladi, K.; Greige-Gerges, H.; Nazari, Q. A.; Galindo Rodríguez, S. A.; Román, R. Á.; Fessi, H.; Elaissari, A. Nanoprecipitation Process: From Encapsulation to Drug Delivery. International Journal of Pharmaceutics 2017, 532 (1), 66-81.

(87) Couto, R.; Chambon, S.; Aymonier, C.; Mignard, E.; Pavageau, B.; Erriguible, A.; Marre, S. Microfluidic Supercritical Antisolvent Continuous Processing and Direct Spray-Coating of Poly(3-Hexylthiophene) Nanoparticles for OFET Devices. Chem. Commun. 2015, 51 (6), 1008-1011.

(88) Botet, R.; Roger, K. How Do Interactions Control Droplet Size during Nanoprecipitation? Current Opinion in Colloid \& Interface Science 2016, 22, 108-112.

(89) Shimizu, H.; Yamada, M.; Wada, R.; Okabe, M. Preparation and Characterization of Water Self-Dispersible Poly(3-Hexylthiophene) Particles. Polym J 2008, 40 (1), 33-36.

(90) Hu, Z.; Gesquiere, A. J. PCBM Concentration Dependent Morphology of P3HT in Composite P3HT/PCBM Nanoparticles. Chemical Physics Letters 2009, 476 (1-3), 5155.

(91) Tenery, D.; Worden, J. G.; Hu, Z.; Gesquiere, A. J. Single Particle Spectroscopy on Composite MEH-PPV/PCBM Nanoparticles. Journal of Luminescence 2009, 129 (5), 423-429.

(92) Hu, Z.; Tenery, D.; Bonner, M. S.; Gesquiere, A. J. Correlation between Spectroscopic and Morphological Properties of Composite P3HT/PCBM Nanoparticles Studied by Single Particle Spectroscopy. Journal of Luminescence 2010, 130 (5), 771-780.

(93) Darwis, D.; Holmes, N.; Elkington, D.; David Kilcoyne, A. L.; Bryant, G.; Zhou, X.; Dastoor, P.; Belcher, W. Surfactant-Free Nanoparticulate Organic Photovoltaics. Sol. Energy Mater. Sol. Cells 2014, 121, 99-107.

(94) Ganachaud, F.; Katz, J. L. Nanoparticles and Nanocapsules Created Using the Ouzo Effect: Spontaneous Emulsification as an Alternative to Ultrasonic and High-Shear Devices. ChemPhysChem 2005, 6 (2), 209-216.

(95) Fraleoni-Morgera, A.; Marazzita, S.; Frascaro, D.; Setti, L. Influence of a Non-Ionic Surfactant on the UV-Vis Absorption Features of Regioregular Head-to-Tail Poly(3Hexylthiophene) in Water-Based Dispersions. Synthetic Metals 2004, 147 (1-3), 149154.

(96) Schwarz, K. N.; Farley, S. B.; Smith, T. A.; Ghiggino, K. P. Charge Generation and Morphology in P3HT: PCBM Nanoparticles Prepared by Mini-Emulsion and Reprecipitation Methods. Nanoscale 2015, 7 (47), 19899-19904.

(97) Kietzke, T.; Neher, D.; Kumke, M.; Montenegro, R.; Landfester, K.; Scherf, U. A Nanoparticle Approach To Control the Phase Separation in Polyfluorene Photovoltaic Devices. Macromolecules 2004, 37 (13), 4882-4890.

(98) Snaith, H. J.; Friend, R. H. Photovoltaic Devices Fabricated from an Aqueous Dispersion of Polyfluorene Nanoparticles Using an Electroplating Method. Synth. Met. 2004, 147 (1-3), 105-109.

(99) Kietzke, T.; Neher, D.; Kumke, M.; Ghazy, O.; Ziener, U.; Landfester, K. Phase Separation of Binary Blends in Polymer Nanoparticles. Small 2007, 3 (6), 1041-1048.

(100) Burke, K. B.; Stapleton, A. J.; Vaughan, B.; Zhou, X.; Kilcoyne, A. L. D.; Belcher, W. J.; Dastoor, P. C. Scanning Transmission X-Ray Microscopy of Polymer Nanoparticles: 
Probing Morphology on Sub-10 Nm Length Scales. Nanotechnology 2011, 22 (26), 265710.

(101) Ulum, S.; Holmes, N.; Darwis, D.; Burke, K.; David Kilcoyne, A. L.; Zhou, X.; Belcher, W.; Dastoor, P. Determining the Structural Motif of P3HT:PCBM Nanoparticulate Organic Photovoltaic Devices. Sol. Energy Mater. Sol. Cells 2013, 110, 43-48.

(102) Huang, J.-H.; Hsiao, Y.-S.; Richard, E.; Chen, C.-C.; Chen, P.; Li, G.; Chu, C.-W.; Yang, Y. The Investigation of Donor-Acceptor Compatibility in Bulk-Heterojunction Polymer Systems. Appl. Phys. Lett. 2013, 103 (4), 043304.

(103) Sun, Y.; Chien, S.-C.; Yip, H.-L.; Chen, K.-S.; Zhang, Y.; Davies, J. A.; Chen, F.-C.; Lin, B.; Jen, A. K.-Y. Improved Thin Film Morphology and Bulk-Heterojunction Solar Cell Performance through Systematic Tuning of the Surface Energy of Conjugated Polymers. J. Mater. Chem. 2012, 22 (12), 5587.

(104) Ulum, S.; Holmes, N.; Barr, M.; Kilcoyne, A. L. D.; Gong, B. B.; Zhou, X.; Belcher, W.; Dastoor, P. The Role of Miscibility in Polymer:Fullerene Nanoparticulate Organic Photovoltaic Devices. Nano Energy 2013, 2 (5), 897-905.

(105) Dam, H. F.; Holmes, N. P.; Andersen, T. R.; Larsen-Olsen, T. T.; Barr, M.; Kilcoyne, A. L. D.; Zhou, X.; Dastoor, P. C.; Krebs, F. C.; Belcher, W. J. The Effect of Mesomorphology upon the Performance of Nanoparticulate Organic Photovoltaic Devices. Solar Energy Materials and Solar Cells 2015, 138, 102-108.

(106) Al-Mudhaffer, M. F.; Holmes, N. P.; Kumar, P.; Barr, M. G.; Cottam, S.; Crovador, R.; Jones, T. W.; Lim, R.; Zhou, X.; Holdsworth, J.; Belcher, W. J.; Dastoor, P. C.; Griffith, M. J. Relating Nanoscale Structure to Optoelectronic Functionality in Multiphase Donor-Acceptor Nanoparticles for Printed Electronics Applications. MRC 2020, 10, 600-608.

(107) Subianto, S.; Balu, R.; de Campo, L.; Sokolova, A.; Dutta, N. K.; Choudhury, N. R. Sulfonated Thiophene Derivative Stabilized Aqueous Poly(3-Hexylthiophene):PhenylC 61 -Butyric Acid Methyl Ester Nanoparticle Dispersion for Organic Solar Cell Applications. ACS Appl. Mater. Interfaces 2018, 10 (50), 44116-44125.

(108) Kosco, J.; Bidwell, M.; Cha, H.; Martin, T.; Howells, C. T.; Sachs, M.; Anjum, D. H.; Gonzalez Lopez, S.; Zou, L.; Wadsworth, A.; Zhang, W.; Zhang, L.; Tellam, J.; Sougrat, R.; Laquai, F.; DeLongchamp, D. M.; Durrant, J. R.; McCulloch, I. Enhanced Photocatalytic Hydrogen Evolution from Organic Semiconductor Heterojunction Nanoparticles. Nat. Mater. 2020, 19 (5), 559-565.

(109) Müller, C. On the Glass Transition of Polymer Semiconductors and Its Impact on Polymer Solar Cell Stability. Chem. Mater. 2015, 27 (8), 2740-2754.

(110) Reese, M. O.; Gevorgyan, S. A.; Jørgensen, M.; Bundgaard, E.; Kurtz, S. R.; Ginley, D. S.; Olson, D. C.; Lloyd, M. T.; Morvillo, P.; Katz, E. A.; Elschner, A.; Haillant, O.; Currier, T. R.; Shrotriya, V.; Hermenau, M.; Riede, M.; R. Kirov, K.; Trimmel, G.; Rath, T.; Inganäs, O. et al. Consensus Stability Testing Protocols for Organic Photovoltaic Materials and Devices. Solar Energy Materials and Solar Cells 2011, 95 (5), 1253-1267.

(111) Clafton, S. N.; Huang, D. M.; Massey, W. R.; Kee, T. W. Femtosecond Dynamics of Excitons and Hole-Polarons in Composite P3HT/PCBM Nanoparticles. J. Phys. Chem. B 2013, 117 (16), 4626-4633.

(112) Chen, D.; Liu, F.; Wang, C.; Nakahara, A.; Russell, T. P. Bulk Heterojunction Photovoltaic Active Layers via Bilayer Interdiffusion. Nano Lett. 2011, 11 (5), 20712078.

(113) Chen, D.; Nakahara, A.; Wei, D.; Nordlund, D.; Russell, T. P. P3HT/PCBM Bulk Heterojunction Organic Photovoltaics: Correlating Efficiency and Morphology. Nano Lett. 2011, 11 (2), 561-567. 
(114) Treat, N. D.; Brady, M. A.; Smith, G.; Toney, M. F.; Kramer, E. J.; Hawker, C. J.; Chabinyc, M. L. Interdiffusion of PCBM and P3HT Reveals Miscibility in a Photovoltaically Active Blend. Adv. Energy Mater. 2011, 1 (1), 82-89.

(115) Al-Mudhaffer, M. F.; Griffith, M. J.; Feron, K.; Nicolaidis, N. C.; Cooling, N. A.; Zhou, X.; Holdsworth, J.; Belcher, W. J.; Dastoor, P. C. The Origin of Performance Limitations in Miniemulsion Nanoparticulate Organic Photovoltaic Devices. Solar Energy Materials and Solar Cells 2018, 175, 77-88.

(116) Feron, K.; Ulum, S.; Holmes, N. P.; Kilcoyne, A. L. D.; Belcher, W. J.; Zhou, X.; Fell, C. J.; Dastoor, P. C. Modelling Transport in Nanoparticle Organic Solar Cells Using Monte Carlo Methods. Appl. Phys. Lett. 2013, 103 (19), 193306.

(117) Hoppe, H.; Sariciftci, N. S. Morphology of Polymer/Fullerene Bulk Heterojunction Solar Cells. J. Mater. Chem. 2006, 16 (1), 45-61.

(118) Naveed, H. B.; Zhou, K.; Ma, W. Interfacial and Bulk Nanostructures Control Loss of Charges in Organic Solar Cells. Acc. Chem. Res. 2019, 52 (10), 2904-2915.

(119) Holmes, N. P.; Marks, M.; Cave, J. M.; Feron, K.; Barr, M. G.; Fahy, A.; Sharma, A.; Pan, X.; Kilcoyne, D. A. L.; Zhou, X.; Lewis, D. A.; Andersson, M. R.; van Stam, J.; Walker, A. B.; Moons, E.; Belcher, W. J.; Dastoor, P. C. Engineering Two-Phase and Three-Phase Microstructures from Water-Based Dispersions of Nanoparticles for EcoFriendly Polymer Solar Cell Applications. Chem. Mater. 2018, 30 (18), 6521-6531.

(120) Vaughan, B.; Williams, E. L.; Holmes, N. P.; Sonar, P.; Dodabalapur, A.; Dastoor, P. C.; Belcher, W. J. Water-Based Nanoparticulate Solar Cells Using a Diketopyrrolopyrrole Donor Polymer. Phys. Chem. Chem. Phys. 2014, 16 (6), 2647.

(121) Redecker, M.; Bradley, D. D. C.; Inbasekaran, M.; Wu, W. W.; Woo, E. P. High Mobility Hole Transport Fluorene-Triarylamine Copolymers. Advanced Materials 1999, 11 (3), 241-246.

(122) Darwis, D.; Elkington, D.; Ulum, S.; Bryant, G.; Belcher, W.; Dastoor, P.; Zhou, X. Novel Low Voltage and Solution Processable Organic Thin Film Transistors Based on Water Dispersed Polymer Semiconductor Nanoparticulates. Journal of Colloid and Interface Science 2013, 401, 65-69.

(123) Gehan, T. S.; Bag, M.; Renna, L. A.; Shen, X.; Algaier, D. D.; Lahti, P. M.; Russell, T. P.; Venkataraman, D. Multiscale Active Layer Morphologies for Organic Photovoltaics through Self-Assembly of Nanospheres. Nano Lett. 2014, 14 (9), 5238-5243.

(124) Labastide, J. A.; Baghgar, M.; Dujovne, I.; Venkatraman, B. H.; Ramsdell, D. C.; Venkataraman, D.; Barnes, M. D. Time- and Polarization-Resolved Photoluminescence of Individual Semicrystalline Polythiophene (P3HT) Nanoparticles. J. Phys. Chem. Lett. 2011, 2 (17), 2089-2093.

(125) Nagarjuna, G.; Baghgar, M.; Labastide, J. A.; Algaier, D. D.; Barnes, M. D.; Venkataraman, D. Tuning Aggregation of Poly-(3-Hexylthiophene) within Nanoparticles. ACS Nano 2012, 6 (12), 10750-10758.

(126) Pedersen, E. B. L.; Pedersen, M. C.; Simonsen, S. B.; Brandt, R. G.; Böttiger, A. P. L.; Andersen, T. R.; Jiang, W.; Xie, Z. Y.; Krebs, F. C.; Arleth, L.; Andreasen, J. W. Structure and Crystallinity of Water Dispersible Photoactive Nanoparticles for Organic Solar Cells. J. Mater. Chem. A 2015, 3 (33), 17022-17031.

(127) Prosa, T. J.; Winokur, M. J.; McCullough, R. D. Evidence of a Novel Side Chain Structure in Regioregular Poly(3-Alkylthiophenes). Macromolecules 1996, 29 (10), 3654-3656.

(128) Meille, S. V.; Romita, V.; Caronna, T.; Lovinger, A. J.; Catellani, M.; Belobrzeckaja, L. Influence of Molecular Weight and Regioregularity on the Polymorphic Behavior of Poly(3-Decylthiophenes). Macromolecules 1997, 30 (25), 7898-7905. 
(129) Hoppe, H.; Sariciftci, N. S. Organic Solar Cells: An Overview. J. Mater. Res. 2004, 19 (7), 1924-1945.

(130) Destouesse, E.; Chambon, S.; Courtel, S.; Hirsch, L.; Wantz, G. Solution-Processed Small-Molecule Bulk Heterojunctions: Leakage Currents and the Dewetting Issue for Inverted Solar Cells. ACS Appl. Mater. Interfaces 2015, 7 (44), 24663-24669.

(131) Elumalai, N. K.; Uddin, A. Open Circuit Voltage of Organic Solar Cells: An In-Depth Review. Energy Environ. Sci. 2016, 9 (2), 391-410.

(132) Piersimoni, F.; Chambon, S.; Vandewal, K.; Mens, R.; Boonen, T.; Gadisa, A.; Izquierdo, M.; Filippone, S.; Ruttens, B.; D’Haen, J.; Martin, N.; Lutsen, L.; Vanderzande, D.; Adriaensens, P.; Manca, J. V. Influence of Fullerene Ordering on the Energy of the Charge-Transfer State and Open-Circuit Voltage in Polymer:Fullerene Solar Cells. J. Phys. Chem. C 2011, 115 (21), 10873-10880.

(133) Vandewal, K.; Oosterbaan, W. D.; Bertho, S.; Vrindts, V.; Gadisa, A.; Lutsen, L.; Vanderzande, D.; Manca, J. V. Varying Polymer Crystallinity in Nanofiber Poly(3Alkylthiophene): PCBM Solar Cells: Influence on Charge-Transfer State Energy and Open-Circuit Voltage. Appl. Phys. Lett. 2009, 95 (12), 123303.

(134) Vaughan, B.; Stapleton, A.; Xue, B.; Sesa, E.; Zhou, X.; Bryant, G.; Belcher, W.; Dastoor, P. Effect of a Calcium Cathode on Water-Based Nanoparticulate Solar Cells. Appl. Phys. Lett. 2012, 101 (5), 053901.

(135) Labastide, J. A.; Baghgar, M.; Dujovne, I.; Yang, Y.; Dinsmore, A. D.; G. Sumpter, B.; Venkataraman, D.; Barnes, M. D. Polymer Nanoparticle Superlattices for Organic Photovoltaic Applications. J. Phys. Chem. Lett. 2011, 2 (24), 3085-3091.

(136) Bag, M.; Gehan, T. S.; Renna, L. A.; Algaier, D. D.; Lahti, P. M.; Venkataraman, D. Fabrication Conditions for Efficient Organic Photovoltaic Cells from Aqueous Dispersions of Nanoparticles. RSC Adv. 2014, 4 (85), 45325-45331.

(137) Feron, K.; Ulum, S.; Sesa, E.; Gong, B. B.; Belcher, W. J.; Zhou, X.; Fell, C. J.; Dastoor, P. C. The Effect of Calcium-Induced Fullerene Migration on the Performance of Thermally Stable Nanoparticle Organic Solar Cells. Journal of Applied Physics 2014, $116(12), 124502$.

(138) Holmes, N. P.; Ulum, S.; Sista, P.; Burke, K. B.; Wilson, M. G.; Stefan, M. C.; Zhou, X.; Dastoor, P. C.; Belcher, W. J. The Effect of Polymer Molecular Weight on P3HT:PCBM Nanoparticulate Organic Photovoltaic Device Performance. Solar Energy Materials and Solar Cells 2014, 128, 369-377.

(139) Han, X.; Bag, M.; Gehan, T. S.; Venkataraman, D.; Maroudas, D. Analysis of Hole Transport in Thin Films and Nanoparticle Assemblies of Poly(3-Hexylthiophene). Chemical Physics Letters 2014, 610-611, 273-277.

(140) Cho, J.; Cheon, K. H.; Ha, J.; Chung, D. S. Water-Based High-Performance Polymer Field Effect Transistors Enabled by Heat-Assisted Surfactant Elimination. Chemical Engineering Journal 2016, 286, 122-127.

(141) Bag, M.; Gehan, T. S.; Algaier, D. D.; Liu, F.; Nagarjuna, G.; Lahti, P. M.; Russell, T. P.; Venkataraman, D. Efficient Charge Transport in Assemblies of SurfactantStabilized Semiconducting Nanoparticles. Adv. Mater. 2013, 25 (44), 6411-6415.

(142) Reese, M. O.; White, M. S.; Rumbles, G.; Ginley, D. S.; Shaheen, S. E. Optimal Negative Electrodes for Poly(3-Hexylthiophene): [6,6]-Phenyl C61-Butyric Acid Methyl Ester Bulk Heterojunction Photovoltaic Devices. Appl. Phys. Lett. 2008, 92 (5), 053307.

(143) Barnes, T. M.; Bergeson, J. D.; Tenent, R. C.; Larsen, B. A.; Teeter, G.; Jones, K. M.; Blackburn, J. L.; van de Lagemaat, J. Carbon Nanotube Network Electrodes Enabling Efficient Organic Solar Cells without a Hole Transport Layer. Appl. Phys. Lett. 2010, 96 (24), 243309. 
(144) Almyahi, F.; Andersen, T. R.; Fahy, A.; Dickinson, M.; Feron, K.; Belcher, W. J.; Dastoor, P. C. The Role of Surface Energy Control in Organic Photovoltaics Based on Solar Paints. J. Mater. Chem. A 2019, 7 (15), 9202-9214.

(145) Larsen-Olsen, T. T.; Andreasen, B.; Andersen, T. R.; Böttiger, A. P. L.; Bundgaard, E.; Norrman, K.; Andreasen, J. W.; Jørgensen, M.; Krebs, F. C. Simultaneous Multilayer Formation of the Polymer Solar Cell Stack Using Roll-to-Roll Double Slot-Die Coating from Water. Solar Energy Materials and Solar Cells 2012, 97, 22-27.

(146) Ferretti, A. M.; Zappia, S.; Scavia, G.; Giovanella, U.; Villafiorita-Monteleone, F.; Destri, S. Surfactant-Free Miniemulsion Approach for Low Band Gap Rod-Coil Block Copolymer Water-Processable Nanoparticle Fabrication: Film Preparation and Morphological Characterization. Polymer 2019, 174, 61-69. 